\title{
Perpetrators vs. Auditors: Factors that Influence the Occurrence of Fraud and Audit Interventions
}

\author{
Alyssa Sui Jing Ong
}

Follow this and additional works at: https://researchrepository.wvu.edu/etd

\section{Recommended Citation}

Ong, Alyssa Sui Jing, "Perpetrators vs. Auditors: Factors that Influence the Occurrence of Fraud and Audit Interventions" (2018). Graduate Theses, Dissertations, and Problem Reports. 7223.

https://researchrepository.wvu.edu/etd/7223

This Dissertation is protected by copyright and/or related rights. It has been brought to you by the The Research Repository @ WVU with permission from the rights-holder(s). You are free to use this Dissertation in any way that is permitted by the copyright and related rights legislation that applies to your use. For other uses you must obtain permission from the rights-holder(s) directly, unless additional rights are indicated by a Creative Commons license in the record and/ or on the work itself. This Dissertation has been accepted for inclusion in WVU Graduate Theses, Dissertations, and Problem Reports collection by an authorized administrator of The Research Repository @ WVU.

For more information, please contact researchrepository@mail.wvu.edu. 
Perpetrators vs. Auditors: Factors that Influence the Occurrence of Fraud and Audit Interventions

Alyssa Sui Jing Ong

Dissertation submitted

To the College of Business and Economics

At West Virginia University

In partial fulfillment of the requirements for the degree of

Doctor of Philosophy in

Accounting

Richard Riley Jr., Ph.D., Chair
A. Scott Fleming, Ph.D.
D. Kip Holderness, Ph.D.
Lisa Dilks, Ph.D.

Department of Accounting
Morgantown, West Virginia 2018

Keywords: fraud, fraud deterrence, fraud detection, auditor-client interaction

(C) 2018 Alyssa Ong 


\section{ABSTRACT \\ Perpetrators vs. Auditors: Factors that Influence the Occurrence of Fraud and Audit Interventions}

\section{Alyssa Sui Jing Ong}

This dissertation is comprised of three studies that examine two personalities that influence fraud occurrence and interventions that auditors can make to deter fraud and remain objective during the audit.

The first study examines whether the rationalization attribute of the fraud triangle applies to individuals with high levels of trait impulsivity. Specifically, I seek to test the attributes of the fraud triangle- pressure, opportunity, and rationalization-in the context of trait-impulsivity. According to the fraud triangle theory, opportunity, pressure, and rationalization are present when individuals decide to engage in the fraudulent act. This theory might not hold true for impulsive individuals who have a different concept of time, prefer smaller, frequent rewards, and lack control when impulses arise. While I manipulate the pressure and opportunity attributes, I examine if individuals actually rationalize their fraud behavior. Prior research suggests that when individuals have the sudden urge to do something, individuals with high levels of trait impulsivity translate that impulse into behavior more rapidly than individuals with low levels of trait impulsivity. The results of the simulation suggest that when there was opportunity and pressure, impulsive individuals were quicker to make decisions to engage in or refrain from fraud behaviors than non-impulsive individuals. Impulsive individuals seem to bypass any consideration about the potential consequences (risk of detection, emotional discord, etc.) and this contrasts with non-impulsive individuals who are more deliberative, choosing to consider various factors beforehand. These perspectives interact with neutralization and rationalization of the fraud act.

The second study examines how first impressions and auditor mindsets interact to influence auditors' risk judgments. Auditors form first impressions as they interact with client personnel while gathering audit evidence. Prior first-impression research suggests that individuals' first impressions influence their subsequent judgments through a subconscious process which makes it difficult to avoid biased judgments associated with them. In auditing, we expect a positive (negative) first impression to decrease (increase) auditor objectivity and cause auditors to become less (more) sensitive to misstatement risk; our findings from an experiment with practicing auditors support this expectation. Importantly, we also show that encouraging auditors to focus on being effective without concern for audit costs (i.e., an effectiveness mindset) attenuates first impression biases relative to encouraging them to focus on audit costs (i.e., an efficiency mindset). Given that client inquiry is an important component of the audit, these findings have direct implications for auditor effectiveness.

Lastly, study three focuses on how auditors can potentially deter fraud. When auditors perceive fraud risk during an audit, AU 316 (AICPA 2002) recommends varying the nature, timing, or extent of audit procedures. However, previous studies indicate that while auditors typically vary the extent and timing of audit procedures, they do not vary the nature of audit procedures, which is most likely to detect fraud. We posit that an additional benefit to altering the nature of audit 
procedures is that it may also deter fraud. Auditors create ambiguity when they vary audit procedures. As most individuals are averse to ambiguity, varying audit procedures for each audit cycle will create ambiguity for clients and make it difficult to predict the testing auditors would select. Consequently, it would raise the perceived level of difficulty for individuals to commit fraud. This study examines whether creating ambiguity by varying the nature of audit procedures deters fraud, and whether this deterrence is dependent on individuals' narcissism. 


\section{DEDICATION}

To Dr. Kala Stroup, the best honors advisor and mentor I could have ever wished for 


\section{ACKNOWLEDGEMENTS}

Many people have contributed to my development over the last few years. I would first like to acknowledge the Association of Certified Fraud Examiners and the Institute for Fraud Prevention for providing the financial support necessary to complete my dissertation. This dissertation would not be possible without the sincere help and guidance from my committee members: Drs. Richard Riley (chair), Scott Fleming, Kip Holderness, and Lisa Dilks.

The last four years would have been more difficult without the support and encouragement of the Accounting Department at West Virginia University, my honors advisors from the University of Kansas Honors Program, and faculty from the University of Kansas Business School. Special thanks to the professors who contributed their time and expertise to teach me how to conduct research; namely, Richard Riley, Kip Holderness, Surendra Singh, Catherine Shwoerer, Minyoung Kim, and Kala Stroup. I wish to thank my fellow WVU College of Business and Economics' Ph.D. students for their friendship and support during this journey. Finally, I'd like to thank Neeli Bendapudi, then Dean of the University of Kansas Business School, for her guidance when I approached her as a sophomore with the aspirations of obtaining a Ph.D.

Last but not least, I would like to thank my family. The support and prayers from my husband, my parents, my brother, my grandparents, and church family kept me grounded. Above all, to God be the glory. 


\section{TABLE OF CONTENTS}

ABSTRACT

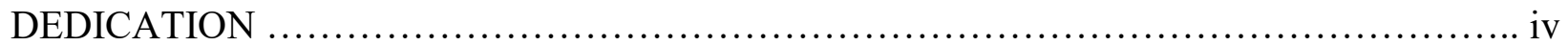

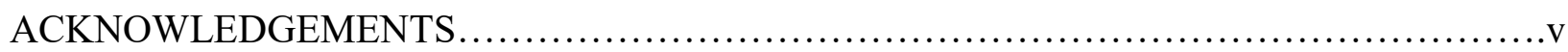

LIST OF FIGURES …................................................................................................ viii

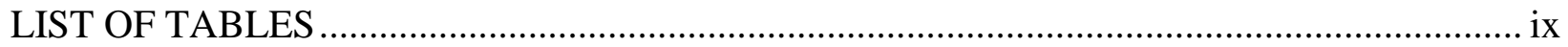

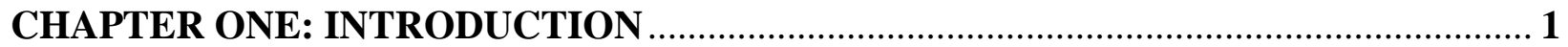

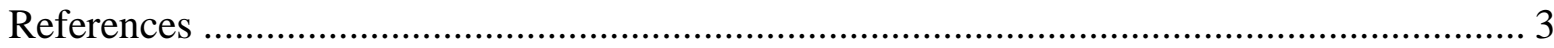

CHAPTER TWO: NEUTRALIZATION VS. RATIONALIZATION: DOES THE FRAUD TRIANGLE HOLD WHEN INDIVIDUALS ARE IMPULSIVE? ................................. 5

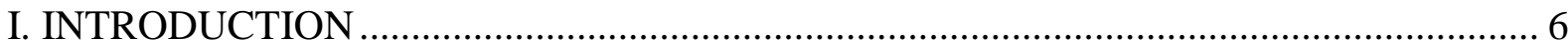

II. BACKGROUND AND HYPOTHESES DEVELOPMENT …....................................... 9

III. EXPERIMENTAL DESIGN AND METHODS .......................................................... 19

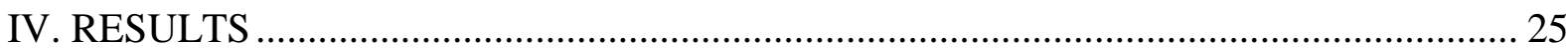

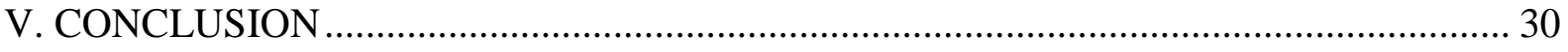

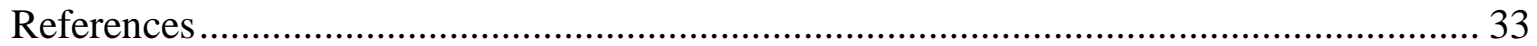

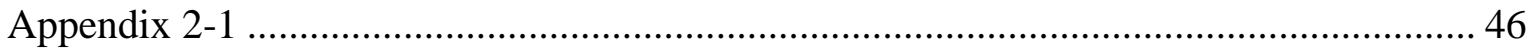

CHAPTER THREE: THE EFFECTS OF FIRST IMPRESSIONS AND MINDSETS ON

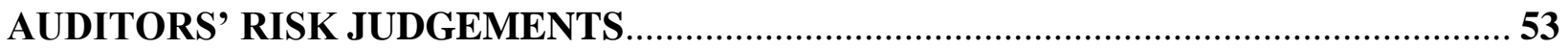

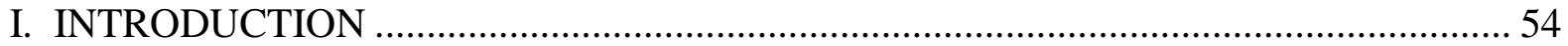

II. BACKGROUND AND HYPOTHESES DEVELOPMENT .......................................... 57

III.EXPERIMENTAL DESIGN AND METHODS ...................................................... 64

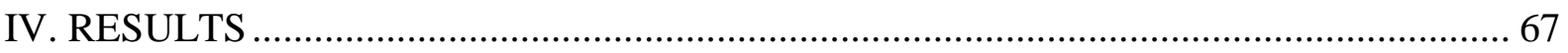

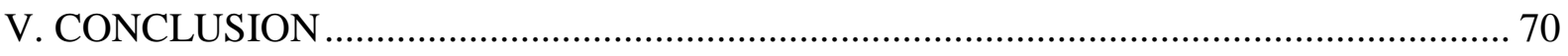

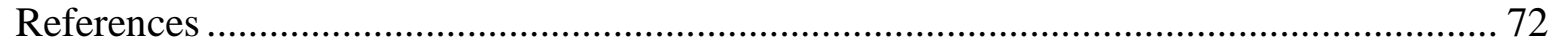

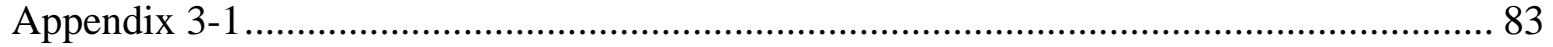

CHAPTER FOUR: CHANGING THE NATURE OF AUDIT PROCEDURES TO DETER

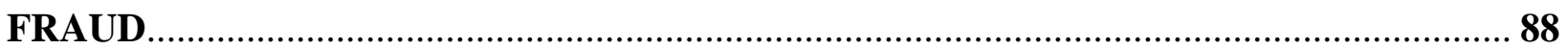

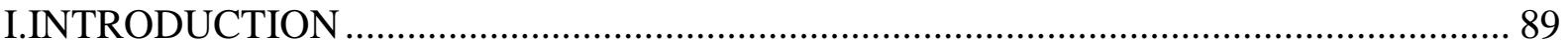

II. BACKGROUND AND HYPOTHESES DEVELOPMENT ........................................ 92

III. EXPERIMENTAL DESIGN AND METHODS ......................................................... 98

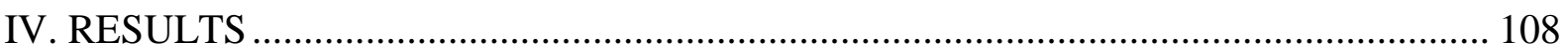

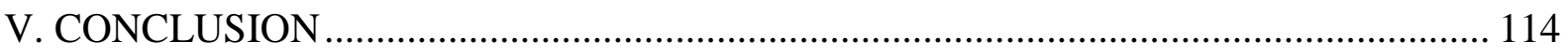




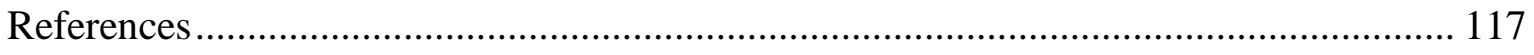

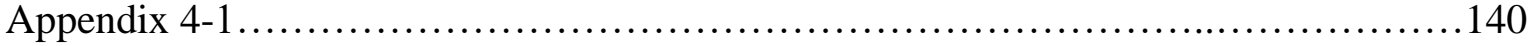

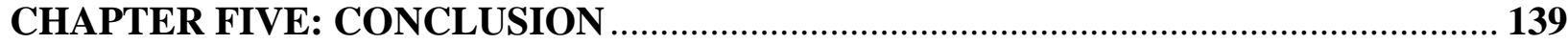

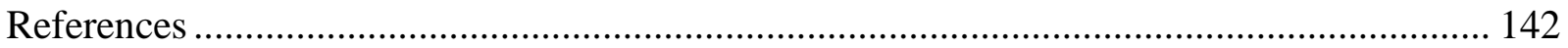




\section{LIST OF FIGURES}

Figure 2-1: The Fraud Triangle.......................................................

Figure 2-2: The Reflective-Impulsive Model..................................... 38

Figure 2-3: Experiment Sequence.............................................. 39

Figure 2-4: Graph of Frequency of the No. of Periods Participants Chose to Commit

Fraud ............................................................. 40

Figure 2-5: Graph of Est. Marginal Means of Time Taken to Make Decision for Impulsive

Individuals......................................................41

Figure 2-6: Graph of Est. Marginal Means of Time Taken to Make Decision for

Non-impulsive Individuals.......................................... 42

Figure 3-1: Graph of Est. Marginal Means of Inventory Valuation.................... 75

Figure 3-2: Graph of Est. Marginal Means of Risk of Material Misstatement...............76

Figure 4-1: Meta-Model of Fraud and White Collar Crime.......................... 120

Figure 4-2: Theory of Planned Behavior............................................. 121

Figure 4-3: Experiment Sequence............................................. 122

Figure 4-4: Graph of No. of Participants that Chose to Take a Processor in Each Period... 123

Figure 4-5: Graph of Proportion of Fraud Occurrence................................ 124

Figure 4-6: Graph of Est. Marginal Means of the Proportion of Fraud Occurrence..........125 


\section{LIST OF TABLES}

Table 2-1: Participant Demographics........................................ 43

Table 2-2: Descriptive Statistics ............................................... 44

Table 2-3: ANCOVA Results for Time Taken to Decision .......................... 45

Table 3-1: Participant Demographics............................................... 77

Table 3-2: Descriptive Statistics for First Impressions ….......................... 78

Table 3-3: Descriptive Statistics for Perceived First Impressions ....................... 79

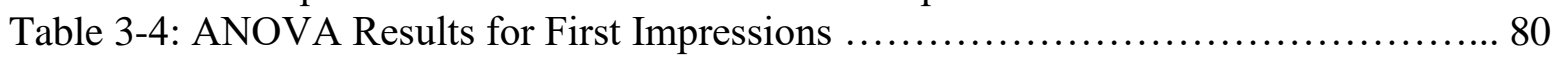

Table 3-5: ANCOVA Results for First Impressions .................................. 81

Table 3-6: ANCOVA Results for Perceived First Impressions .......................... 82

Table 4-1: Participant Demographics............................................ 126

Table 4-2: Pilot Tests Changes across Time........................................ 127

Table 4-3: Descriptive Statistics............................................... 128

Table 4-4: Cell Means for Participants' Proportion of Fraud Occurrence...................129

Table 4-5: ANCOVA Analysis on the Willingness to Commit Fraud.................... 130 


\section{CHAPTER ONE: INTRODUCTION}

The purpose of this dissertation is to contribute to knowledge on fraud, specifically as it applies to fraud occurrence and audit intervention. Most of what is known about the fraudulent act is descriptive (Beasley et al. 2014, ACFE 2016). We know that fraud perpetrators are most likely male, in his late 30s or early 40s, and is college educated (ACFE 2016). However, this does not mean that everyone who fits into this profile has committed fraud or will commit fraud. The anecdotal 10-80-10 Rule of Ethics states that $10 \%$ of the population will always commit fraud when the opportunity presents itself, $80 \%$ of the population might commit fraud depending on the circumstances, and the remaining $10 \%$ of the population will never commit fraud (AGA 2017). Personality impacts an individual's behavior (Collins and Schmidt 1993) and could be associated with individuals' in the $80 \%$ category's decision to engage in fraud behaviors. A deeper understanding of what personality characteristics are associated with individuals' choice to perpetrate a fraud can contribute to our knowledge on why some individuals will commit fraud when the opportunity is present while some others will refrain from doing so. Specifically for this dissertation, I examine how impulsivity and narcissism affects individuals' actions when the opportunity to commit fraud is present. Next, I examine how auditors' first impression of the client can affect the audit, especially when fraudsters are known to manage their impression when auditors are present (Sheridan 2016).

Auditors are in constant contact with clients to gather information during the audit. Through this process, auditors may meet with new client personnel throughout the audit of a familiar client. It is also normal for auditors to be assigned to new engagements, thus meeting with members of client personnel for the first time. Audit standards emphasize the importance of risk assessment in auditing and the need for auditors to remain objective (AICPA 2014; PCAOB 2007; AICPA 2006a, 2006b, 2006c). However, auditors can be biased by their first impressions of the client. Anecdotally, fraudsters have been known to manage their impression to keep auditors from being objective during the audit. For example, Crazy Eddie, 
Sam Antar had his employees wine and dine the auditors and encouraged his female employees to get friendly with them. He admitted that "the chumminess helped us become more likable to our auditors and corrode their professional skepticism" (Antar 2018). In the ZZZZ Best fraud scheme, Barry Minkow successfully manipulated the auditors by establishing social contacts with them and their wives, knowing that if the auditors" wives saw him as a "nice kid", they could defend him if the auditors express concern about the company (Matulich and Currie 2016, p.84). The first impression formation is a subconscious process and occurs almost instantaneously (Willis and Todorov 2006). In this dissertation I examine how auditors can mitigate this first impression bias and stay objective when carrying out tasks on the audit plan.

Audit standards recommend that auditors vary audit procedures when there is a risk of material misstatement due to fraud (AICPA 2002). However, prior research suggests that auditors rarely make changes to the audit plan (Zimbelman 1997; Glover et al. 2003). In addition to helping with fraud detection, the variation in audit procedures could also assist with fraud deterrence. This change in audit procedures would make things less predictable for potential fraudsters and possibly reduce the rate of fraud occurrence.

In this dissertation, I contribute to the fraud occurrence and audit intervention efforts by conducting three different experiments. First, in Chapter Two, I conduct an experiment to examine if the rationalization attribute of the fraud triangle applies to individuals who are impulsive by presenting individuals with the opportunity to steal when pressure and internal audit rates are manipulated. Empirically examining whether the rationalization attribute of the fraud triangle applies to impulsive individuals will contribute to our understanding of the Fraud Triangle (Albrecht 1991) and situations in which it does not apply. Second, I conduct an experiment examining how first impressions can bias auditor judgment and how being in a certain mindset can mitigate this bias in Chapter Three. Fraud perpetrators may distract auditors from the fraud by providing auditors with a positive first impression, causing auditors to make an incorrect judgment and lowering their fraud risk assessments of the company. Being in the right mindset from the inception of auditor-client interactions may mitigate this bias and assist with fraud detection. Third, I conduct an 
experiment to examine how auditor intervention of varying the nature of audit procedures can lead to fraud deterrence. Individuals are generally averse to ambiguity (Ellsberg 1961). The ambiguity created when auditors frequently change the nature of audit procedures can potentially serve as a deterrent, reducing the likelihood of fraud occurrence as individuals are uncomfortable when ambiguity is present. This study is presented in Chapter Four.

This dissertation is organized as follows: chapters 2 through 4 include specific details of the three studies briefly mentioned above. Each chapter contains an introduction to the study, overview of the relevant literature and hypotheses development, methodology, results, and discussion of limitations and implications. Lastly, chapter 5 includes a summary of the results and suggestions for future research.

\section{References}

Albrecht, W.S. 1991. Fraud in Governmental Entities: The Perpetrators and Types of Fraud. Government Finance Review, 7(6), 27-30.

American Institute of Certified Public Accountants (AICPA). (2014). AICPA Code of Professional Conduct.

American Institute of Certified Public Accountants (AICPA). (2006a). Audit Evidence. Statement on Auditing Standards No. 106. New York, NY: AICPA.

American Institute of Certified Public Accountants (AICPA). (2006b). Audit Risk and Materiality in Conducting an Audit. Statement on Auditing Standards No. 107. New York, NY: AICPA.

American Institute of Certified Public Accountants (AICPA). (2006c). Performing Audit Procedures in Response to Assessed Risks and Evaluating the Audit Evidence Obtained. Statement on Auditing Standards No. 110. New York, NY: AICPA.

American Institute of Certified Public Accountants (AICPA). (2002). Consideration of Fraud in a Financial Statement Audit. Statement on Auditing Standards No. 99. New York, NY: AICPA.

Antar, S. (2018). Crazy Eddie Fraud. Retrieved March 22, 2018, from https://whitecollarfraud.com/crazyeddie/crazy-eddie-fraud/

Association of Government Accountants (AGA). Retrieved March 4, 2017, from https://www.agacgfm.org/Fraud-Prevention-Toolkit/Fraud-Awareness-Mitigation/FraudTriangle.aspx

Association of Certified Fraud Examiners (ACFE). 2016. Report to the Nations on Occupational Fraud and Abuse. Austin, TX: ACFE.

Beasley, M., Branson, B., \& Hancock, B. 2014. Report on the Current State of Enterprise Risk Oversight: Opportunities to Strengthen Integration with Strategy. North Carolina State University, American Institute of CPAs. 
Collins, J. M., \& Schmidt, F. L. (1993). Personality, integrity, and white collar crime: A construct validity study. Personnel Psychology, 46(2), 295-311.

Ellsberg, D. (1961). Risk, ambiguity, and the Savage axioms. Quarterly Journal of Economics, 75, 643669.

Glover, S. M., Prawitt, D. F., Schultz Jr, J. J., \& Zimbelman, M. F. (2003). A test of changes in auditors' fraud-related planning judgments since the issuance of SAS No. 82. Auditing: A Journal of Practice \& Theory, 22(2), 237-251.

Matulich, S., \& Currie, D. M. (Eds.). (2016). Handbook of Frauds, Scams, and Swindles: Failures of Ethics in Leadership. CRC Press.

Public Company Accounting Oversight Board (PCAOB). (2007) An Audit of Internal Control over Financial Reporting that is Integrated with an Audit of Financial Statements. Auditing Standards No. 5. Washington, D.C.: PCAOB

Sheridan, T. A. (2016). Managerial fraud: Executive impression management, beyond red flags. Routledge.

Willis, J., \& Todorov, A. (2006). First impressions: Making up your mind after a 100-ms exposure to a face. Psychological science, 17(7), 592-598.

Zimbelman, M. F. (1997). The effects of SAS No. 82 on auditors' attention to fraud risk factors and audit planning decisions. Journal of Accounting Research, 75-97. 
CHAPTER TWO: NEUTRALIZATION VS. RATIONALIZATION: DOES THE FRAUD TRIANGLE HOLD WHEN INDIVIDUALS ARE IMPULSIVE?

\author{
Alyssa S.J. Ong \\ West Virginia University \\ asong@mix.wvu.edu
}




\section{INTRODUCTION}

The General Theory of Crime (Gottfredson and Hirschi 1990) states that self-control is an important element that influences individuals' decision to commit fraud. However, this does not mean that individuals with low levels of self-control will commit fraud when given the opportunity (Pratt 2015). This finding indicates that there are other factors that influence individuals' decision to commit fraud beyond their level of self-control. In interviews with convicted fraudsters, Cressey $(1950,1953)$ observed that fraudsters rationalize the action internally to reduce emotional discord. The fraud triangle theory (Albrecht 1991) posits that individuals rationalize before the first fraudulent act. Impulsive individuals act without much deliberation (Collins 2017). As such, it is possible that impulsive individuals would not rationalize before committing fraud. Trompeter et al. (2014) suggest that there should be more empirical studies examining individuals' personality as it relates to economic crime. Specifically, Trompeter et al. (2014) stress that accounting research that incorporates work from the areas of psychology and organizational behavior may be beneficial to broaden our understanding of individuals' perception of opportunity. In addition, Anand et al. (2015) call for fraud to be studied with different methods because it is perpetrated in many ways by people who have different personality characteristics, background, thought process, etc. In this study, I investigate whether the fraud triangle, specifically the attribute of rationalization, is applicable to impulsive individuals.

Impulsivity is a trait that influences individuals' behaviors throughout a multitude of situations and is associated with the ability to control actions and thoughts (Barratt 1983). Impulsivity is defined as a "type of behavior characterized by a tendency to act impulsively or without prior reflection or thought" (Collins 2017, Romer et al. 2009). Hofmann et al. (2007) state that every day, "people are tempted by their impulses, urges, and cravings."- while others are perceived to be more virtuous, have more self-control and are able to consistently ward off impulse temptations and keep their sights on long-term goals and standards. Further, some people give in to their impulse temptations more than others (Hoffman et al. 2008). Examining 
individual differences in trait impulsivity is important as they depict a persistent susceptibility for a host of potentially problematic behaviors due to a lack of control (Friese and Hofmann 2009). In addition to acting without prior reflection or thought, impulsive individuals perceive time differently- Wittmann and Paulus (2007) find that individuals with high trait impulsivity overestimate the duration of time intervals in time judgment tasks. They also find that when compared to non-impulsive individuals, impulsive individuals choose to receive immediate, smaller rewards over delayed, greater rewards. In the context of fraud, impulsive individuals might be more inclined to engage in asset misappropriation fraud that has a smaller reward and a faster conversion to cash than non-impulsive individuals. Personality traits can be used to predict behavior (Paunonen and Ashton 2001) and prior work in white-collar crime indicate the importance of understanding personality traits that could influence individuals to commit fraud (Ramamoorti 2008, Alalehto 2003, Perri 2011). However, in the area of fraud research, there is also a need to go beyond personality traits and study situations in which the fraudulent act occurs (Anand et al. 2015). I hypothesize that individuals' response to fraud behavior will vary depending on their level of trait impulsivity.

The Reflective-Impulsive Model (RIM) (Strack and Deutsch 2004) is a conceptual framework for the materialization of impulsive behavior that consists of reflective and impulsive mechanisms which jointly influence behavior. Based on this model, impulses are traced to an associative network from long-term memory. Once an object is encountered, affect that is associated with the object is immediately activated and these affect associations are precursors of impulsive behavior (Strack and Deutsch 2004, Hofmann et al. 2008). The impulsive system activates behavior without much thought whereas the reflective system activates behavior after deliberation of a future state and evaluation of the probability with which the state will be accomplished through the behavior (Strack et al. 2006). The reflective system has the ability to override the behavioral intentions in the impulsive system when not lacking in resources and motivation (Hofmann et al. 2008). As there are two-systems in the RIM that can influence behavior, the specific system used to activate behavior that leads to the individuals' engagement in or resistance from a fraudulent act can 
differ between individuals with varying levels of trait impulsivity. I predict that individuals more strongly influenced by trait impulsivity will commit fraud by activating behavior through the impulsive system without much deliberation about the consequence and rationalization.

I examined individuals' fraud behavior (willingness to commit fraud and presence of rationalization/neutralization) when precursors of fraud (pressure and opportunity) are present in the context of trait impulsivity and the Reflective-Impulsive Model. I designed a 2x2x2 simulation, collecting data from 306 participants. In the simulation, participants had the opportunity to decide to misappropriate company assets via an expense reimbursement fraud for personal gain. I hypothesize and find that unlike nonimpulsive individuals, impulsive individuals spend less time when making decisions to engage in or refrain from fraud behavior when financial pressure is high compared to when pressure is low. Given the opportunity to commit fraud, impulsive individuals are also more likely than non-impulsive individuals to ignore factors such as internal audit tests and financial pressure. Most importantly, I show that when precursors to fraud are present, impulsive individuals take less time than non-impulsive individuals when deciding to engage in or refrain from fraud behavior. This demonstrates the lack of deliberation on behalf of impulsive individuals before making the decision to commit fraud, suggesting that the belief that pressure, opportunity, and rationalization have to be present before a fraud is committed might not be true for impulsive individuals.

This study makes several contributions to extant literature. First, by examining whether the rationalization attribute of the fraud triangle applies to impulsive individuals, I build upon the existing forensic accounting and fraud examination literature by providing new insights into how personality affects individuals' willingness to commit fraud. The findings also provide a foundation for future fraud models that encompass impulsive individuals. The ACFE's 2016 Report to the Nations list the different methods that fraud perpetrators use to conceal fraud and reduce the chances of detection (ACFE 2016). Methods used to conceal the fraud act when frauds are premeditated versus unplanned frauds can possibly be different. 
Fraudsters can alter documents as they engage in the planned fraudulent act or engage in the fraudulent act first and execute a concealment plan by destroying or creating documents later to "cover their tracks". Knowledge of how impulsive individuals' thought processes differ from others before the fraud behavior can provide insights into fraud concealment methods and pave the way for more fraud concealment research. Second, by looking at the reflective and impulsive systems that influence the activation of fraud behavior, I respond to the call of Anand et al. (2015) to study the situations in which the fraudulent act occurs. Examining impulsivity and the conceptual framework through the RIM when fraud decisions are made also answers the call by Trompeter et al. (2014) to use personality traits to enhance our understanding of the interaction between situational and individual factors of the fraudulent act.

The remainder of this study proceeds as follows: Section II provides a background review of the relevant literature and the development of hypotheses. Section III is a general outline of the research method and the experimental design of the study. Section IV provides results of the experimental study and Section $\mathrm{V}$ includes a discussion and concluding remarks.

\section{BACKGROUND AND HYPOTHESES DEVELOPMENT}

\section{Fraud Perpetrators}

Hermanson et al. (2017) identify the first time offender as the "situational fraudster" who typically is a middle-aged male, middle class, well-educated, and a trusted employee in the company. When the fraud is discovered, the fraudulent act is considered "out-of-character" for the situational fraudster. Dorminey et al. (2010) also identify perpetrators who are constantly looking for opportunities to commit fraud as "predator fraudsters". Fraudulent acts can be committed alone or in collusion with others. Solo frauds are less costly and the perpetrator is typically older, more-educated when compared to perpetrators of collusive frauds (Bishop et al. 2016). The ACFE's 2016 Report to the Nations report that over 50\% of the cases involve perpetrators working alone and $88 \%$ of the perpetrators are first time offenders (ACFE 2016). In this study, 
I examine solo frauds perpetrated by the situational fraudster. Below is a discussion of fraud models that apply to solo frauds.

\section{Fraud Models}

Cressey (1953) posits that three attributes are necessary for individuals to commit fraud: (1) pressure, (2) opportunity, and (3) rationalization. This theory is now commonly known as the "fraud triangle" (Albrecht 1991), depicted in Figure 2-1, and subsequent models and studies of fraud such as the Fraud Scale (Albrecht et al. 1984), the M.I.C.E. acronym (Kranacher et al. 2011), the Fraud Diamond (Wolfe and Hermanson 2004), the Fully Ascribed Meta-Model of White-Collar Crime (Dorminey et al. 2012), and the revised Fraud Triangle (Boyle et al. 2018) modify and build on Cressey's original idea. The revised Fraud Triangle modified the rationalization attribute of the triangle, defining it as capability to include fraudsters' personal characteristics (Boyle et al. 2018). However, the ability to rationalize fraud remains a critical part of the capability attribute. All these fraud models establish that for solo, accidental fraudsters, the rationalization attribute must be present before fraud occurs. I am building on fraud examination and forensic accounting literature by examining how the rationalization attribute applies to impulsive individuals. Gaining insight into individuals' thought process when the idea of committing fraud is planted will shed light on how impulsive individuals differ from non-impulsive individuals when making decisions to commit fraud.

\section{[Insert Figure 2-1 about here]}

\section{Reflective-Impulsive Model (RIM)}

The Reflective-Impulsive Model is a dual-process conceptual framework that "explains social behavior as a joint function of reflective and impulsive processes" (Strack and Deutsch 2004, p.220). Dualprocessing models draw on the belief that individuals have memory systems that process information in fundamentally different ways (Smith and DeCoster 2000, McClelland, McNaughton, and O’Reilly 1995, Alvarez and Squire 1994). On one hand there is the associative processing mode, which is based on 
knowledge that is accumulated from experiences and the use of that knowledge to process information quickly and automatically when similar situations occur. On the other hand, the rule-based processing mode incorporates symbolically represented rules structured by language and logic as the basis to processing decisions and occurs optionally when cognitive capacity and motivation are present (Smith and DeCoster 2000). A psychology concept similar to the associative processing mode and the impulsive system under the RIM is heuristics, defined as "methods for arriving at satisfactory solutions with modest amounts of computation" (Simon 1990, p.11). Individuals use heuristics to reduce the cognitive load associated with decision making (Tversky and Kahneman 1974). In contrast, need for cognition refers to individuals' tendency to participate in deep, engaging thoughts to understand and make sense of experiences (Cacioppo, Petty, and Kao 1984, Cacioppo and Petty 1982, Cohen et al. 1955). Individuals with a high need for cognition can be described as thinkers and, in the context of dual-processing models, would have the rulebased processing mode as their dominant processing system.

This dual-process RIM model assumes that behavior is controlled by the reflective and impulsive systems, each with the capability to run in parallel, interact with each other, and operate based on different principles. The impulsive system is always engaged in processing whereas the reflective system may be disengaged depending on cognitive capacity or levels of arousal. A stimulus enters the reflective system when intensity is great (Strack, Werth and Deutsch 2006). When this happens, the impulsive and reflective systems are running in parallel. The end point for both the reflective and impulsive system is the behavioral schemata that activates behavior (Strack and Deutsch 2004). When behavioral schemata from the impulsive and reflective systems are at odds, the behavior that is activated depends on the relative strength of the schemata activation. Figure 2-2 is a visual representation of the RIM adapted from Strack and Deutsch (2004).

[Insert Figure 2-2 about here] 
Environmental/external cues (e.g., observing a bakery with a cake at the display window), is perceived by an individual and enters both the reflective and impulsive processing systems. The impulsive system activates behavior (e.g., walking into the bakery to purchase some cake) by linking the perceived external cues with behavioral schemata based on previous affective associations (e.g., the anticipation of the pleasure of sweet taste and smell of cakes from prior experience). This spreading activation occurs efficiently in the impulsive system, using a minimal amount of cognitive resources (Deutsch and Strack 2008). Strack and Deutsch (2004) also find that the impulsive system is focused on pleasure-seeking and pain prevention. During the operation of the impulsive system, it generates internal cues activating affective, non-affective feelings, and behavioral tendencies which are all perceived by the reflective system (Deutsch and Strack 2008, Hofmann et al. 2007). The reflective system uses the external and internal cues to form judgment (e.g., should the cake be purchased if he/she is on a diet), activate the behavioral schemata through a process of intending (Gollwitzer 1999) that automatically activates the schemata if the behavior has not already been executed, which leads to behavior (e.g. purchase of the cake as a reward, or walking away from the bakery empty-handed to keep up with diet goals). The reflective system requires a great amount of cognitive resources, operates at a slower pace (Strack and Deutsch 2004, Hofmann et al. 2007), fulfills executive functions, deliberate plans in new situations, and comes up with alternative plans when habits fail (Lieberman et al. 2002). In short, the reflective system initiates behavioral schemata after deliberating on the action drawing from prior knowledge, facts, and values whereas the impulsive system initiates behavioral schemata through fast activation of associative links between contents (Strack et al. 2006, Strack and Deutsch 2004). The specific schemata that ultimately leads to behavior (e.g., purchasing the cake or not) depends on the relative strength of schemata activation (e.g. does the reflective or impulsive system have a stronger influence in this situation?).

From the RIM perspective, the reflective system makes judgments and evaluations, puts together action plans for goal pursuit, and inhibits responses to impulses when the situation is not aligned with the 
individual's long-term expectations (Hofmann et al. 2008). In other words, the reflective system is like an individual's self-control center. In the fraud setting, most models assume when there is pressure, individuals consider the opportunity to commit the fraud, the ability to conceal the fraud, and will neutralize to justify the act. Using a dual systems model like the RIM, this would translate into the use of the reflective system to fully consider the opportunity before the activation of behavioral schemata to commit or not to commit the fraudulent act. Just as some individuals might be tempted to commit fraud when they identify the opportunity, people are constantly tempted with impulses daily (Hofmann et al. 2007). Individuals face situations where their uninhibited impulses interfere with long-term goals, standards, or moral conflict (Bogg and Roberts 2004, Carver 2005, Tangney et al. 2004). A process-oriented approach such as the RIM provides more information on when and why individual's decision to act based on impulse is determined by reflective and impulsive influences (Hofmann et al. 2008). Compared to individuals who are non-impulsive, impulses translate more readily into behavior through the impulsive system when individuals are impulsive (Hofmann et al. 2009). Frederick (2005) created the Cognitive Reflection Test (CRT), a set of three questions intended to measure individual's processing system preference and "assess individuals' ability to restrain an impulsive wrong answer in favor of a reflective right answer". As the CRT measures the reflective processing preference, Cueva et al. (2015) adapted the CRT measure by defining the impulsive answers to the same questions from Frederick (2005) thereby creating the iCRT measure. Using the CRT questions, there are now two sets of possible answers. A set of answers (CRT) which indicate individuals prefer the reflective processing system and a set of impulsive answers (iCRT), which individuals preferring the impulsive processing system gravitate towards. Individuals who's dominant processing system is the impulsive system are more likely to be impulsive than individuals who prefer the reflective system.

\section{Impulsivity (Trait)}

Every major system of personality, such as psychotism and sensation-seeking, has a component of trait impulsivity (Whiteside and Lynam 2001). This trait can be described as the tendency to act upon 
feeling and temptation to obtain a reward (hedonic thrill) without much consideration for rules (Romer et al. 2009). Trait impulsivity is expected to gradually decrease with age (Steinberg et al. 2008). Prior research on individual differences treat impulsivity as a multifaceted construct with dimensions like the inability to stop an action once a decision has been made, high sensitivity to immediate rewards, low tolerance for delayed rewards, and the lack of deliberation of consequences when responding to impulses (De Wit, 2009, Romer et al. 2009, Gullo and Dawe 2008, Whiteside and Lynam 2003). Wittman and Paulus (2007) find that impulsive individuals perceive time differently from non-impulsive individuals. They tend to perceive that a certain duration of time is longer than it is in reality and discount the value of future rewards, for example, preferring a gain of $\$ 166$ now (present value) over a gain of $\$ 48210$ years from now (future value of $\$ 166$ at $11.25 \%$ ), more than individuals who have more self-control (Wittmann and Paulus 2007). This difference in time perception causes impulsive individuals to choose smaller, instant rewards ( $\$ 0.01$ every 2 seconds) more often over future rewards ( $\$ 0.24$ every 32 seconds) even though those future rewards may be greater (Wittmann and Paulus 2007). An individual with high trait impulsivity should have problems with keeping impulses under control once the impulse is activated and have a lower level of intelligence (Shamosh et al. 2008). Therefore, impulses that are activated automatically in a particular situation should proceed easily into behavior for individuals with high levels of trait impulsivity (Friese and Hofmann 2009).

Impulses encourage the need for immediate gratification (Strack et al. 2006) and different individuals respond to the same set of impulses differently (Hoffmann et al. 2008). For example, a group of people are meeting in a room with a bowl of candy in sight. Remembering from past experiences that candy tastes great, makes them feel good, and evoke happy memories, all of them are tempted by the same set of impulses. However, different people in the room will respond differently. Some might choose to take multiple pieces throughout the meeting before feeling like the need is satisfied, some might take one piece and stop there, whereas others might choose to refrain from the candy- reminding themselves of their goal to eat healthily. Impulsive individuals, with low tolerance for delayed rewards, would seek gratification much 
faster than non-impulsive individuals -heading straight towards the candy bowl at the very start of the meeting. Bringing it to the fraud setting, most individuals have a positive association with money (i.e., it is better to have more money than what is currently owned) but when given the opportunity to steal, not everyone will engage in fraudulent behaviors. Given the opportunity to increase their financial position, impulsive individuals might "dive in head first" compared to non-impulsive individuals. The time taken to act on the opportunity would be much less for impulsive individuals compared to non-impulsive individuals due to the lack of deliberation. This leads to the discussion on the conditions that increase the likelihood of fraud occurrence.

\section{Precursors of Fraud}

According to the Cressey Theory, pressure to commit fraud can arise from having a "non-shareable financial need", to maintain fraudsters' image in society, or to have a better quality of life (Dorminey et al. 2012, Cressey 1953). When financial pressure is high, individuals are more likely to commit fraud compared to individuals with low financial pressure. Opportunity is perceived as the ability to commit the act itself and the ability to conceal the act to prevent detection (Trompeter et al. 2014, Dorminey et al. 2012). When individuals' spot a weakness in internal controls of a company, opportunity is thought to be present as there is a possibility to commit the act given weak or overlooked internal controls. Individuals with high trait impulsivity will be quicker to make a decision regarding this opportunity than individuals with low trait impulsivity. Also, individuals' response to this internal control weakness would depend on the influence of the reflective/impulsive processing system. Fraud literature posit that for fraud to occur, pressure, opportunity, and rationalization have to be present (Cressey 1953). The third attribute, rationalization, is discussed next.

\section{Justification: Rationalization vs. Neutralization}

Dissonance happens when individuals have to make decisions between two beliefs or actions that are not compatible (Brehm and Cohen 1962, Festinger 1962). According to Festinger (1962), dissonance is 
greatest when the two options hold equal appeal. The theory of cognitive dissonance states that when individuals have two cognitions that are inconsistent with the other, individuals will tend to seek consistency among the cognitions to eliminate the dissonance (Festinger 1962). Rationalization and neutralization are ways individuals use to reduce or eliminate dissonance. Rationalization is the need for the perpetrator to normalize the act, justify that the act is for a greater good, to reduce the emotional discord and remain in their “moral comfort zone" (Trompeter et al. 2014, Dorminey et al. 2012, Cressey 1953). Prior research suggest that justification of the act can occur before or after the fraudulent act (Dorminey et al. 2012, Fritsche 2005, Schonbach 1990, Snyder and Higgins 1988, Sykes and Matza 1957). In the forensic accounting literature, Albrecht (1991) described rationalization as occurring before the first fraud act. In the areas of social psychology and sociology, neutralization, a term that is rarely used in forensic accounting or fraud examination literature, is thought to take place before individuals engage in norm-contradicting behavior (Fritsche 2005); rationalization, on the other hand, is assumed to occur after the behavior that goes against social norm is executed to normalize the act (Sykes and Matza 1957) and to maintain a sense of control (Schonbach 1990; Snyder and Higgins 1988). Throughout the rest of the paper, I refer to neutralization as occurring before individuals make decisions to engage in norm-contradicting behavior and rationalization as occurring after the decision has been made.

\section{General Theory of Crime}

The General Theory of Crime (Gottfredson and Hirschi 1990) asserts that self-control is the crucial element in influencing individuals' decision to commit crime. Individuals with low self-control are thought to be more likely to commit crime compared to individuals with high self-control because they have a lower ability to resist reacting in accordance to their impulses (Pratt and Cullen 2005, Mischel et al. 1989). This perspective is consistent with the concept of reflective vs. impulsive acts and trait impulsivity for individuals that might commit fraud depending on the situation. The 10-80-10 Rule (most likely anecdotal) states that 10 percent of the population will never commit fraud, 10 percent of the population will definitely 
commit fraud given the opportunity (predators), and 80 percent of the population could choose to commit fraud depending on the situation (situational fraudsters) (AGA 2017). Although prior research has shown that individuals with low self-control are more likely to commit fraud when compared to other individuals, when presented with the opportunity most will not commit fraud (Perkins and Wanserski 2017, Pratt 2015). Pratt (2015) also finds that individuals who have the same level of self-control differ on their display of selfcontrol variability- they could be deliberative in some situations and impulsive in others. This is an indicator that beyond his/her level of self-control, there is more that affects an individual's decision to commit fraud especially when the individual belongs to the 80 percent of the population under the 10-80-10 Rule.

Together, research on the fraud triangle and the General Theory of Crime suggests that even when all three attributes are present for an individual, there is a possibility that he will commit fraud or vice versa. This implies that there are other individual-level factors, such as individuals' cognitive processing system and trait impulsivity that are influencing the activation or inhibition of fraud behavior. The assumption that all attributes of the fraud triangle have to be present before a fraudulent act can occur implies that the fraudulent act has to be premeditated. If so, the situational fraudster has conducted a comprehensive analysis of the situation before carrying out the fraudulent act, using the reflective system from the ReflectiveImpulsive Model to put together an action plan (Strack and Deutsch 2004) and neutralizing any emotional discord to stay in their moral comfort zone for this new situation. On the other hand, impulsive individuals tend to act first when the impulse arises, using the impulsive system and giving little consideration to whether the fraud can be detected or justifying their actions beforehand. Any emotional discord or justification for their actions would take place after, suggesting that impulsive individuals engage in rationalization, not neutralization.

\section{Hypotheses Development}

Theory predicts that when the opportunity to commit fraud is high due to the low likelihood of detection, individuals will be more likely to engage in fraud behaviors. When the opportunity to commit 
fraud is low due to the high likelihood of detection, individuals will be less likely to engage in fraud behaviors. Opportunities to commit fraud are not readily available or apparent to individuals on a day-to-day basis. When the opportunity to commit fraud arises, impulsive individuals will be more focused on the chance to increase personal gain over the likelihood of detection compared to non-impulsive individuals. Impulsive individuals are also more likely to ignore financial pressure when the opportunity to commit fraud is present when compared to non-impulsive individuals. When individuals ignore factors like pressure and likelihood of detection, focusing only on increasing their financial position when making decisions to commit fraud, neutralization does not occur. I predict that impulsive individuals will focus on their financial status and disregard other factors such as pressure and detection. This leads to the following hypothesis:

\section{$\mathrm{H}_{1}$ : When the opportunity presents itself, impulsive individuals are more likely to focus on their financial status when choosing to engage or refrain from fraudulent behavior compared to non- impulsive individuals.}

All else equal, theory states that when the pressure to commit fraud is high due to the lack of resources to maintain a certain lifestyle, individuals will be more likely to engage in fraud behaviors. When the pressure to commit fraud is low due to the low financial pressure, individuals will be less likely to engage in fraud behaviors. Impulsive individuals in the high pressure condition will more readily engage in fraudulent behaviors than impulsive individuals in the low pressure condition. In contrast with impulsive individuals, non-impulsive individuals will deliberate more before arriving at their decision to engage in fraudulent behavior when pressure is high than when pressure is low. Impulsive individuals in the high pressure condition will take less time to arrive at their decision to engage in fraudulent behavior when compared to impulsive individuals in the low pressure condition. This leads to the following hypothesis:

\section{H2: When pressure is high, impulsive individuals will take less time when deciding to engage or refrain from fraudulent behavior than when pressure is low.}


Impulsive individuals are quick to take action when making decisions, rationalizing their behavior to engage in fraud behaviors after the act has taken place if the act contradicts with their personal beliefs. Consequently, the time taken to arrive at each decision to engage in fraud behavior is shorter than nonimpulsive individuals, who will take more time to think about the decision because they need to neutralize any dissonance about the decision beforehand. This leads to the following hypothesis:

\section{H3: When precursors to fraud are present, impulsive individuals will choose to engage or refrain from fraud behaviors in less time than non-impulsive individuals.}

\section{EXPERIMENTAL DESIGN AND METHODS}

\section{Participants and Compensation}

In this study I examine individuals' reaction given the opportunity to commit a reimbursement fraud. The 2016 ACFE Report to the Nations report that perpetrators for all the frauds in the sample came from 17 different departments (ACFE 2016). As any individual working for a company may be in a position to submit reimbursements, participants can be from any background making Amazon Mechanical Turk an appropriate platform to recruit participants. 426 individuals were recruited from Amazon Mechanical Turk (MTurk) to participate in Part One of this two-part study. The requirements listed for participation in this study on MTurk were (1) individuals had to be in the United States and (2) their MTurk approval rating had to be $98 \%$ and above.

In Part One, participants completed the pre-simulation questions and in Part Two, participants completed the simulation. Participants were awarded \$0.01 for their efforts in Part One and were promised a bonus of $\$ 0.50$ when they completed Part Two. Participants' were not able to gain access to Part 2 of the study if they completed the Part One survey multiple times or if they were located outside the United States.

Seven observations were rejected due to a violation of the location requirement and another 17 observations were rejected because the participants completed the same study more than once. All other participants received a specific qualification which gave them access to Part Two when it was ready. Seven days after 
Part One was completed, Part Two of the study was made available to the rest of the pre-qualified participants on MTurk. Participants were notified about Part Two when it was available and follow-up emails were sent to remind participants about this opportunity. Participants received $\$ 1$ as a reward for completing Part Two, the aforementioned $\$ 0.50$ bonus for completing both parts of the study, and an additional bonus based on their performance in the simulation from Part Two. The additional bonus was earned in Lira during the simulation and then converted to dollars at the rate of $\$ 1$ for every 15 Lira. A detailed description of how participants earned Lira in the simulation is provided under the design section. The highest amount a participant received from the study was \$11.18 and the lowest amount paid to a participant was \$1.51. 306 participants completed both parts of the study. I tested the hypotheses using the 306 complete observations. Table 2-1 presents the participant demographics of the 306 participants.

[Insert Table 2-1 Here]

\section{Design}

A 2 (within) x 2 (within) x 2 (between) experiment was designed to involve a manipulation of the opportunity to commit fraud (within: high or low), the pressure to commit fraud (within: high or low), and trait impulsivity (between: high or low). Data were collected electronically via Qualtrics survey platform and MouselabWEB, a process tracing tool that was used to monitor the information acquisition process of individuals when they were making decisions. A description of the study was posted on MTurk and all individuals who met the two requirements set for the study were able to access the Qualtrics link to complete Part One. In Part One, participants completed the Barratt Impulsiveness Scale, part of the Narcissism Spectrum Scale ${ }^{1}$, the Social Value Orientation Slider Scale, the Risk Propensity Scale, the Cognitive Reflection Test, and the Berlin Numeracy Test. Participants were also asked to provide

\footnotetext{
${ }^{1}$ The Narcissism Spectrum Scale (NSS) (Malkin 2015) is a 9-item scale measuring three types of narcissism: echoism, healthy narcissism, and extreme narcissism. Echoism describes individuals who focus more on others at the expense of their own needs. Healthy narcissists are confident, capable of helping others and requesting for help. Extreme narcissists are manipulative, selfseeking, argumentative, and have fluctuating self-esteem. In this study I am interested in in extreme narcissists therefore I use the three items that correspond to the extreme factor in this experiment.
} 
information regarding their age, gender, years of work experience, and indicate if they have had any interaction with internal auditors in the past.

In Part Two of the study, participants read the case instructions and were asked to assume that they were an employee of WebSmart, Inc., a marketing company, and their job required them to travel each period. The case study was adapted from Holderness and Sultan (2014). Participants had to correctly answer questions about the case study before moving on to the simulation. They clicked on a link from Qualtrics to open a MouselabWEB webpage containing the simulation. The simulation in MouselabWEB lasted 10 periods. At the beginning of the simulation participants were given a small endowment of 25 Lira. In each period, participants had the opportunity to commit expense reimbursement fraud or not commit fraud at all. If they chose to commit fraud, they had the chance of adding an additional 10 Lira to their bank balance. They received a salary of 35 Lira for each period, and they could see their bank balance during each period in the simulation. Information about the household expenses (pressure) and the percentage of expense reimbursement requests selected for internal audit (opportunity) for the period were hidden behind MouselabWEB boxes. Participants could see what information the boxes contained, but the specific values were only visible when they moused over those boxes. The software records the time participants mouse in and out of the boxes and the time participants spend on the two options. In every period, there was a $20 \%$ chance that the internal audit personnel would detect the fraud. If a participant chose to commit fraud during any of the 10 periods and it was detected by the auditors, an additional 10 Lira was deducted from the participant's bank balance for each period fraud was discovered. At the end of 10 periods, participants were directed back to Qualtrics to complete the final section of the study. In the final section, participants answered some post-experiment questions in Qualtrics. Participant bonus based on the simulation was determined by converting the number of Lira they had on their bank balance after 10 periods to dollars at 
the rate of $\$ 1$ for every 15 Lira. All compensation for participation and the bonus based on performance in the simulation was paid through MTurk. Figure 2-3 is a visual depiction of the experiment sequence. ${ }^{2}$

[Insert Figure 2-3 about here]

\section{First Independent Variable - Precursors of Fraud: Pressure}

Participants received a 35 Lira salary for each period they were employed and received information about their annual household expenses in one of the MouselabWEB boxes. At any point in time during the simulation participants were able to see the balance in their bank account. Annual household expenses could be higher or lower than their salary for the period. In periods of high pressure, household expenses were 40 Lira, which was 5 Lira higher than their 35 Lira salary. When pressure was low, their household expenses were 30 Lira. They were only able to view the amount of household expenses incurred when they moved their cursor over the specific household expenses box. In the simulation, it was possible for participant's bank balance to be negative.

\section{Second Independent Variable - Precursors of Fraud: Opportunity}

The participant's opportunity to successfully commit expense reimbursement fraud was related to the extent that the internal audit department examined reimbursement records. The participants were informed that the internal audit department has many responsibilities and does not examine every expense reimbursement disbursement. Each period, the extent of the internal audit of expense reimbursements were hidden behind a MouselabWEB box. To access the audit information, participants would have to move their cursor over the specific box. Participants were told that if the extent of the internal audit on expense reimbursement was $10 \%$, it meant that there was a $10 \%$ probability that the fraud was going to be detected by the auditors. As operationalized in the simulation, when perceived opportunity to commit fraud is high, extent of the internal audit of expense reimbursement records was $10 \%$. On the other hand, participants were

\footnotetext{
${ }^{2}$ A pilot test was conducted with 25 students to test Part Two and ensure that the case instructions were clear, the simulation paths worked well, and there were no other mechanical issues with the MouselabWEB pages.
} 
told that when the perceived opportunity to commit fraud is low, the extent of the internal audit of expense reimbursement was $30 \%$.

\section{Third Independent Variable- Impulsivity}

Trait impulsivity was measured with the 30-item Barratt Impulsiveness Scale (BIS) (Patton et al. 1995). The Barratt Impulsiveness Scale (BIS) was the most widely used scale to measure trait impulsivity (Stanford et al. 2009, Patton et al. 1995, Barratt et al. 1975). Based on the BIS, a high score could be a result of relatively strong impulsive processes and/or relatively weak reflective processes (Stanford et al. 2009, Barratt et al. 1975). An individual with a high BIS score may have a personal challenge with keeping impulses under control once the impulse is activated and possess a lower level of intelligence (Shamosh et al. 2008). Participants completed this scale one week before participating in the simulation.

\section{Dependent Variable - Decision to Commit Fraud}

For each period in the simulation, participants were presented with two choices: (1) submit an inflated expense reimbursement request or (2) submit the expense reimbursement request without inflating it. On MouselabWEB, participants had two buttons representing the choices described above. For each period, participants were required to decide if they wanted to submit their reimbursement request as is or submit an inflated reimbursement request, knowing that if the inflated reimbursement request was not detected by the internal auditor, they would gain financially from the decision to inflate their reimbursement request. Participants were not able to move on to the next period of the simulation until they chose an option and clicked on the "submit" button. Participants' decision to commit fraud was recorded as a dummy variable in each period, with 1 indicating that they decided to inflate the reimbursement request and 0 if otherwise ${ }^{3}$.

\footnotetext{
${ }^{3}$ FRAUD_OCCURRENCE_PROPORTION, a variable computed by adding up all the times a participant decided to steal then divided by the 10 periods in the simulation, was used as a dependent variable for sensitivity analysis. Results obtained using FRAUD_OCCURRENCE_PROPORTION is qualitatively similar to the dummy variable reported in the results section of the study when comparing between impulsive and non-impulsive individuals. Fraud amount was not used as a dependent variable as 


\section{Dependent Variable - Time Taken to Make Decisions about Inflating Reimbursement}

To test how much participants engage in any rationalization/neutralization to justify their decisions to engage or refrain from committing fraud, the amount of time participants spent on the pressure box, the opportunity box, and the time spent hovering around the two decision buttons was recorded with MouselabWEB. The use of MouselabWEB enabled the recording of the amount of time participants spent on the information provided by capturing the movement of the cursor on the screen. To access the information, participants had to move the mouse pointer over the boxes on the screen with labels indicating what information was hidden beneath. When the pointer was over a specific box, the corresponding information was displayed. The time taken to make decisions about inflating reimbursement was obtained by adding up the time spent on the pressure box, the opportunity box, and the decision buttons before participants elected to submit their reimbursement requests. The more time participants spent on the information given, the more likely participants were engaging in neutralization. Impulsive individuals, with the tendency to activate behavior quickly, should not have spent as much time as non-impulsive individuals when deciding to engage or refrain from fraud as they were not likely to engage in neutralization.

\section{Control Variables ${ }^{4}$}

Participants answered questions from multiple scales to measure constructs that could affect their decisions in the simulation. To measure individuals' general risk-taking tendencies, the 7-item Risk Propensity Scale (Meertens and Lion 2008) was used. The 1-item Berlin Numeracy test (Cokely et al. 2012) was used to measure risk literacy whereas the "Extreme" subscale questions from the Narcissism Spectrum Scale (Malkin 2015) was used to measure individuals' narcissistic tendencies. The Berlin Numeracy test and part of the NSS were included as prior research find that narcissism and risk literacy affect individuals'

\footnotetext{
the amount of inflation is a constant 10 Lira each period and the outcome would be similar to the FRAUD_OCCURRENCE_PROPORTION variable.

${ }^{4}$ These variables were measured in Part 1 of the study one week before Part Two, which contained the simulation, was presented to the participant.
} 
decision to commit fraud. In addition, I used the Social Value Orientation Slider Scale (Murphy et al. 2011) to measure the magnitude of concern individuals' have for others. Other control variables collected include age, gender, work experience, and prior interaction with internal auditors. For the ANCOVA analysis, control variables that had p-values more than 0.450 were removed. This did not change the significance of the ANCOVA results.

\section{RESULTS}

\section{Descriptive Statistics}

As reported earlier, 426 participants completed Part One of the study advertised on MTurk but only 306 participants completed both parts of the study. The data from participants who completed the entire study were used to test the hypotheses presented in this paper. The simulation generated 3060 observation periods from the 306 participants for conducting empirical analysis. ${ }^{5}$ Of the 3060 periods played in the simulation, participants chose to commit fraud during 1207 periods. Fraud was detected during 310 periods, which was about $25 \%$ of all fraud occurrences. At a participant-level, 241 participants $(78.76 \%)$ chose to commit fraud at least once during the simulation. Figure 2-4 shows the number of times participants chose to commit fraud during the simulation. Table 2-2 presents descriptive statistics on key variables, including those that were used to conduct statistical tests in the study.

[Insert Table 2-2 and Figure 2-4 about here]

\section{The Effect of Opportunity on Individuals' Decision to Commit Fraud}

Theory dictates that individuals are more likely to choose to commit fraud when the opportunity to commit fraud is high than when the opportunity to commit fraud is low (Albrecht et al. 2008). I conducted a Chi-Square test (untabulated) to examine if this is true for this study and find that when the opportunity to commit fraud is high, individuals are more likely to commit fraud than when the opportunity to commit

\footnotetext{
5 The simulation lasted for 10 periods for each participant.
} 
fraud is low $\chi^{2}(1, \mathrm{~N}=3060)=211.254, \mathrm{p}<0.001$. The first hypothesis predicts that when the opportunity presents itself, impulsive individuals will be more likely to focus on increasing their financial gain over other factors when making the decision to commit fraud than non-impulsive individuals. To test this hypothesis, I split the continuous IMPULSIVITY variable at the median to get two conditions: high impulsivity and low impulsivity. From the MouselabWEB simulation, it is possible to identify periods when participants do not mouse over the pressure box (PRESSURE_MS =0) and the opportunity box (OPPORTUNITY_MS =0). Without looking at the information hidden beneath the boxes, the only information available to the participants in each period is their bank balance. I infer that when participants do not take the time to look at the household expenses or the possibility of detection, they are solely interested in making the decision to inflate their reimbursement request or refrain from doing so based on the number on their bank balance. A Chi-Square test was done to test H1. The results (untabulated) suggest that impulsive individuals were significantly more likely to make the decision to commit fraud or refrain from it by looking only at their bank balance compared to non-impulsive individuals, $\chi^{2}(1$, $\mathrm{N}=3060)=70.614, \mathrm{p}<0.001$, thus supporting Hypothesis 1 . The disregard for factors other than bank balance suggest that impulsive individuals do not engage in neutralization before deciding to commit fraud or refrain from it.

\section{The Effect of Pressure on Impulsive Individuals' Decision to Commit Fraud}

Per theory, it is expected that individuals are more likely to commit fraud when financial pressure is high than when financial pressure is low (Albrecht et al. 2008). A Chi-Square test (untabulated) examining if this holds true for this study provides support for the theory, indicating that individuals are more likely to decide to inflate reimbursement requests when the financial pressure is high compared to when financial pressure is low, $\chi^{2}(1, \mathrm{~N}=3060)=3.559, \mathrm{p}=0.059$. Hypothesis 2 posits that when pressure is high, impulsive individuals will take less tim7e when deciding to engage or refrain from fraudulent behavior than when 
pressure is low. Examining only observations when IMPULSIVITY is high ${ }^{6}$, an untabulated t-test of PRESSURE (high vs. low) and time taken to arrive at decision (TIME_TAKEN_TO_DECISION_MS) suggests that impulsive individuals take less time to make decisions about committing fraud in periods of high pressure than in periods of low pressure $(t=1.49, \mathrm{p}=0.068$, one-tailed $)$.

In Hypothesis 1, I find that impulsive individuals are more likely than non-impulsive individuals to focus on their bank balance when making decisions. To reduce the likelihood that the marginally significant result obtained from the t-test to examine Hypothesis 2 above is driven by the low amounts of TIME_TAKEN_TO_DECISION_MS when the participants focus only on their bank balance, I exclude 842 observations of participants in periods where they only looked at their bank balance as a robustness check. Untabulated results of the t-test excluding the 842 observations yielded similar results to the earlier t-test. Impulsive individuals take less time to make decisions to commit fraud or refrain from it when pressure is high than when pressure is low $(\mathrm{t}=1.829, \mathrm{p}=0.034$, one-tailed). Hypothesis 2 is supported.

\section{The Effect of Pressure, Opportunity, and Impulsivity on Individuals' Decision to Commit Fraud}

Hypothesis 3 predicts that when precursors to fraud are present, impulsive individuals will choose to engage or refrain from fraud behaviors in less time than non-impulsive individuals. A PRESSURE (high vs. low) x OPPORTUNITY (high vs. low) x IMPULSIVITY (continuous) ANCOVA was used to test Hypothesis 3. There is a marginally significant three-way interaction between PRESSURE, OPPORTUNITY, and IMPULSIVITY, $\mathrm{F}(50,2837)=1.260, \mathrm{p}=0.052$, one-tailed. Results are summarized in Table 2-3. To conduct simple effects tests and to graph the results, the IMPULSIVITY variable was split at the median. Analysis of Figure 2-5 and Figure 2-6 suggests that individuals react differently when OPPORTUNITY is low compared to when OPPORTUNITY is high. When OPPORTUNITY is low, impulsive and non-impulsive individuals

\footnotetext{
${ }^{6}$ Examining observations for non-impulsive individuals (IMPULSIVITY-low) to see if the results are different from impulsive individuals, I find that non-impulsive individuals react differently to impulsive individuals when pressure is high - non-impulsive individuals spend more time deliberating about inflating reimbursement requests when pressure is high compared to when pressure is low ( $t=1.741, p=0.041$, one-tailed, untabulated).
} 
are not impacted by PRESSURE and do not differ much in the amount of time taken to decide to commit fraud or refrain from it. A simple effects test confirms that there is no significant difference in the amount of time individuals take to decide to commit fraud or refrain from it when PRESSURE is high versus low (Impulsive individuals: $\mathrm{p}=0.331$, one-tailed; Non-impulsive individuals: $\mathrm{p}=0.350$, one-tailed). Figure 2-5 also shows that when OPPORTUNITY to commit fraud is high, impulsive individuals spend less time reaching a decision when PRESSURE is high but they take a longer time deliberating when PRESSURE is low. Even though it seems the difference between time taken when PRESSURE is high and when PRESSURE is low is great, simple effects tests indicate that there is no significant difference in the time taken to arrive at a decision ( $\mathrm{p}=0.126$, one-tailed) for impulsive individuals. Figure $2-6$ depicts the time taken to decision for non-impulsive individualso as longer when PRESSURE is high compared to when PRESSURE is low. Simple effect test for non-impulsive individuals when OPPORTUNITY is high confirms that the difference between time taken to arrive at a decision is significantly higher when PRESSURE is high than when PRESSURE is low ( $\mathrm{p}=0.022$, one-tailed). From the two figures, the results suggest that impulsive individuals take less time to make decisions about whether to submit inflated reimbursements or otherwise than non-impulsive individuals. As a robustness test, participants were divided into impulsive and non-impulsive groups using the CRT and iCRT scores. Results for simple effects tests and figures show similar patterns as the IMPULSIVITY variable. Hypothesis 3 is supported.

[Insert Table 2-3, Figures 2-5, and 2-6 about here]

\section{Additional Analyses}

Dividing participants into impulsive versus non-impulsive groups using the IMPULSIVITY variable, a Chi-Square test demonstrates that there is no significant difference in the decision to submit inflated reimbursement requests between the two groups $\mathcal{X}^{2}(1, \mathrm{~N}=3060)=2.169, \mathrm{p}=0.141$. As a robustness test, another Chi-square test was done using the CRT and iCRT scores to divide participants into impulsive 
versus non-impulsive groups. The results support the finding from the IMPULSIVITY variable, suggesting there is no difference between the decision to submit inflated reimbursement requests among the two groups, $\chi^{2}(1, \mathrm{~N}=3060)=0.138, \mathrm{p}=0.710$. These findings indicate that any differences found between impulsive and non-impulsive variables are not driven by one group stealing more or less than the other. To attempt to understand participants' considerations during the simulation, participants answered six post-simulation questions that led to six different process variables. BANK_BALANCE_INFLUENCE measured how much participants were influenced by their bank balance when they made the decision to commit fraud or refrain from it. An untabulated t-test examining the BANK_BALANCE_INFLUENCE and IMPULSIVITY (high vs. low) suggest that impulsive individuals were more influenced by their bank balance when making decisions in the simulation compared to non-impulsive individuals $(\mathrm{t}=1.639, \mathrm{p}=0.051$, onetailed). This is consistent with $\mathrm{H} 1$.

For Hypothesis 2 the focus was centered on impulsive individuals. Besides focusing on impulsive individuals, I also examine the difference in reaction between impulsive and non-impulsive individuals when there are differences in pressure. Additional analyses were conducted to determine if there is a difference between TIME_TAKEN_TO_DECISION_MS and IMPULSIVITY (high vs. low) when PRESSURE is high and when PRESSURE is low. T-tests (untabulated) suggest that when PRESSURE is high, impulsive individuals spend significantly less time on decision making than non-impulsive individuals $(\mathrm{t}=2.459, \mathrm{p}=0.007$, one-tailed). However, when PRESSURE is low, the average time taken to make decisions between impulsive and non-impulsive individuals is not-significant ( $\mathrm{t}=0.662, \mathrm{p}=0.264$, one-tailed). A test of process variables exploring the influence of pressure (PRESSURE_INFLUENCE) on their decision to commit fraud suggest that impulsive individuals are more influenced by PRESSURE compared to nonimpulsive individuals $(\mathrm{t}=0.726, \mathrm{p}=0.062$, one-tailed $)$. 
Some other process variables collected at the end of the simulation were REMORSE, which recorded participants' remorse over making decisions related to submitting inflated reimbursements, and DIFFICULT_DECISION, a variable that captured the emotional difficulty participants faced when deciding to inflate reimbursements. Both variables were measured on a one to seven scale, with seven being very difficult for DIFFICULT_DECISION and strongly agree about feeling remorse for submitting inflated reimbursement requests for REMORSE. An untabulated t-test of DIFFICULT_DECISION demonstrates that non-impulsive individuals found it significantly more difficult to submit inflated reimbursements than impulsive individuals ( $\mathrm{p}=0.043$, two-tailed). Non-impulsive individuals provided a higher rating for the REMORSE variable ( $\mathrm{p}=0<0.01$, two-tailed, untabulated), suggesting that immediately after the simulation, they already felt more remorseful over their decisions compared to impulsive individuals. Taken altogether, non-impulsive individuals seem to be neutralizing the decision during the simulation, taking a much longer time to arrive at a decision each period when compared to impulsive individuals. Even then, non-impulsive individuals were more likely to still struggle emotionally regarding their decision after the simulation than impulsive individuals.

\section{CONCLUSION}

Consistent with theory, individuals commit fraud at a higher rate when financial pressure is high and when opportunity to commit fraud without detection is high. The purpose of this study is to examine whether fraud triangle parts of the pressure, opportunity, and the neutralization attributes hold for impulsive individuals. I investigated the impact of individuals' impulsivity on their decisions to commit fraud when precursors to fraud behavior is present. I find that given the opportunity, impulsive individuals are more likely than non-impulsive individuals to be willing to ignore other factors (e.g. internal audit detection when making decisions related to fraud). When pressure is high, impulsive individuals will react faster and make decisions regarding fraud quicker than when pressure is low. Although impulsive and non-impulsive 
individuals react differently time-wise when opportunity to commit fraud is high, impulsive individuals still take less time overall when making decisions to commit fraud or to refrain from doing so. This shows that impulsive individuals are more likely to use the impulsive processing system without engaging the reflective processing system. Non-impulsive individuals, more likely to use the reflective processing system, also report having more difficulty when deciding to engage in fraud behavior. This suggests that they were using the reflective processing system to reduce any emotional discord before making the decision. As a whole, results show that non-impulsive individuals take more time to make fraud decisions, suggesting that they may engage in neutralization before deciding to commit fraud whereas impulsive individuals bypass the neutralization attribute of the fraud triangle when reaching the decision to commit fraud or refrain from it.

The manipulated pressure condition in this simulation does not mirror the multitude of pressures individuals face in everyday life. The threat of fraud detection in the simulation was also not of the same magnitude as it would be if fraud was detected by internal auditors of companies. The minimal consequence to the participants when the fraud is detected meant that participants could have been bolder and decided to commit fraud at a higher rate than they probably would have in a different situation. One limitation of this paper is that I do not examine methods to reduce the influence of individuals' impulsive tendencies when they are tempted to react to their impulses in the presence of an opportunity to commit fraud. Prior work in psychology find that working memory training helps to stifle the impulsive tendency and increase the strength of the reflective process to help individuals keep to their health goals (Houben et al. 2011). One method to reduce the influence of the impulsive process when it relates to unhealthy behaviors is to conduct attentional bias modification training, which encourages individuals to detach their focus on unhealthy stimuli (Fadardi and Cox 2009, Koningsbruggen et al. 2014). Another limitation of this study is the results are not generalizable to collusive frauds and predators as the research focuses on solo frauds perpetrated by situational fraudsters. 
These results provide new insight into the impact of pressure, opportunity, and impulsivity on decisions to commit fraud. More importantly, the results contribute to the white-collar crime literature and show that the fraud triangle does not apply to impulsive individuals as they bypass the neutralization phase when making decisions to commit fraud. Future research should examine if there are other situations where the fraud triangle might not be applicable. Further research should also be done on methods to reduce impulsive tendencies that are already in psychology to determine if those can be applied in the fraud deterrence setting. 


\section{References}

Alalehto, T. (2003). Economic crime: Does personality matter? International Journal of Offender Therapy and Comparative Criminology, 47(3), 335-355.

Albrecht, C., Kranacher M., Albrecht, S. (2008). Asset Misappropriation Research White Paper for the Institute for Fraud Prevention. Available on http://www.theifp.org/research-grants/IFP-Whitepaper5.pdf

Albrecht, W.S. (1991). Fraud in Governmental Entities: The Perpetrators and Types of Fraud. Government Finance Review, 7(6), 27-30.

Albrecht, W. S., K. R. Howe, and M. B. Romney. (1984). Deterring Fraud: The Internal Auditor's Perspective. Altomonte Springs, FL: The Institute of Internal Auditors' Research Foundation.

Alvarez, P., and Squire, L. R. (1994). Memory consolidation and the medial temporal lobe: a simple network model. Proceedings of the National Academy of Sciences, 91(15), 7041-7045.

Anand, V., Dacin, M. T., and Murphy, P. R. (2015). The continued need for diversity in fraud research. Journal of Business Ethics, 131(4), 751-755.

Association of Certified Fraud Examiners (ACFE). (2016). Report to the Nations on Occupational Fraud and Abuse. Austin, TX: ACFE.

Association of Government Accountants (AGA). Retrieved March 4, 2017, from https://www.agacgfm.org/Fraud-Prevention-Toolkit/Fraud-Awareness-Mitigation/Fraud-Triangle.aspx

Barratt, E. S., Patton, J., and Stanford, M. (1975). Barratt Impulsiveness Scale. Barratt-Psychiatry Medical Branch, University of Texas.

Barratt, E. S. (1983). The biological basis of impulsiveness: the significance of timing and rhythm disorders. Personality and individual differences, 4(4), 387-391.

Bishop, C.C., Hermanson, D.R., Riley, and R.A. Jr. (2016). Collusive Fraud: Leader, Fraud, and Organizational Characteristics. Working Paper

Bogg, T., and Roberts, B. W. (2004). Conscientiousness and health-related behaviors: a meta-analysis of the leading behavioral contributors to mortality. Psychological Bulletin, 130(6), 887.

Boyle, D. M., DeZoort, F. T., Hermanson, and D. R., Wolfe, D. T. (2018). Improving fraud risk management with an enhanced Fraud Triangle. Fraud Magazine. Retrieved online http://www.fraudmagazine.com/article. aspx . $i d=4295000903 \&$ Site $=$ ACFEWEB

Brehm, J. W., and Cohen, A. R. (1962). Explorations in cognitive dissonance. Hoboken, NJ, US: John Wiley \& Sons Inc.

Cacioppo, J. T., Petty, R. E., and Feng Kao, C. (1984). The efficient assessment of need for cognition. Journal of personality assessment, 48(3), 306-307.

Cacioppo, J. T., and Petty, R. E. (1982). The need for cognition. Journal of personality and social psychology, 42(1), 116.

Carver, C. S. (2005). Impulse and constraint: Perspectives from personality psychology, convergence with theory in other areas, and potential for integration. Personality and Social Psychology Review, 9(4), 312-333.

Cohen, A. R., Stotland, E., and Wolfe, D. M. (1955). An experimental investigation of need for cognition. The Journal of Abnormal and Social Psychology, 51(2), 291.

Cokely, E. T., Galesic, M., Schulz, E., Ghazal, S., and Garcia-Retamero, R. (2012). Measuring risk literacy: The Berlin numeracy test. Judgment and Decision Making, 7(1), 25.

Collins English Dictionary Online, Retrieved March 3, 2017, from https://www.collinsdictionary.com/us/dictionary/english/impulsivity

Cressey, D. R. (1950). The criminal violation of financial trust. American Sociological Review, 15(6), 738743. 
Cressey, D. R. (1953). Other people's money; a study of the social psychology of embezzlement. New York, NY: The Free Press.

Cueva, C., Iturbe-Ormaetxe, I., Mata-Pérez, E., Ponti, G., Sartarelli, M., Yu, H., and Zhukova, V. (2016). Cognitive (ir) reflection: New experimental evidence. Journal of Behavioral and Experimental Economics, 64, 81-93.

De Wit, H. (2009). Impulsivity as a determinant and consequence of drug use: a review of underlying processes. Addiction biology, 14(1), 22-31.

Deutsch, R., and Strack, F. (2008). Variants of Judgment and Decision Making; The Perspective of the Reflective-Impulsive Model. Intuition in judgment and decision making, 39-53.

Dorminey, J. W., Fleming, A. S., Kranacher, M., and Riley, R. A. (2010). Beyond the fraud triangle. The CPA Journal, 80(7), 17-23.

Dorminey, J., Fleming, A. S., Kranacher, M. J., and Riley Jr, R. A. (2012). The evolution of fraud theory. Issues in Accounting Education, 27(2), 555-579.

Fadardi, J. S., and Cox, W. M. (2009). Reversing the sequence: reducing alcohol consumption by overcoming alcohol attentional bias. Drug and alcohol dependence, 101(3), 137-145.

Festinger, L. (1962). Cognitive dissonance. Scientific American, 207(4), 93-106.

Frederick, S. (2005). Cognitive reflection and decision making. The Journal of Economic Perspectives, 19(4), 25-42.

Friese, M., and Hofmann, W. (2009). Control me or I will control you: Impulses, trait self-control, and the guidance of behavior. Journal of Research in Personality, 43, 795-805.

Fritsche, I. (2005). Predicting deviant behavior by neutralization: Myths and findings. Deviant Behavior, 26(5), 483-510.

Gollwitzer, P. M. (1999). Implementation intentions: Strong effects of simple plans. American psychologist, 54(7), 493.

Gottfredson, M. R., and T. Hirschi. (1990). A General Theory of Crime. Stanford, CA: Stanford University Press.

Gullo, M. J., \& Dawe, S. (2008). Impulsivity and adolescent substance use: Rashly dismissed as "allbad"?. Neuroscience \& Biobehavioral Reviews, 32(8), 1507-1518.

Hermanson, D. R., Justice, S. E., Ramamoorti, S., and Riley Jr, R. A. (2017). Unique characteristics of predator frauds. Journal of Forensic Accounting Research, 2(1), A31-A48.

Hofmann, W., Rauch, W., and Gawronski, B. (2007). And deplete us not into temptation: Automatic attitudes, dietary restraint, and self-regulatory resources as determinants of eating behavior. Journal of Experimental Social Psychology, 43(3), 497-504.

Hofmann, W., Friese, M., and Wiers, R. W. (2008). Impulsive versus reflective influences on health behavior: A theoretical framework and empirical review. Health Psychology Review, 2(2), 111-137.

Hofmann, W., Strack, F., \& Deutsch, R. (2008). Free to buy? Explaining self-control and impulse in consumer behavior. Journal of Consumer Psychology, 18(1), 22-26.

Holderness, Jr., D. Kip, Negangard, E. M., and Sultan, J. (2018). Are Individuals More Likely to Misappropriate During Economic Recessions or Expansions? An Examination of the Relative Impact of Pressure and Opportunity. Journal of Forensic and Investigative Accounting, 10(1), 15-37.

Houben, K., Wiers, R. W., and Jansen, A. (2011). Getting a grip on drinking behavior: training working memory to reduce alcohol abuse. Psychological science, 22(7), 968-975.

Koningsbruggen, G. M., Veling, H., Stroebe, W., and Aarts, H. (2014). Comparing two psychological interventions in reducing impulsive processes of eating behaviour: Effects on self-selected portion size. British Journal of Health Psychology, 19(4), 767-782.

Kranacher, M. J., R. A. Riley Jr., and J. T. Wells. (2011). Forensic Accounting and Fraud Examination. New York, NY: John Wiley \& Sons 
Lieberman, M. D., Gaunt, R., Gilbert, D. T., and Trope, Y. (2002). Reflection and reflexion: A social cognitive neuroscience approach to attributional inference. Advances in experimental social psychology, 34, 199-249.

Malkin, C. (2015). Rethinking Narcissism: The Bad---and Surprising Good---About Feeling Special. HarperCollins.

McClelland, J. L., McNaughton, B. L., and O'reilly, R. C. (1995). Why there are complementary learning systems in the hippocampus and neocortex: insights from the successes and failures of connectionist models of learning and memory. Psychological review, 102(3), 419.

Meertens, R. M., and Lion, R. (2008). Measuring an individual's tendency to take risks: The risk propensity scale1. Journal of Applied Social Psychology, 38(6), 1506-1520.

Mischel, W., Shoda, Y., and Rodriguez, M. L. (1989). Delay of gratification in children. Science, 244(4907), 933.

Murphy, R. O., Ackermann, K. A., and Handgraaf, M. (2011). Measuring social value orientation. Judgment and Decision Making. 6(8), 771-781.

Patton, J. H., and Stanford, M. S. (1995). Factor structure of the Barratt impulsiveness scale. Journal of Clinical Psychology, 51(6), 768-774.

Paunonen, S. V., and Ashton, M. C. (2001). Big five factors and facets and the prediction of behavior. Journal of Personality and Social Psychology, 81(3), 524.

Perkins, R., and J. Wanserski. 2017. Beyond Fraud Geometry: The Fraud Flow Model. Working paper, Mercer University.

Perri, F. S. (2011). White-Collar Criminals: The 'Kinder, Gentler, Offender?. Journal of Investigative Psychology and Offender Profiling, 8(3), 217-241.

Pratt, T. C., and Cullen, F. T. (2005). Assessing macro-level predictors and theories of crime: A metaanalysis. Crime and justice, 32, 373-450.

Pratt, T. C. (2015). A reconceptualized model of self-control and crime: specifying the role of self-control variability. Criminal justice and behavior, 42(6), 662-679.

Ramamoorti, S. (2008). The psychology and sociology of fraud: Integrating the behavioral sciences component into fraud and forensic accounting curricula. Issues in Accounting Education, 23(4), 521533.

Romer, D., Betancourt, L., Giannetta, J. M., Brodsky, N. L., Farah, M., and Hurt, H. (2009). Executive cognitive functions and impulsivity as correlates of risk taking and problem behavior in preadolescents. Neuropsychologia, 47(13), 2916-2926.

Schönbach, P. (2010). Account episodes: The management or escalation of conflict. Cambridge University Press.

Shamosh, N. A., Deyoung, C. G., Green, A. E., Reis, D. L., Johnson, M. R., Conway, A. R., Engle, R. W., Braver, T. S., and Gray, J. R. (2008). Individual differences in delay discounting: relation to intelligence, working memory, and anterior prefrontal cortex. Psychological Sciences. 19, 904-911.

Simon, H. (1990). Reason in human affairs. Stanford University Press.

Smith, E. R.,and DeCoster, J. (2000). Dual-process models in social and cognitive psychology: Conceptual integration and links to underlying memory systems. Personality and social psychology review, 4(2), 108-131.

Snyder, C. R., and Higgins, R. L. (1988). Excuses: their effective role in the negotiation of reality. Psychological bulletin, 104(1), 23.

Stanford, M. S., Mathias, C. W., Dougherty, D. M., Lake, S. L., Anderson, N. E., and Patton, J. H. (2009). Fifty years of the Barratt Impulsiveness Scale: An update and review. Personality and Individual Differences, 47(5), 385-395. 
Steinberg, L., Albert, D., Cauffman, E., Banich, M., Graham, S., and Woolard, J. (2008) Age differences in sensation seeking and impulsivity as indexed by behavior and self-report: evidence for a dual systems model. Developmental Psychology, 44, 1764-78.

Strack, F., and Deutsch, R. (2004). Reflective and impulsive determinants of social behavior. Personality and Social Psychology Review, 8(3), 220-247.

Strack, F., Werth, L., and Deutsch, R. (2006). Reflective and impulsive determinants of consumer behavior. Journal of Consumer Psychology, 16(3), 205-216.

Sykes, G. M., and Matza, D. (1957). Techniques of neutralization: A theory of delinquency. American sociological review, 22(6), 664-670.

Tangney, J. P., Baumeister, R. F., and Boone, A. L. (2004). High self-control predicts good adjustment, less pathology, better grades, and interpersonal success. Journal of Personality, 72(2), 271-324.

Trompeter, G. M., Carpenter, T. D., Jones, K. L., and Riley Jr, R. A. (2014). Insights for research and practice: What we learn about fraud from other disciplines. Accounting Horizons, 28(4), 769-804.

Tversky, A., and Kahneman, D. (1974). Judgment under uncertainty: Heuristics and biases. science, 185(4157), 1124-1131.

Whiteside, S. P., and Lynam, D. R. (2001). The five factor model and impulsivity: Using a structural model of personality to understand impulsivity. Personality and Individual Differences, 30(4), 669-689.

Wittmann, M., and Paulus, M. P. (2008). Decision making, impulsivity and time perception. Trends in Cognitive Sciences, 12(1), 7-12.

Wolfe, D. T., and D. Hermanson. (2004). The Fraud Diamond: Considering the four elements of fraud. The CPA Journal (December). 
FIGURE 2-1

The Fraud Triangle (Albrecht 1991)

\section{The Fraud Triangle}

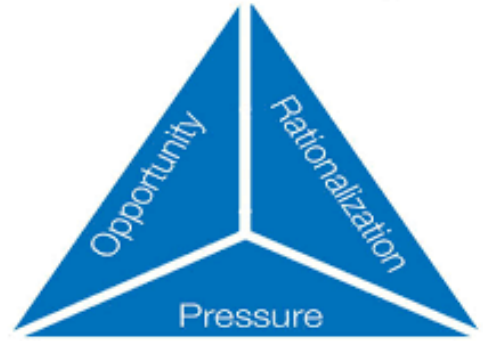


FIGURE 2-2

The Reflective-Impulsive Model (Adapted from Strack and Deutsch 2004)

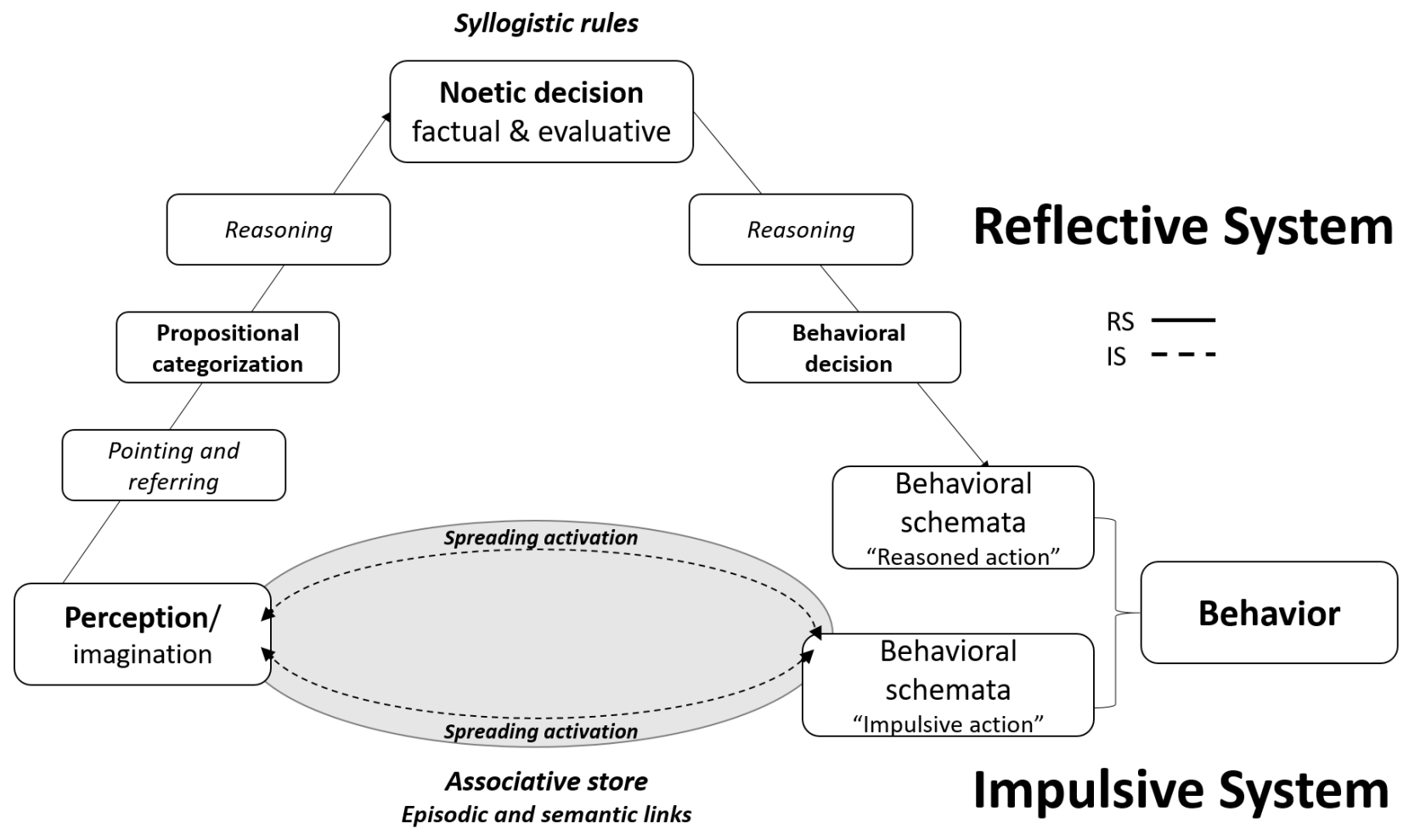


FIGURE 2-3

\section{Experiment Sequence}

\section{Methods - Experiment Sequence}

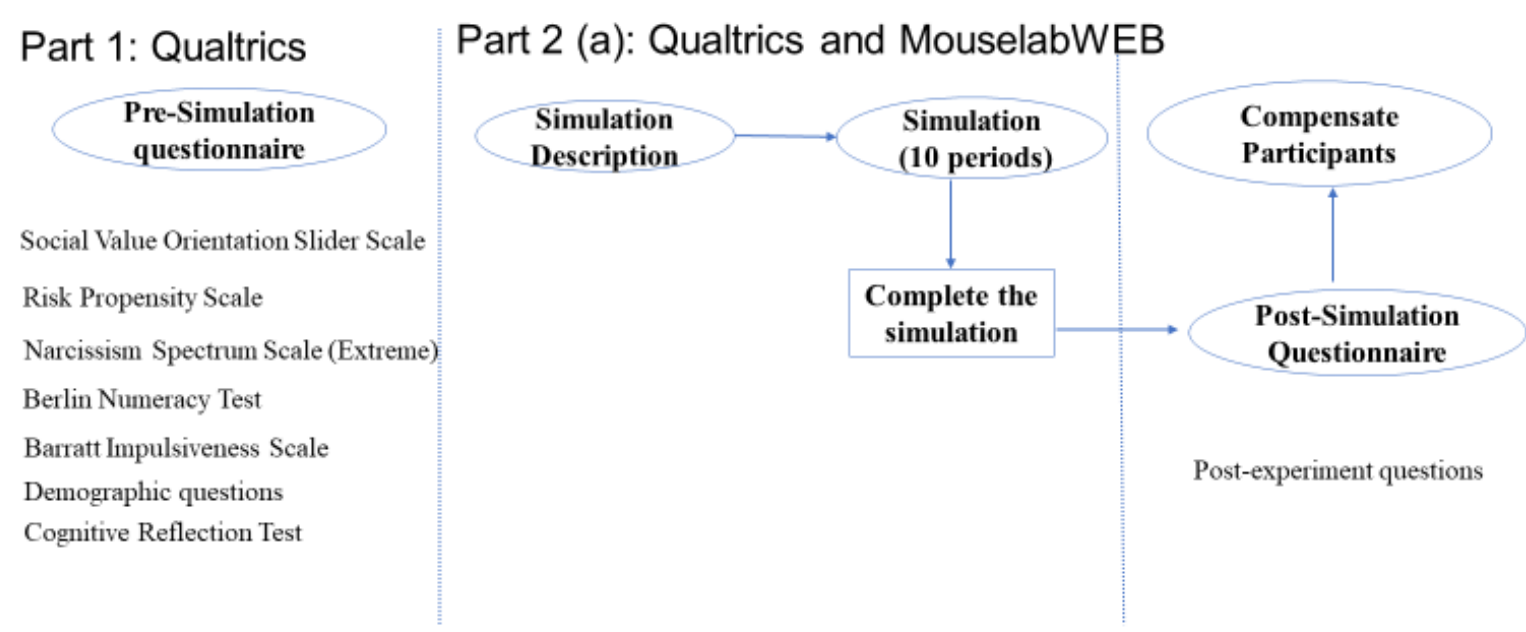


FIGURE 2-4

Graph of Frequency of the Number of Periods Participants Chose to Commit Fraud

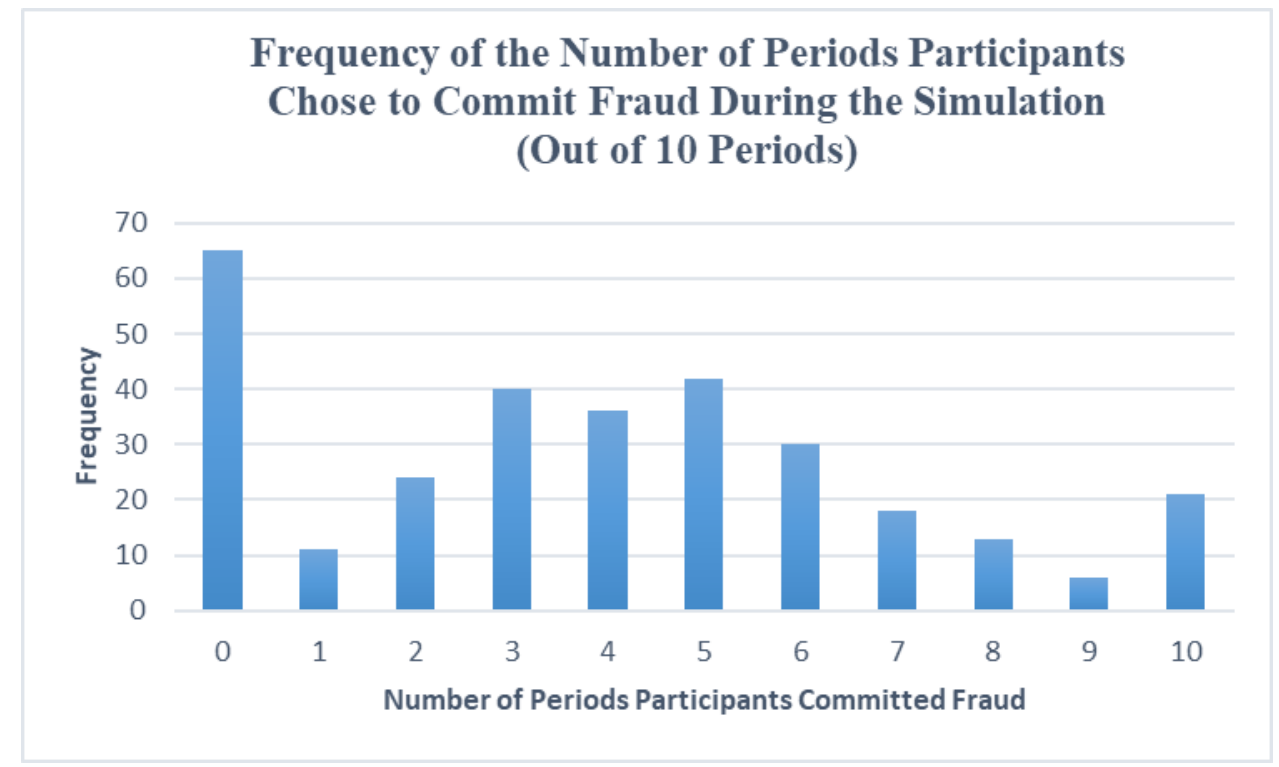


FIGURE 2-5

Graph of Estimated Marginal Means of Time Taken to Make Decision for Impulsive Individuals

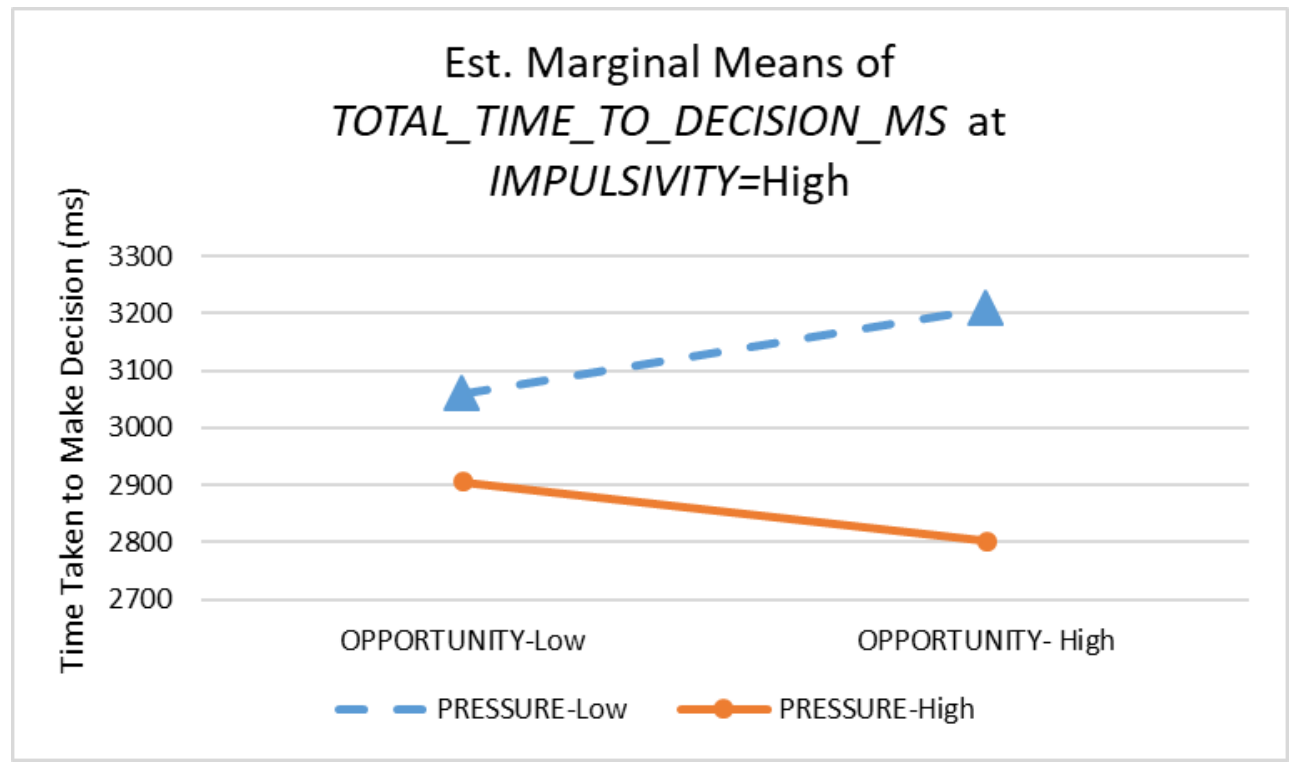


FIGURE 2-6

Graph of Estimated Marginal Means of Time Taken to Make Decision for Non-Impulsive Individuals

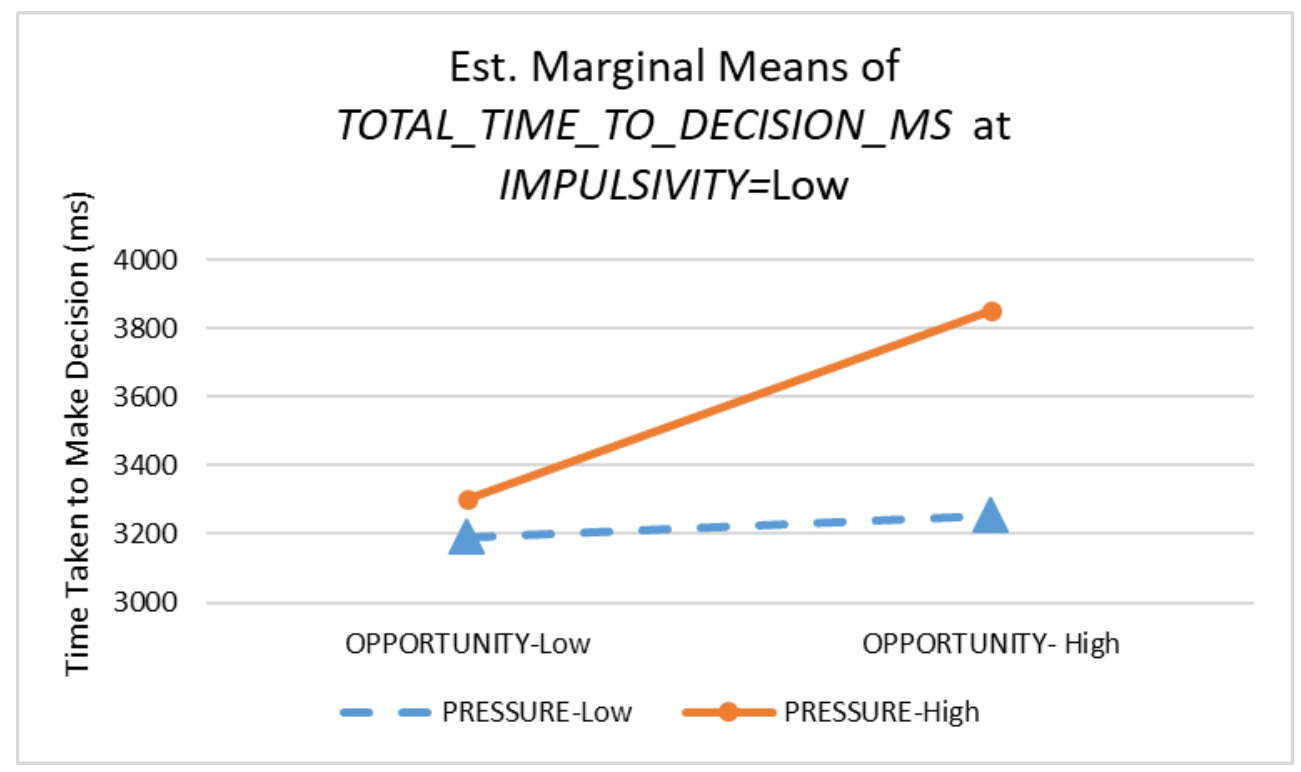


TABLE 2-1

Participant Demographics

\begin{tabular}{|c|c|c|c|c|}
\hline & & & Number & Percent \\
\hline \multirow[t]{3}{*}{ Gender } & Female & & 198 & $65 \%$ \\
\hline & Male & & 108 & $35 \%$ \\
\hline & $\mathrm{n}$ & & 306 & $100 \%$ \\
\hline \multirow[t]{4}{*}{ Interacted with Internal Auditors } & Yes & & 115 & $38 \%$ \\
\hline & No & & 191 & $62 \%$ \\
\hline & $\mathrm{n}$ & & 306 & $100 \%$ \\
\hline & $\underline{n}$ & Mean & $(S . D)$. & \\
\hline Age & 306 & 36.88 & $(10.510)$ & \\
\hline Years of Work Experience & 306 & 15.98 & $(10.303)$ & \\
\hline
\end{tabular}


TABLE 2-2

\section{Descriptive Statistics}

Periods Played (N)

Periods when Fraud Occurred

\begin{tabular}{cc} 
Number & Percent \\
\hline 3060 & $100 \%$ \\
1207 & $39.44 \%$ \\
310 & $10.13 \%$
\end{tabular}

Periods when Fraud was Detected

Number of Times Participants Chose to Commit Fraud During the Simulation (Out of 10

Periods)

Zero

$65 \quad 21.24 \%$

One Time

Two Times

$11 \quad 3.59 \%$

Three Times

$24 \quad 7.84 \%$

Four Times

$40 \quad 13.07 \%$

Five Times

$36 \quad 11.76 \%$

Six Times

42

$13.73 \%$

Seven Times

$30 \quad 9.80 \%$

Eight Times

$18 \quad 5.88 \%$

Nine Times

13

$4.25 \%$

Ten Times

6

$1.96 \%$

Total Number of Participants in Simulation

21

$6.86 \%$

306

$100 \%$

Variables

OPPORTUNITY_MS

PRESSURE_MS

INFLATION_CHOICE_MS

TIME_TAKEN_TO_DECISION_MS

BEGINNING_BALANCE_LIRA

FRAUD_OCCURRENCE_PROPORTION

REMORSE

BANK_BALANCE_INFLUENCE

PRESSURE_INFLUENCE

OPPORTUNITY_INFLUENCE

PERCEIVED_OPPORTUNITY

DIFFICULT_DECISION

IMPULSIVITY

NARCISSISM

RISK_PROPENSITY

\begin{tabular}{|c|c|c|c|c|c|}
\hline$\underline{n}$ & Minimum & Maximum & Mean & Median & Std Error \\
\hline 3060 & 0 & 69987 & 839.94 & 566.5 & 33.85 \\
\hline 3060 & 0 & 50388 & 1494.18 & 599.5 & 53.29 \\
\hline 3060 & 1 & 56693 & 897.57 & 505.5 & 32.44 \\
\hline 3060 & 1 & 72963 & 3231.7 & 2010.0 & 83.12 \\
\hline 3060 & -15 & 140 & 38.03 & 35.0 & 0.36 \\
\hline 306 & 0 & 1 & 0.39 & 0.4 & 0.00 \\
\hline 306 & 1 & 7 & 4.84 & 5.0 & 0.03 \\
\hline 306 & 1 & 7 & 3.66 & 4.0 & 0.04 \\
\hline 306 & 1 & 7 & 3.35 & 3.0 & 0.03 \\
\hline 306 & 1 & 7 & 4.53 & 5.0 & 0.04 \\
\hline 306 & 1 & 7 & 4.03 & 4.0 & 0.03 \\
\hline 306 & 1 & 7 & 4.67 & 5.0 & 0.02 \\
\hline 306 & 31 & 109 & 57.71 & 57.0 & 0.21 \\
\hline 306 & 3 & 15 & 8.6 & 8.0 & 0.05 \\
\hline 306 & 7 & 52 & 24.57 & 23.5 & 0.18 \\
\hline
\end{tabular}


TABLE 2-3

ANCOVA Analysis: Effect of Pressure, Opportunity, and Impulsivity on Time Taken to Make the Decision to Commit Fraud

Model: Dependent variable: TIME_TAKEN_TO_DECISION (Adjusted $\mathrm{R}^{2}=0.124$ )

\begin{tabular}{lrrrrr}
\hline Source & DF & Sum of Squares & Mean Square & F value & P \\
\hline Model & 222 & 12110000000.00 & 54567905.87 & 2.946 & $<0.001$ \\
Error & 2837 & 52550000000.00 & 18524014.48 & & \\
Corrected Total & 3059 & 64670000000 & & & \\
\hline Source & DF & Sum of Squares & Mean Square & F value & P \\
\hline ID & 1 & 256628023.00 & 256628023.00 & 13.854 & $<0.001$ \\
PERIOD & 1 & 4362936356.00 & 4362936356.00 & 235.529 & $<0.001$ \\
NARCISSIM & 1 & 25302520.72 & 25302520.72 & 1.366 & 0.243 \\
AGE & 1 & 202666208.80 & 202666208.80 & 10.941 & 0.001 \\
GENDER & 1 & 68009389.41 & 68009389.41 & 3.671 & 0.055 \\
INTERNAL_AUDIT_EXPERIENCE $_{\text {SOCIAL_VALUE_ORIENTATION }}$ & 1 & 160605988.70 & 160605988.70 & 8.670 & 0.003 \\
CAUGHT_BY_AUDITORS & 1 & 132071344.20 & 132071344.20 & 7.130 & 0.008 \\
PRESSURE & 1 & 251388622.00 & 251388622.00 & 13.571 & $<0.001$ \\
OPPORTUNITY $^{\prime}$ & 1 & 66989009.89 & 66989009.89 & 3.616 & 0.057 \\
IMPULSIVITY $_{\text {PRESSURE*OPPORTUNITY }}{ }^{\mathrm{b}}$ & 1 & 19672559.22 & 19672559.22 & 1.062 & 0.303 \\
IMPULSIVITY*PRESSURE $^{\mathrm{b}}$ & 54 & 2689594578.00 & 49807307.00 & 2.689 & $<0.001$ \\
IMPULSIVITY*OPPORTUNITY $^{\mathrm{b}}$ & 1 & 24247662.41 & 24247662.41 & 1.309 & 0.127 \\
IMPULSIVITY*PRESSURE *OPPORTUNITY $^{\mathrm{b}}$ & 53 & 1297819063.00 & 24487152.13 & 1.322 & 0.030 \\
& 53 & 1477144357.00 & 27870648.25 & 1.505 & 0.005 \\
& & 1167212308.00 & 23344246.17 & 1.260 & 0.052
\end{tabular}

Simple effects:

IMPULSIVITY is High

\begin{tabular}{|c|c|c|c|c|c|}
\hline $\begin{array}{l}\text { Simple effect of PRESSURE } \\
\text { under OPPORTUNITY-Low }\end{array}$ & 1 & 3671836.30 & 3671836.30 & 0.191 & 0.331 \\
\hline $\begin{array}{l}\text { Simple effect of PRESSURE } \\
\text { under OPPORTUNITY-High }\end{array}$ & 1 & 25212067.52 & 25212067.52 & 1.310 & 0.126 \\
\hline \multicolumn{6}{|l|}{ MPULSIVITY is Low } \\
\hline $\begin{array}{l}\text { Simple effect of PRESSURE } \\
\text { under OPPORTUNITY-Low }\end{array}$ & 1 & 2848855.30 & 2848855.30 & 0.148 & 0.350 \\
\hline $\begin{array}{l}\text { Simple effect of PRESSURE } \\
\quad \text { under OPPORTUNITY-High }\end{array}$ & 1 & 78684332.84 & 78684332.84 & 4.089 & 0.022 \\
\hline
\end{tabular}

${ }^{\mathrm{b}}$ The hypothesis tests are one-tailed tests therefore the interaction p-values have been halved. 


\section{Appendix 2-1}

\section{Research Study Materials}

\section{Barratt Impulsiveness Scale}

Instructions: People differ in the ways they act and think in different situations. This is a test to measure some of the ways in which you act and think. Read each statement and select the statement that is appropriate on the right side. Do not spend too much time on any statement. Answer quickly and honestly.

\begin{tabular}{|c|c|c|c|}
\hline 1 & 2 & 3 & 4 \\
\hline Rarely/Never & Occasionally & Often & Almost Always/Always \\
\hline
\end{tabular}

1. I plan tasks carefully.

2. I do things without thinking.

3. I make-up my mind quickly.

4. I am happy-go-lucky.

5. I don't "pay attention".

6. I have "racing" thoughts.

7. I plan trips well ahead of time.

8. I am self controlled.

9. I concentrate easily.

10. I save regularly.

11. I "squirm" at plays or lectures.

12. I am a careful thinker.

13. I plan for job security.

14. I say things without thinking.

15. I like to think about complex problems.

16. I change jobs.

17. I act "on impulse".

18. I get easily bored when solving thought problems.

19 . I act on the spur of the moment.

20. I am a steady thinking.

21 . I change residences.

22. I buy things on impulse.

23. I can only think about one thing at a time.

24. I change hobbies.

25. I spend or charge more than I earn.

26. I often have extraneous thoughts when thinking.

27. I am more interested in the present than the future.

28. I am restless at the theater or lectures.

29. I like puzzles.

30. I am future oriented. 


\section{Narcissism Spectrum Scale (Extreme subscale only)}

On a scale of 1 (strongly disagree) to 5(strongly agree), indicate how much you agree or disagree with each item.

1. I secretly believe I'm better than most people.

2. Obstacles rarely slow me down.

3. I'm great at a lot of things compared to most people.

\section{Risk Propensity Scale}

Instructions: Please indicate the extent to which you agree or disagree with the following statement by choosing the option you prefer (1=totally disagree, $9=$ totally agree). Please do not think too long before answering; usually your first inclination is also the best one.

1. Safety first.

2. I do not take risks with my health.

3. I prefer to avoid risks.

4. I take risks regularly.

5. I really dislike not knowing what is going to happen.

6. I usually view risks as a challenge.

7. I view myself as a ..... (1=risk avoider, $9=$ risk seeker).

\section{Social Value Orientation}

Instructions: In this task you have been randomly paired with another person, whom we will refer to as the other. This other person is someone you do not know and will remain mutually anonymous. All of your choices are completely confidential. You will be making a series of decisions about allocating resources between you and this other person. For each of the following questions, please indicate the distribution you prefer most by marking the respective position along the midline. You can only make one mark for each question.

Your decisions will yield money for both yourself and the other person. In the example below, a person has chosen to distribute money so that he/she receives 50 dollars, while the anonymous other person receives 40 dollars.

There are no right or wrong answers, this is all about personal preference. After you have made your decision, write the resulting distribution of money on the spaces on the right. As you can see, your choices will influence both the amount of money you receive as well as the amount of money the other receives.

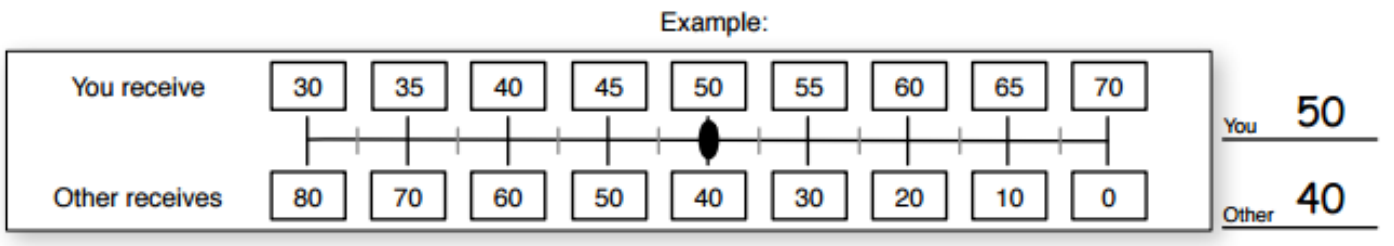



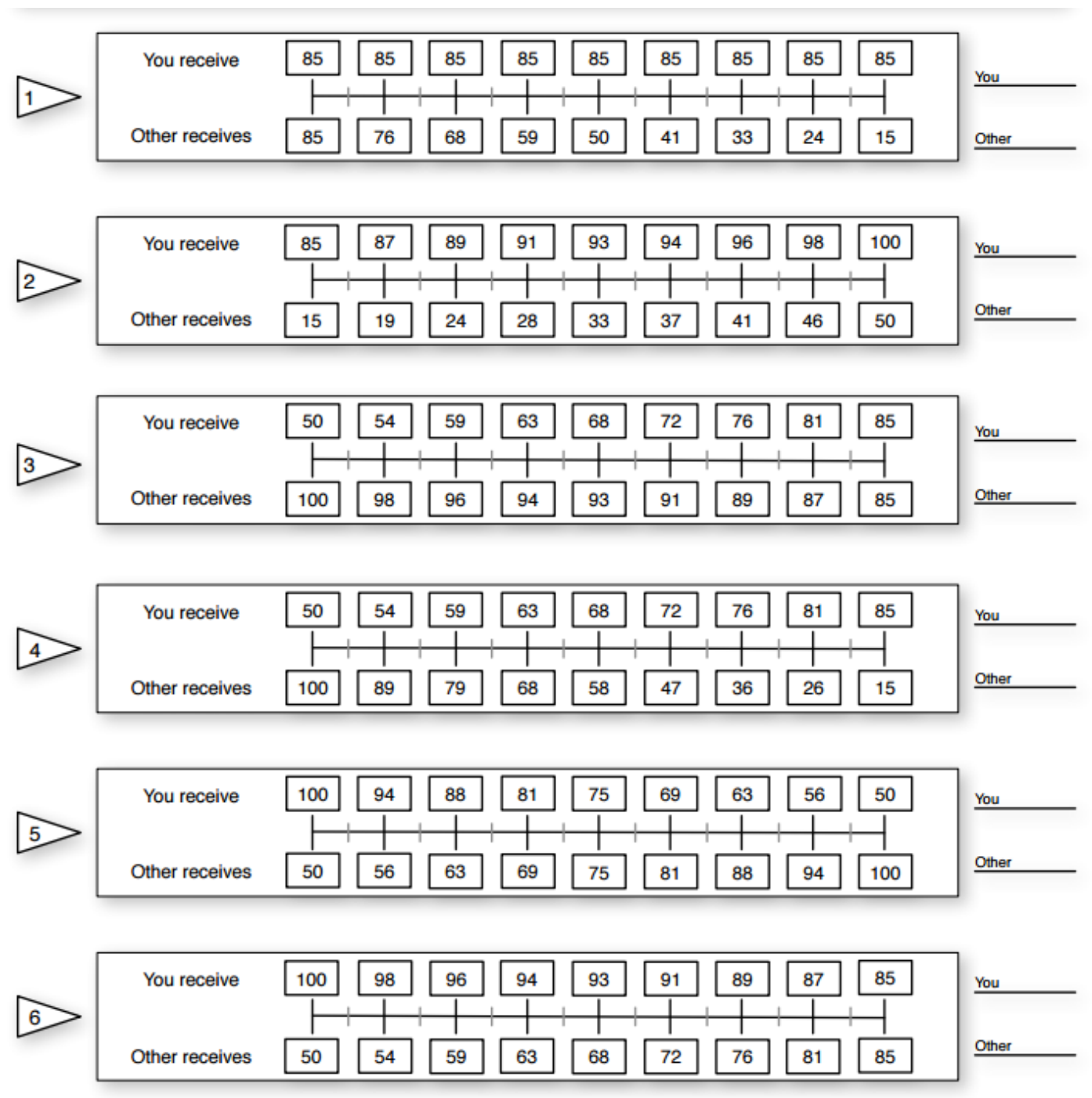

\section{Cognitive Reflection Test (CRT)}

Instructions: Below are three items that vary in difficulty. Answer as many as you can.

(1) A bat and a ball cost $\$ 1.10$ in total. The bat costs $\$ 1.00$ more than the ball. How much does the ball cost? cents

(2) If it takes 5 machines 5 minutes to make 5 widgets, how long would it take 100 machines to make 100 widgets? minutes

(3) In a lake, there is a patch of lily pads. Every day, the patch doubles in size. If it takes 48 days for the patch to cover the entire lake, how long would it take for the patch to cover half of the lake? days

CRT Answer: (1) 5 (2) 5 (3) 47

iCRT Answer: (1) 10 (2) 100 (3) 24 


\section{Berlin Numeracy Test (Single-item median format)}

Instructions: Please answer the question below. Do not use a calculator.

1. Out of 1,000 people in a small town 500 are members of a choir. Out of these 500 members in the choir 100 are men. Out of the 500 inhabitants that are not in the choir 300 are men. What is the probability that a randomly drawn man is a member of the choir? (Please indicate the probability in percent). $\%$ Answer: $25 \%$.

\section{Demographic Questions}

1. Age

2. Gender

3. Years of Work Experience

4. During your work experience, have you interacted with internal auditors?

\section{Simulation Instructions}

WebSmart, Inc. is a marketing company that provides marketing strategies and consulting for its clients.

For this simulation, please assume that you are an employee of WebSmart, and that your job requires you to travel to meet with clients each period.

This simulation will last for multiple periods. At the beginning, you have 25 Lira in your bank balance. You will receive a salary of 35 Lira per period if you remain employed by WebSmart, Inc. As your job requires you to travel, you have expense reimbursement requests to submit to WebSmart's Accounting Department every period.

With the expense reimbursements, you have the opportunity every time you submit a reimbursement to provide the Accounting Department with the right expense amount or to inflate the reimbursement by 10 Lira. For example, if the amount you spent on travel for the period is 200 Lira, you would submit 200 Lira as the amount for reimbursement. If you choose to inflate the reimbursement, you would submit 210 Lira as the amount for reimbursement. The additional 10 Lira would then go towards paying for your household expenses or to your bank balance. In other words, inflating the reimbursement would increase your financial position.

WebSmart, Inc. has internal auditors who are tasked with ensuring the company's internal controls are working well. Each period, the internal auditors will select a portion of the expense reimbursement requests to verify the expense amounts and documentation provided by the employees. In periods of high opportunity to inflate reimbursement, the internal auditors will verify $10 \%$ of expense reimbursement requests. This means that there is a $10 \%$ chance that any inflated expense reimbursement requests will be detected. In periods of low opportunity to inflate reimbursement, the internal auditors will verify $30 \%$ of expense reimbursements requests. The chance of detection in periods of low opportunity is $30 \%$.

\section{Audit Procedures}

If you submit an inflated expense reimbursement request and the internal auditors did not detect the inflated request, 10 Lira will be added to increase your financial position. However, if you decide to submit an inflated expense reimbursement request and the internal auditors detect it, you will be penalized and have 10 Lira deducted from your bank balance after household expenses are taken into account. 
Each period will proceed as follows:

1. You will see your bank balance, the opportunity to inflate reimbursement requests, and your household expenses for the period. Too see the information, move your cursor to the corresponding boxes during the simulation.

2. Knowing that you will receive 35 Lira each period as salary, you will decide whether to inflate your expense reimbursement request or submit the expense reimbursement request as is. If you decide not to inflate your expense reimbursement request, your Bank Balance for the next period= Bank Balance for the current period + Salary - Household Expenses for this period.

3. The internal auditors will verify the reimbursement requests at the end of the period. If you decided to inflate the expense reimbursement request, you will learn if the internal auditors detected the reimbursement inflation.

a) If the internal auditors do not detect the inflated reimbursement request, your Bank Balance for the next period $=$ Bank Balance for this period + Salary- Household Expenses +10 Lira

b) If the internal auditors detect the inflated reimbursement request, your Bank Balance for the next period= Bank Balance for this period +Salary- Household Expenses -10 Lira

4. You will then move on to the next period in the simulation.

At the conclusion of this simulation, you will be compensated based upon the Lira you have in the bank. The conversion rate is 15 Lira to $\$ 1$. For example, 75 Lira are worth $\$ 5$.

\section{Case Comprehension Questions}

1. What is your salary per period?

- 10 Lira

- 15 Lira

- 20 Lira

- 25 Lira

- 30 Lira

- 35 Lira

2. How many Lira will you have at the beginning of the simulation?

- 10 Lira

- 15 Lira

- 20 Lira

- 25 Lira

- 30 Lira

- 35 Lira

3. Your current bank balance is 10 Lira and your household expense for this period is 40 Lira. Assume that you decide to inflate your expense reimbursement request. How many Lira will you have on your bank balance if the internal auditors did not notice the inflated request?

- 10 Lira

- 15 Lira

- 20 Lira

- 25 Lira

- 30 Lira 
- 35 Lira

4. Your current bank balance is 25 Lira and your household expense for this period is 30 Lira. Assume that you decide to inflate your expense reimbursement request. How many Lira will you have on your bank balance if the internal auditors detected that the expense reimbursement request is inflated?

- 10 Lira

- 15 Lira

- 20 Lira

- 25 Lira

- 30 Lira

- 35 Lira

\section{MouselabWEB Simulation}

Period $n$

Bank Balance:

Salary: 35 Lira

Your household expenses and the internal auditors expense reimbursement verification extent is available below. Do you choose to inflate your expense reimbursement request for this period?

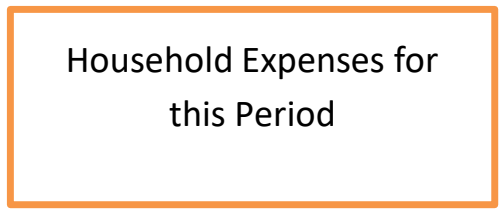

$$
\begin{aligned}
& \text { \% of Expense Reimbursement } \\
& \text { Requests Selected for Internal } \\
& \text { Audit }
\end{aligned}
$$

\section{Choice Buttons}

Button A: Yes, I would like to submit an inflated expense reimbursement request.

Button B: No, I would like to submit the expense reimbursement request as is.

If participants chose Button A and the auditors detected the inflated reimbursement

This period, the internal auditors selected your expense reimbursement request as part of their internal audit and the inflated amount was discovered. 10 Lira will be deducted from your bank balance in the next period.

If participants chose Button A but the auditors did not detect the inflated reimbursement

This period, the internal auditors did not select your expense reimbursement request as part of their internal audit. Consequently, the inflated amount was not discovered. 10 Lira will be added to your bank balance in the next period.

If participants chose Button B, they moved to the next period.

\section{Post-Simulation Questions}

1. How difficult was the decision to inflate reimbursements for you? (Not difficult-Very difficult, 7point scale)

2. I feel bad about submitting inflated reimbursement requests during the simulation. (Strongly disagree- Strongly agree, 7-point scale) 
3. The perceived opportunity to inflate expense reimbursement requests without detection in the simulation is (Very low-Very high, 7-point scale)

4. How much did the household expense listed influence your decision to inflate or not to inflate the expense reimbursement request? (Minimum influence-Maximum influence, 7-point scale)

5. How much did the percentage of expense reimbursement request selected for internal audit listed influence your decision to inflate or not to inflate the expense reimbursement request? (Minimum influence-Maximum influence, 7-point scale)

6. How much did your displayed bank balance influence your decision to inflate or not to inflate the expense reimbursement request? (Minimum influence-Maximum influence, 7-point scale) 


\title{
CHAPTER THREE: THE EFFECTS OF FIRST IMPRESSIONS AND MINDSETS ON AUDITORS' RISK JUDGMENTS
}

\author{
D. Kip Holderness \\ West Virginia University \\ kip.holderness@mail.wvu.edu \\ Alyssa S.J. Ong \\ West Virginia University \\ asong@mix.wvu.edu \\ Mark F. Zimbelman \\ Brigham Young University \\ mz@byu.edu
}




\section{INTRODUCTION}

Auditors frequently interact with client personnel to gather information during an audit.

Given human resource turnover in both auditing and at audit clients, auditors often meet with client personnel for the first time and form first impressions. Prior research suggests that first impressions strongly influence individuals' assessments of evidence (Porter, Gustaw \& ten Brinke 2010). The purpose of this paper is to examine how first impressions of client personnel affect auditor risk judgments and whether auditor mindset attenuates the effects of first impressions on auditors' risk judgments.

Risk judgments are an important part of the audit process because they directly impact audit quality. Recent auditing standards have emphasized the importance of risk assessment in auditing (IAASB 2006a, 2006b, 2006c; PCAOB 2007; AICPA 2006a, 2006b, 2006c). Auditors assess misstatement risks during the planning phase of an audit and use their risk assessments to plan the evidence to collect to test the validity of management's assertions. Additionally, auditors make regular risk judgments throughout the audit to determine the likelihood or risk that the client's financial statements are materially misstated. Because of this risk-based approach to auditing, erroneous conclusions could result if first impressions lead to inappropriate risk judgments (Fukukawa \& Mock 2011).

Objectivity is central to making appropriate risk judgments because it requires auditors to be "impartial" and "intellectually honest" and should reduce cognitive biases (AICPA 2014, 6). Consequently, interventions or policies that help auditors maintain objectivity should help them better assess risk and may help them overcome first-impression biases. Regarding overcoming first-impression biases, prior research in psychology suggests that, because first impressions are subconscious, interventions may not help auditors overcome their effects on judgment. Auditors in the field (e.g., seniors and associates) have been shown to be influenced by the mindset preferred by their superiors (e.g., managers and partners) (Griffith et al. 2015). For example, when auditors believe the audit partner is focused more on effectiveness than efficiency, 
auditors become more...We explore the impact of auditor mindset on first impressions to determine how this potential intervention interacts with auditors' first impressions to influence their risk judgments.

Prior research on first impressions differ on the type of individuals selected as participants. Some use students (Dunning et al. 1990; Peters and Gawronski 2011; Rule, Tskhay, Freeman \& Ambady 2014) whereas others recruit professionals (Porter \& ten Brinke 2009; Evans, Kleine, Landry \& Crosby 2000; Nordholm 1980). A psychology study found that students are overconfident when making judgments of others based only on first impressions, even when the judgments were wrong half the time (Dunning et al. 1990). A different psychology study with participants recruited online found that appearances are weighted more heavily over other information provided when predicting individual characteristics and this can have serious effects on accuracy (Olivola \& Todorov 2010). When jurors form positive first impressions of the defendant, more evidence is required to convict the defendant as guilty and the sentence is more lenient compared to when jurors form negative first impressions of the defendant (Porter \& ten Brinke 2009). Smith and Kida (1991) suggest that to effectively examine heuristic judgements of auditors, having auditors, instead of students, as participants working on an audit task is more appropriate since they are less susceptible to the same types of cognitive biases found in studies using student participants.

This study explores whether auditor mindset influences the effects of first impressions on judgments of risk the valuation of inventory. We hypothesize that in the efficiency mindset, auditors' valuations of inventory are more favorable to the client when the first impression of the client is positive than when the first impression is negative. In addition, we predict that auditors in the efficiency mindset will be more affected by first impression biases when compared to auditors in the effectiveness mindset.

We designed a $2 \times 2$ experiment to test our hypotheses. We used pre-recorded videos to simulate a client inquiry in which auditors were asked to discuss inventory valuation with a member of client personnel. After watching the videos, auditors were asked to provide a risk judgment and estimate the value of the client's inventory. 124 auditors recruited from various Big Four, regional, and local accounting firms 
participated in our experiment. We manipulated first impressions by using either a positive or negative first impression video at the beginning of the inquiry. We manipulated mindset by encouraging auditors to either be effective or efficient. We hypothesize and find that auditors in the efficiency mindset are more likely to be swayed by their first impressions of the client when making audit judgments than auditors in the effectiveness mindset. We show that when auditors are in the effectiveness mindset, first impression biases are attenuated such that they place greater emphasis on the evidence provided when compared to auditors in the efficiency mindset. Specifically, when auditors are in the effectiveness mindset, the assessment of inventory is similar regardless of their first impression of the client, suggesting that the focus is on the evidence.

This paper makes several contributions to research in psychology and auditing. First, we extend the research on first impressions by examining auditors' interaction with client personnel. This unique setting is different than those from prior psychology research on first impressions because professional auditing standards dictate that auditors remain objective throughout the audit (AICPA 2014). Second, from a practical perspective, our results suggest ways that audit firms can potentially improve audit quality by helping auditors overcome the natural tendency to be biased by first impressions. Specifically, our results suggest that when auditors are encouraged to think critically about evidence, subconscious first impression biases are attenuated.

The remainder of this paper proceeds as follows: Section II provides a background review of the relevant literature and the development of hypotheses. Section III is a general outline of the research method and our experimental design. Section IV provides results of the experiment and Section V includes a discussion and concluding remarks. 


\section{First Impressions}

\section{BACKGROUND AND HYPOTHESES DEVELOPMENT}

First impressions are formed when individuals interact within a social setting. Psychology research on first impressions shows that individuals categorize those they meet based on their traits such as confidence, persistence, stubbornness, and conceitedness (Moskowitz \& Roman 1992). For example, Moskowitz \& Roman (1992) state that "categorizing the actions of others in trait terms is both a common and an important aspect of person perception and social judgment." Prior studies have shown that individuals spontaneously categorize the behavior of others and that such categorization is not a behavior that can be controlled or inhibited (Newman \& Uleman 1990; Winter \& Uleman 1984; Winter, Uleman, \& Cunniff 1985). Moreover, this categorization occurs almost instantaneously - individuals can form first impressions within 100 milliseconds of meeting other individuals (Willis \& Todorov 2006). Research on first impressions identifies several important implications. For example, first impressions guide how one interacts with others, what information is stored, and how one will predict the behaviors of others (Feldman 1981; Fiske \& Neuberg 1990; Gingerich, Regehr, \& Eva 2011; Wood 2014).

Most research on first impressions involves participants looking at a picture or watching a short video clip of an individual and then making judgments about various characteristics of the individual including such things as sexual orientation, drug use, education level, gun ownership, relationship status, aggressive tendencies, political leanings, and others. Accuracy of first impressions based solely on appearance is around 55\% (Dunning, Griffin, Milojkovic, \& Ross 1990; Tversky \& Kahneman 1974; Olivola \& Todorov 2010). In addition, people are generally overconfident in their ability to predict the traits of others based on appearances and rely heavily on appearance even in the presence of other cues.

First impressions can bias subsequent information processing in two ways. First, they can serve as an anchor, and may cause people to discount subsequent, more relevant information received after a first impression is formed. For example, in a study examining the effects of first impressions on jurors' 
judgments, Porter and ten Brinke (2009) find that "first impressions of trustworthiness based on facial appearance may play a major role in the assessment of credibility and ensuing decisions about the target." Specifically, jurors who formed positive first impressions of a defendant required more evidence to convict the defendant as guilty and recommended a more lenient sentence, relative to jurors who formed negative first impressions of a defendant. Their results suggest jurors may anchor on first impressions and discount subsequent, more-relevant evidence, even though jurors are meant to base their decisions solely on evidence. When prior impressions are discovered to be false, the first impressions are not easy to reverse even with the addition of new information (Rule, Tskhay, Freeman \& Ambady 2014; Peters \& Gawronski 2011).

Second, first impressions may lead to the creation of stereotypes, which are then reinforced by confirmation bias during subsequent interaction (Snyder, Tanke, \& Berscheid 1977). This idea is consistent with individuals' tendency to seek confirming evidence (McMillan \& White 1993; Nickerson 1998). Thus, when subjects form a negative first impression of an individual, they seek evidence that confirms their negative first impression. In contrast, when subjects form a positive first impression of an individual, they are likely to seek evidence that confirms their positive first impression and discount or ignore evidence to the contrary (Snyder et al. 1977).

In order to gather evidence during an audit, auditors frequently meet with client personnel.

Consistent with extant literature, we expect auditors to be subject to the biases inherent in the formation of first impressions. However, the extent to which first impressions bias auditors' subsequent judgments is likely contingent on auditor mindset, as discussed next.

\section{Auditor Mindset}

Mindset is "an attitude or the manner with which a person approaches a situation" (Collins English Dictionary 2018). Gollwitzer (1990) defined it as a set of judgmental criteria and cognitive processes when approaching a situation. Mindsets can lead individuals to objectively consider information presented or to 
focus in on certain elements to quickly make decisions. In the area of psychology, Action Phase Theory states that individuals in a deliberative mindset are in the process of deciding what, if any, action to take, while individuals in an implemental mindset are in the process of planning an action they have already decided to take (Freitas, Gollwitzer, \& Trope 2004; Gollwitzer 1990). Research has associated the deliberative mindset with a higher degree of objectivity, further psychological distance from the decision, increased memory retention, increased ability to process information, and higher openness toward incidental stimuli (Heckhausen \& Gollwitzer 1987; Gollwitzer 1990; Gollwitzer, Heckhausen, \& Stellar 1990; Gollwitzer \& Bayer 1999; Fujita, Gollwitzer, \& Oettinger 2007; Buttner, Wieber, Schulz, Bayer, Gloreck, \& Gollwitzer 2014). Individuals in the deliberative mindset are more objective and more willing to attend to risk factors, whereas individuals in the implemental mindset are less objective and less willing to attend to risk factors due to their focus on getting the task done and their reluctance to be sidetracked (Taylor \& Gollwitzer 1995; Buttner et al 2014). When individuals are in an implemental mindset, they demonstrate significantly lower objectivity and breadth of attention, as well as increased optimism - all of which increase the probability of potentially risky outcomes (Rasso 2015; Buttner et al. 2014; Puca 2004; Taylor \& Gollwitzer 1995).

During an audit, auditors are faced with two competing demands - effectiveness and efficiency. Effectiveness refers to the quality of the auditor's conduct of the engagement and decisions about detected errors, whereas efficiency refers to the timeliness and cost of performing the audit (Knechel \& Sharma 2012). We posit that auditors who are in the effectiveness mindset, are in a mindset that is similar to the deliberative mindset from the Action Phases Theory. In an auditing context, auditors may adopt an effectiveness mindset when they focus an audit plan on providing sufficient evidence to test management's assertions in their financial statements. They actively consider steps to take to ensure that sufficient evidence is gathered to provide adequate assurance. Auditors who are focused on effectiveness also have a 
higher degree of objectivity and the ability to incorporate more information when processing evidence relative to auditors who are in an efficiency mindset.

The efficiency mindset is similar to the implemental mindset from the Action Phases Theory. Auditors with an efficiency mindset have a "check-the-box" mentality, and work to complete each task as quickly as possible. Auditors may adopt an efficiency mindset as they carry out each step in the audit plan. In this study about audit judgement we use efficiency and effectiveness, widely-recognized audit concepts, as the two contrasting mindsets.

Once a mindset is activated, the mindset has the potential to influence information processing in subsequent tasks even though the tasks may be unrelated (Griffith, Hammersley, Kadous, \& Young 2015; Buttner et al. 2014; Fujita, Gollwitzer, \& Oettingen 2007). With step-by-step audit programs that firms use to maintain audit consistency (Griffith, Hammersley, \& Kadous 2014), auditors tend to approach the audit with an efficiency mindset. A study conducted by Griffith et al. (2015) demonstrated that being in an effectiveness mindset enhances auditors' ability to include contradictory information from multiple sources and provide better accounting estimates. A relevant characteristic of the audit setting is the significant time pressure under which auditors operate, particularly during busy season (Smith 2000). Auditors are generally uncompensated for the time it takes to gather additional audit evidence and the time necessary to gather additional evidence may cause the audit to go over budget, which can lead to negative performance reviews for auditors. Budget concerns and pressure from audit clients constantly put auditors under time constraints (Arnold 1997; Cook \& Kelley 1988; Waggoner \& Cashell 1991).

We posit that in many cases, the time pressures inherent in auditing cause concerns for efficiency to influence auditors to a greater degree than concerns for effectiveness. The likelihood of efficiency concerns prevailing over effectiveness concerns is exacerbated because, on most audits, there is a low likelihood of material misstatement. Thus, auditors' concern for efficiency may prompt them to adopt an efficiency mindset to complete the audit quickly rather than remaining in the effectiveness mindset to appropriately 
plan how to gather sufficient audit evidence and critically incorporate all the information on hand. Once in the efficiency mindset, auditors are less likely to objectively consider audit evidence, focusing instead on performing audit tasks quickly. In addition, auditors in an efficiency mindset may be less sensitive to factors suggesting higher risk.

This expectation is consistent with prior auditing research. For example, Coram et al. (2004) find that in the presence of high time pressure, auditors accept doubtful audit evidence regardless of the risk of misstatement. In addition, auditors under high time pressure failed to test all items in a selected sample when the perceived audit risk was low (Coram, Ng, \& Woodliff 2004). Braun (2000) finds that auditors take less time to complete audit procedures as time pressure increases and results in less attention to audit evidence and the qualitative aspect of misstatements; Braun's (2000) study and subsequent research shows that time pressure led auditors to be efficient at completing tasks but not effective in detecting potential fraudulent financial reporting (Braun 2000, Hogan et al. 2008, Janvrin \& Jeffrey 2007). The results of these studies suggest that time pressure may lead auditors to adopt an efficiency mindset, which reduces objectivity and sensitivity to risk. As the formation of first impressions is a subconscious process, we believe that auditors who are in the efficiency mindset will find it hard to ignore first impression influences and place more emphasis on the first impression of the client instead of the evidence provided during the audit. Specifically, we expect first impressions to be negatively correlated with risk judgments and positively correlated with inventory valuation when auditors are in the efficiency mindset. Stated formally:

H1A: Auditors in an efficiency mindset who form positive first impressions of the client will provide a higher dollar amount when valuing inventory than auditors who form negative first impressions.

H18: Auditors in an efficiency mindset who form positive first impressions of the client will provide lower risk judgments when assessing the risk of material misstatement than auditors who form negative first impressions. 
We expect auditors in the efficiency mindset to be primarily concerned with completing the audit in a timely manner. Because of this focus on efficiency, they will be more susceptible to first impression biases in comparison with auditors who are in an effectiveness mindset. One potential intervention for reducing the effects of first impressions during the audit is to encourage auditors to focus on the evidence, as discussed next.

\section{The Effect of Auditor Mindset and First Impression Valence on Risk Factor Detection}

Auditor mindset should affect the way first impressions influence the analysis of subsequent audit evidence in two ways - through sensitivity to risk factors and susceptibility to confirmation bias. First, mindset can influence sensitivity to risk factors. Taylor and Gollwitzer (1995) find that individuals focused on deliberation have "significantly poorer mood, significantly lower self-esteem, and significantly lower perceived invulnerability to risk" than individuals with an implemental mindset who are focused on completing tasks quickly. Extending this to auditing, when auditors are deliberating and incorporating available evidence, being in an effectiveness mindset could be the time when they think more about the objectives of the audit. Based on the discussion thus far, we expect auditors in the effectiveness mindset to be more sensitive to risk factors than auditors in an efficiency mindset, regardless of first impression valence (i.e., positive vs negative). The increased sensitivity to risk factors for auditors in the effectiveness mindset suggests that first impressions will carry less relative influence on their risk judgments when compared with auditors in the efficiency mindset, and relatively more weight on subsequent audit evidence. In other words, auditors in an effectiveness mindset will be sufficiently focused on audit evidence that the relative importance of first impressions will be diminished when compared with auditors in an efficiency mindset.

In contrast, auditors who are in an efficiency mindset are less likely to adequately consider risk factors that are portrayed by clients during an inquiry, primarily because goal implementation may blind individuals to risk and impair objectivity (Taylor \& Gollwitzer 1995). Their focus on completing the audit 
efficiently may prevent them from fully incorporating risk factors into their risk judgments. In a recent study, Rasso (2015) finds that auditors in an efficiency mindset demand less evidence before making subsequent audit judgments than auditors in an effectiveness mindset, which suggests that auditors in an efficiency mindset place less value on audit evidence. Even though auditors in an efficiency mindset may fail to pay attention to risk factors that arise during client inquiry, the formation of first impressions is subconscious and should have some bearing on subsequent auditor judgments. Thus, auditors in an efficiency mindset will place greater relative weight on their first impression of the client compared to auditors in an effectiveness mindset, and their first impression of the client will be a more significant factor when assessing in their risk judgments relative to auditors in an effectiveness mindset. This conjecture is consistent with the work of Porter and ten Brinke (2009), which suggests that first impression biases may lead to irrational decisions even when other evidence is available because individuals are generally highly influenced by first impressions.

As discussed previously, first impressions may also lead to confirmation bias (Snyder et al. 1977), which can cause auditors to seek evidence that supports their first impression. The degree to which auditors are subject to confirmation bias is likely contingent on auditor mindset. Individuals who employ motivated reasoning search for rules and creatively combine evidence and information to construct new beliefs and maintain an "illusion of objectivity" to logically support a desired conclusion (Pyszcynski \& Greenberg 1987; Kruglanski 1980). While all auditors may have incentives to engage in motivated reasoning, we expect auditors in an efficiency mindset to be more likely to engage in motivated reasoning than auditors in an effectiveness mindset. This is because auditors in an efficiency mindset are focused on getting the work completed as quickly as possible. Discovering accounting anomalies results in additional work, causing auditors to go over budget.

Auditors who are concerned with audit effectiveness are likely to consider whether there is sufficient evidence to provide reasonable assurance that a client's financial statements are not materially misstated. 
They are therefore more likely to objectively consider audit evidence, rather than engage in confirmation bias to support their first impressions. Thus, auditors in an effectiveness mindset are less likely to engage in confirmation bias than auditors in an efficiency mindset, regardless of first impression valence. In contrast, auditors in an efficiency mindset are focused on quickly completing the audit and are less likely to objectively consider subsequent audit evidence. Therefore, auditors in an efficiency mindset are more likely than auditors in an effectiveness mindset to engage in confirmation bias to support their first impressions. As a result, first impression valence should have a greater effect on auditors in an efficiency mindset than auditors in an effectiveness mindset, which motivates our second hypothesis:

H2A: The difference in the valuation of inventory between positive and negative first impression conditions will be less for auditors in the effectiveness mindset than for those in the efficiency mindset.

$\mathbf{H}_{2 \mathbf{B}}$ : The difference in the risk of material misstatement of inventory between positive and negative first impression conditions will be less for auditors in the effectiveness mindset than for auditors in the efficiency mindset.

\section{EXPERIMENTAL DESIGN AND METHODS}

\section{Participants}

We recruited 181 auditors via email and LinkedIn from Big Four, regional, and local firms to take part in the experiment. Forty-one observations were excluded because auditors did not watch the experimental videos in their entirety. Another 16 observations were excluded from the analysis because the participants failed the manipulation check question. We tested the hypotheses using the remaining 124 observations. Approximately $75 \%$ of our participants are staff or senior auditors. The mean age of our participants is 30 years and the average years of work experience is five years. Table 1 presents the participant demographics of the 124 auditor participants.

[Insert Table 3-1 about here] 


\section{Procedures}

Case materials were adapted from Nöteberg and Hunton (2005). Data were collected electronically via the Qualtrics survey platform. Participants received the link to this study in a recruitment email or via LinkedIn. After consenting to participate in this study, participants read the case background. Participants were instructed to assume that they were part of the audit team assigned to MicroClone, Inc., a company selling computers, and that this was his/her first year working on this assignment. Their supervisor had requested that they gain a better understanding of the appropriate inventory valuation for the company as the company had recently introduced the $5^{\text {th }}$ generation computers, and it was therefore possible that the value of the older $4^{\text {th }}$ generation computers was impaired.

After reading the case background, participants watched a series of videos to simulate a client inquiry in which inventory valuation is discussed with MicroClone's controller. ${ }^{7}$ The first video simulated the introduction to the client, which formed the basis for the participant's first impression. After the introductory video, the participant was asked to click a button in order to ask the controller an additional question. The controller responded in the following video. Each participant viewed nine information video clips in addition to the introductory clip. At the end of the client inquiry with the controller, participants were asked to provide an estimated value for the $4^{\text {th }}$ generation computers' inventory and to assess the risk that the $4^{\text {th }}$ generation computers were materially misstated. In addition, participants were asked to provide an explanation behind their assessment of the valuation. Finally, participants answered post-experiment questions, including the Impression Formation Questionnaire (Snyder et al. 1977) in which they reported their impressions of the controller, as well as demographic questions.

\footnotetext{
${ }^{7}$ A retired partner from one of the Big Four accounting firms played the role of the controller in the videos for this experiment.
} 


\section{First Impression Manipulation}

All participants saw an introductory video that lasted approximately 10 seconds. We manipulated first impression so that half of the participants saw a positive impression video and the other half of the participants saw a negative first impression video. In the positive first impression video, the controller spoke clearly, smiled, and was welcoming when the participant asked for time to talk about the inventory. In the negative first impression video, the controller looked annoyed by the request and grumbled that the auditors always stopped by at the worst times. ${ }^{8}$ All other videos in the client inquiry simulation were the same across conditions.

\section{Mindset Manipulation}

Mindset was also manipulated between participants. The effectiveness and efficiency mindsets of the participants were manipulated at the beginning of the experiment. In the efficiency mindset condition, the audit supervisor's states: "My main concern is that we work efficiently on this audit so that we don't exceed our time budget. I need you to speak to the controller so we can efficiently complete our inventory valuation tests without incurring excess audit costs in this area." In the effectiveness mindset condition, the audit supervisor states: "My main concern is that we effectively perform the inventory testing, and I'm not concerned with how many hours we spend. I need you to speak to the controller so we can effectively perform our inventory valuation tests and reach the appropriate conclusion in this area."

\section{First Dependent Variable - Inventory Valuation}

The first dependent variable in this study is the inventory valuation of $4^{\text {th }}$ generation computers participants provide after evaluating the responses given by the controller and the case information. Participants were told that the finished goods inventory of the company include 2,000 units of $4^{\text {th }}$ generation

\footnotetext{
${ }^{8}$ To select the positive and negative impression videos, we conducted a pilot study in which we recorded several first impression videos and had 26 participants rate the controller in each video using the nine questions from the Impression Formation Questionnaire. We then selected the videos that were rated as most positive and most negative in the pilot study to be used in the main experiment of this study.
} 
computers and 6,000 units of $5^{\text {th }}$ generation computers. Furthermore, they were told that there was a concern about the value of the $4^{\text {th }}$ generation computers because with the $5^{\text {th }}$ generation computers now on the market, the $4^{\text {th }}$ generation computers would become obsolete. There was some evidence that the $4^{\text {th }}$ generation computers should have been valued at $\$ 800$ per unit instead of the current value of $\$ 1,000$ per unit. After meeting with the controller of the company to discuss the inventory issue, auditors were to determine if the current valuation of $\$ 1,000$ per unit for the $4^{\text {th }}$ generation computers is appropriate. Participants were asked to provide a total value of the $4^{\text {th }}$ generation computers between $\$ 1,600,000$ and $\$ 2,000,000$.

\section{Second Dependent Variable - Risk of Material Misstatement}

The second dependent variable in this study was the risk of material misstatement of the value of the $4^{\text {th }}$ generation computers in the inventory account. Participants were asked to rate the risk of material misstatement on scale of one to nine, with one being extremely low risk and nine being extremely high risk. Participant's response to this risk of material misstatement question should be related to their inventory

valuation amount. If they value the inventory of the $4^{\text {th }}$ generation computers to be high, the risk of material misstatement should be low. Conversely, if participants value the inventory of the $4^{\text {th }}$ generation computers to be much lower than the current valuation, the risk of material misstatement should be high.

\section{Control Variables}

We collected and controlled for information related to participants' age, gender, years of work experience in the audit field, firm type, and rank in this study.

\section{RESULTS}

\section{The Effect of First Impression on Risk Factor Detection}

Table 3-2 presents the descriptive statistics by experimental condition for the two dependent variables for this study: (1) inventory valuation and, (2) risk of material misstatement for the $4^{\text {th }}$ generation 
computers inventory account. Results from t-tests comparing these means (untabulated) indicate that when auditors are in the efficiency mindset, a positive first impression results in higher inventory valuations $(\mathrm{t}=$ $1.528 p=0.066$, one-tailed) and lower assessed risk of material misstatement $(\mathrm{t}=1.867, p=0.034$, onetailed). In contrast, when auditors are in the effectiveness mindset, the difference in means are not significant for either the inventory valuation variable $(\mathrm{t}=0.193, p=0.424$, one-tailed $)$ or the risk of material misstatement variable $(\mathrm{t}=0.873, p=0.193$, one-tailed $)$. These results provide preliminary evidence consistent with our hypotheses that auditors in the effectiveness mindset are less influenced by first impressions than auditors in the efficiency mindset.

\section{[Insert Table 3-2 about here]}

While the main analyses of our paper are based on our manipulated conditions, first impressions can vary substantially between subjects. Accordingly, we created another impression variable based on participants' responses to the Impression Formation Questionnaire (Snyder et al. 1977), which is a 9-item scaled used to measure impressions. Analyses using this variable, FIRST IMPRESSION IFQ, is intended as a robustness check. Descriptive statistics for the two dependent variables using the perceived first impression variable and the mindset variable are available in Table $3 .{ }^{9}$ Results from the t-tests using the perceived rather than manipulated variables are generally stronger, and indicate that when auditors are in the efficiency mindset, positive first impressions lead to significantly higher inventory valuations $(\mathrm{t}=2.541 p=$ 0.007 , one-tailed) and lower assessments of the risk of material misstatement $(\mathrm{t}=1.726, p=0.045$, onetailed). When auditors are in the effectiveness mindset, the differences in means of the inventory valuation variable $(\mathrm{t}=0.315, p=0.377$, one-tailed $)$ and the risk of material misstatement variable $(\mathrm{t}=0.581, p=0.282$, one tailed) are not significant. This further supports our hypotheses that auditors in the effectiveness mindset are less influenced by first impressions compared to auditors in the efficiency mindset.

[Insert Table 3-3 about here]

\footnotetext{
${ }^{9}$ FIRST IMPRESSION IFQ was split at the median for this test, but was measured as a continuous variable for the ANOVA.
} 
To formally test our hypotheses, we use ANOVA to analyze our data. For the analysis presented here, control variables with a $p$-value of less than 1.2 in the fully-ascribed model are excluded. Hypothesis 1 predicts that auditors in the efficiency mindset who form positive first impressions will (a) provide a higher inventory valuation and (b) provide lower risk judgments when assessing risk of material misstatement of the inventory account than auditors who form negative first impressions of the client. Hypothesis 2 predicts that the difference in (a) inventory valuation and (b) risk of material misstatement of inventory for the $4^{\text {th }}$ generation computers between positive and negative first impression conditions will be less for auditors in the effectiveness mindset than for auditors in the efficiency mindset. A first impression (positive vs. negative) x mindset (effectiveness vs. efficiency) ANOVA was used to test differences between means for significance. Results are summarized in Table $5 .{ }^{10}$ We test $\mathrm{H} 1$ by examining the simple effects for the efficiency condition in Panels A and B. The results support H1 in that they indicate that within the efficiency mindset condition, auditors who had a positive first impression of the controller assessed higher inventory values ( $p=0.060$, one-tailed) and lower risk of material misstatement ( $p=0.026$, one-tailed) than auditors who had a negative first impression.

We test $\mathrm{H} 2$ by examining how the effect of first impression changes when auditors are in the effectiveness mindset condition. While the interaction of First Impression x Mindset is not statistically significant in panels A and B, we note that the simple effects for First Impression are insignificant in the effectiveness mindset condition for both inventory valuation ( $p=0.424$, one-tailed) and risk of material misstatement ( $p=0.206$, one-tailed). Additional analysis (untabulated) from process variables at the end of the experiment indicate that auditors in the effectiveness condition are more likely to be influenced by the evidence presented ( $r=0.188, p=0.038$ ) when compared to auditors in the efficiency condition. Analysis of

\footnotetext{
${ }^{10}$ We collected data on age, gender, work experience, firm type, and firm role as control variables. Analysis of the fully-ascribed model suggests that results are qualitatively similar to the results presented in the paper.
} 
Figures 1 and 2 also suggest a greater effect of first impression in the efficiency mindset condition compared to the effectiveness mindset condition. Thus, we find partial support for $\mathrm{H} 2$.

[Insert Table 3-5, Figure 3-1, and Figure 3-2 about here]

We perform additional ANOVA analyses using the continuous, measured perceptions of impressions, First Impression IFQ, as a robustness check. Results using the two conditions derived from the perceived first impression score are presented in Table $6^{5}$ and are generally consistent with our main analyses. We find that in the efficiency mindset condition, positive first impressions resulted in significantly higher inventory valuations ( $p=0.006$, one-tailed) and marginally significantly lower risk of material misstatement ( $p=0.036$, one-tailed) when compared to negative first impressions. We find no significant difference for our independent variables in the effectiveness mindset condition. Furthermore, we find a statistically significant interaction between First Impression and Mindset for inventory valuations. These results provide additional support for our hypotheses.

[Insert Table 3-6 about here]

\section{CONCLUSION}

This study examines the impact of first impressions and auditor mindset on auditors' risk assessments. Auditors subconsciously form first impressions of client personnel as they meet with client personnel to gather audit information. Auditors' first impression of the client can bias auditor opinion of the evidence presented during the audit. Time pressure is inherent in auditing, and this might result in the prevalence of the efficiency mindset as auditors are working through audit tasks. Results of this study suggest that auditors in the efficiency mindset are biased by their first impression of clients and this affects the way they view subsequent evidence. When auditors' first impression of client personnel is positive, they view evidence less objectively and judge risk to be lower than if they have a negative first impression of the client. In the same manner, auditors assign a higher inventory value when their first impression of client 
personnel is positive compared to when the first impression is negative. Audit firms need to find ways to alleviate this first impression bias. Although prior research in psychology assumes that first impressions are subconscious and, therefore, unavoidable, we show that encouraging auditors to be in an effectiveness mindset can mitigate first impression biases and enable auditors to remain objective when interacting with new client personnel.

We acknowledge that our study lacks external validity due to our inability to capture key aspects of the field in an experiment. For example, the pressure and incentives to complete the audit are likely much more salient in the real world than they were for our auditors. However, in the short, 10-second, window of the manipulated first impression videos the results show a significant difference in auditors' risk judgments and inventory valuation decisions. Another limitation of our study is the lack of a source other than the controller to verify information or to seek additional confirmatory evidence. An auditor's possible response in the field when not convinced with information provided by the controller would be to seek other sources of evidence; however, doing so would significantly increase audit time pressure.

These results provide insights into the impact of first impressions on audit judgments. We show that auditors' first impressions of client personnel can bias their risk judgments and valuation decisions and thereby have the potential to impair audit quality. Time pressures that auditors face and the "check the box" mentality puts auditors in the efficiency mindset where the focus is to get things done and move to the next task. Future research can examine how other personality traits such as self-esteem, extroversionintroversion, and professional skepticism interact with first impression biases to influence risk assessments and audit judgments. 


\section{References}

American Institute of Certified Public Accountants (AICPA). (2014). AICPA Code of Professional Conduct.

American Institute of Certified Public Accountants (AICPA). (2006a). Audit Evidence. Statement on Auditing Standards No. 106. New York, NY: AICPA.

American Institute of Certified Public Accountants (AICPA). (2006b). Audit Risk and Materiality in Conducting an Audit. Statement on Auditing Standards No. 107. New York, NY: AICPA.

American Institute of Certified Public Accountants (AICPA). (2006c). Performing Audit Procedures in Response to Assessed Risks and Evaluating the Audit Evidence Obtained. Statement on Auditing Standards No. 110. New York, NY: AICPA.

Arnold, V. (1997). Judgment and decision making; Part 1: The impact of environmental factors. In V. Arnold and S. G. Sutton (Eds.), Behavioral accounting research: Foundations and frontiers (pp. 4988). Sarasota, FL.: American Accounting Association.

Braun, R. L. (2000). The effect of time pressure on auditor attention to qualitative aspects of misstatements indicative of potential fraudulent financial reporting. Accounting, Organizations and Society. 243259.

Buttner, O.B., Wieber, F., Schulz, A.M., Bayer, U.C., Florack, A. \& Gollwitzer, P.M. (2014). Visual attention and goal pursuit: Deliberative and implemental mindsets affect breadth of attention. Personality and Social Psychology Bulletin 40(10): 1248-1259.

Collins English Dictionary - Complete \& Unabridged 10th Edition. Retrieved February 21, 2018 from Dictionary.com website http://www.dictionary.com/browse/mindset

Cook, E. \& T. Kelley. (1988). Auditor Stress and Time-Budgets. The CPA Journal (July): 83-86.

Coram, P., Ng, J., \& Woodliff, D. (2004). The effect of risk of misstatement on the propensity to commit reduced audit quality acts under time budget pressure. Auditing: A Journal of Practice \& Theory 23(2): 159-167.

Dunning, D., Griffin, D. W., Milojkovic, J.H., \& Ross, L. (1990). The overconfidence effect in social prediction. Journal of Personality and Social Psychology 58: 568-581

Evans, K. R., Kleine, R. E., Landry, T. D., \& Crosby, L. A. (2000). How first impressions of a customer impact effectiveness in an initial sales encounter. Journal of the Academy of Marketing science, 28(4), 512-526.

Feldman, J.M. (1981). Beyond attribution theory: Cognitive processes in performance appraisal. Applied Psychology 66(2): 127-148.

Fiske, S., \& Neuberg, S. (1990). A Continuum of Impression Formation, from category-based to individuating processes: Influences of information and motivation on attention and interpretation. In M. Zanna (/Ed.), Advances in Experimental and Social Psychology (23rd ed., pp. 1-75). San Diego: Academic Press Inc.

Freitas, A.L., P.M. Gollwitzer, \& Trope, Y. (2004). The influence of abstract and concrete mindsets on anticipating and guiding others' self-regulatory efforts. Journal of Experimental Social Psychology 40: 739-752.

Fujita, K., Gollwitzer, P.M., \& Oettingen, G. (2007). Mindsets and pre-conscious open mindedness to incidental information. Journal of Experimental Social Psychology 43: 48-61.

Fukukawa, H., \& Mock, T. J. (2011). Audit risk assessments using belief versus probability. Auditing, 30(1), 75-99

Gingerich, A., Regehr, G., \& Eva, K.W. (2011). Rater-based assessments are social judgments: rethinking the etiology of rater errors. Academic Medicine, 86(10): S1-S7.

Gollwitzer, P.M. (1990). Action phases and mind-sets. Handbook of Motivation and Cognition: Foundations of Social Behavior, edited by E.T. Higgins and R.M. Sorrentino. New York: Guilford Press 53-92. 
Gollwitzer, P.M., Heckhausen, H., \&Stellar, B. (1990). Deliberative vs. implemental mindsets: cognitive tuning towards congruous thoughts and information. Journal of Personality and Social Psychology 56: 531-542.

Gollwitzer, P.M., \& Bayer, U. (1999). Deliberative versus implemental mindsets in the control of action.

S. Chaiken \& Y. Trope (Eds), Dual Process Theories in Social Psychology. New York: Guilford Press 403422.

Griffith, E. E., Hammersley, J. S., Kadous, K., \& Young, D. (2015). Auditor mindsets and audits of complex estimates. Journal of Accounting Research, 53(1), 49-77.

Griffith, E. E., Hammersley, J. S., \& Kadous, K. (2015). Audits of complex estimates as verification of management numbers: How institutional pressures shape practice. Contemporary Accounting Research, 32(3), 833-863.

Heckhausen, H., \& Gollwitzer, P.M. (1987). Thought contents and cognitive functioning in motivational and volitional states of mind. Motivation and Emotion 11: 101-120.

Hogan, C. E., Rezaee, Z., Riley Jr, R. A., \& Velury, U. K. (2008). Financial statement fraud: Insights from the academic literature. Auditing: A Journal of Practice \& Theory, 27(2), 231-252.

International Auditing and Assurance Standards Board (IAASB) (2006a): Planning an Audit of Financial Statement. International Standard on Auditing 300. New York, NY: International Federation of Accountants.

International Auditing and Assurance Standards Board (IAASB) (2006b): Identifying and Assessing the Risks of Material Misstatement through Understanding the Entity and its Environment. International Standard on Auditing 315. New York, NY: International Federation of Accountants.

International Auditing and Assurance Standards Board (IAASB) (2006c): The Auditor's Responses to Assessed Risks. International Standard on Auditing 330. New York, NY: International Federation of Accountants.

Janvrin, D. J., \& Jeffrey, C. G. (2007). An investigation of auditor perceptions about subsequent events and factors that influence this audit task. Accounting Horizons, 21(3), 295-312.

Knechel, W.R. \& Sharma, D.S. (2012). Auditor-Provided Nonaudit Services and Audit Effectiveness and Efficiency: Evidence from Pre- and Post-SOX Audit Report Lags. Auditing: A Journal of Practice \& Theory 31(4): 85-114.

Kruglanski, A.W. (1980). Lay epistemology process and contents. Psychological Review 87: 70-87.

McMillan, J.J., \& White, R.A. (1993). Auditors' Belief Revision and Evidence Search: The Effect of Hypothesis Frame, Confirmation Bias, and Professional Skepticism. The Accounting Review. 66(3): 443-465.

Moskowitz, G.B. \& Roman, R.J. (1992). Spontaneous trait inference as self-generated primes: implications for conscious social judgment. Journal of Personality and Social Psychology 62 (5): 728-738.

Newman, L.S., \& Uleman, J.S. (1989). Assimilation and contrast effects in spontaneous trait inference. Personality and Social Psychology Bulletin 16: 224-240.

Nickerson. R.S. (1998). Confirmation Bias: A Ubiquitous Phenomenon in Many Guises. Review of General Psychology 2 (2): 175-230.

Nordholm, L. A. (1980). Beautiful patients are good patients: evidence for the physical attractiveness stereotype in first impressions of patients. Social Science \& Medicine. Part A: Medical Psychology \& Medical Sociology, 14(1), 81-83.

Nöteberg, A., and J. E. Hunton. (2005). Client inquiry via electronic communication media: Does the medium matter? Advances in Accounting Behavioral Research 8: 87-112.

Olivola C.Y., \& Todorov, A. (2010). Fooled by first impressions? Reexamining the diagnostic value of appearance-based inferences. Journal of Experimental Social Psychology 46: 315-324 
Peters, K.R., \& Gawronski, B. (2011) Are we puppets on a string? Comparing the impact of contingency and validity on implicit and explicit evaluations. Personality and Social Psychology Bulletin, 37, 557569

Porter, S., Gustaw, C., \& ten Brinke, L. (2010). Dangerous decisions: The impact of first impressions of trustworthiness on assimilation of legal evidence and decisions of guilt. Psychology, Crime and Law, $16,477-491$

Porter, S., \& ten Brinke, L. (2009). Dangerous decisions: A theoretical framework for understanding how judges assess credibility in the courtroom. Legal and Criminological Psychology, 14(1), 119-134.

Pyszczynski, T., \& Greenerg, J. (1987). Toward an integration of cognitive and motivational perspectives on social inference: A biased hypothesis-testing model. In L. Berkowitz (Ed.) Advances in experimental social psychology. 20: 297-340. New York: Academic Press.

Public Company Accounting Oversight Board (PCAOB). (2007) An Audit of Internal Control over Financial Reporting that is Integrated with an Audit of Financial Statements. Auditing Standards No. 5. Washington, D.C.: PCAOB

Puca, R.M. (2004). Action Phases and Goal Setting: being optimistic after decision making without getting into trouble. Motivation and Emotion 28 (2): 121-145.

Rasso, J. T. (2015). Construal instructions and professional skepticism in evaluating complex estimates. Accounting, Organizations and Society, 46, 44-55.

Rule, N. O., Tskhay, K. O., Freeman, J. B., \& Ambady, N. (2014). On the interactive influence of facial appearance and explicit knowledge in social categorization. European Journal of Social Psychology, 44(6), 529-535.

Smith, J. F., \& Kida, T. (1991). Heuristics and biases: Expertise and task realism in auditing. Psychological bulletin, 109(3), 472.

Smith, K.J. (2000). Occupational Stress in Accountancy: A Review. Journal of Business and Psychology, 4(4): 511-524.

Snyder, M., Tanke, E., Berscheid, E. (1977). Social Perception and Interpersonal Behavior: On the selffulfilling nature of social stereotypes. Journal of Personality and Social Psychology 35 (9): 656- 666.

Taylor, S.E., \& Gollwitzer, P.M. (1995). Effects of mindset on positive illusions. Journal of Personality and Social Psychology 69 (2):213-226.

Tversky, A., \& Kahneman, D. (1974). Judgment under uncertainty: Heuristics and biases. Science 12: 455460

Waggoner, J.B., \& Cashell, J.D. (1991). The impact of time pressure on auditors' performance. Ohio CPA Journal 50(1): 27.

Willis, J., \& Todorov, A. (2006). First impressions: Making up your mind after a 100-ms exposure to a face. Psychological science, 17(7), 592-598.

Winter, L., \& Uleman, J.S. (1984). When are social judgments made? Evidence for spontaneous trait inferences. Journal of Personality and Social Psychology 47: 237-252.

Winter, L., Uleman, J. S., \& Cunniff, C. (1985). How automatic are social judgments?. Journal of Personality and Social Psychology, 49(4), 904.

Wood, T. J. (2014). Exploring the role of first impressions in rater-based assessments. Advances in Health Sciences Education, 19(3), 409-427. 
FIGURE 3-1

Graph of Marginal Means of Inventory Valuation according to the Mindset Condition

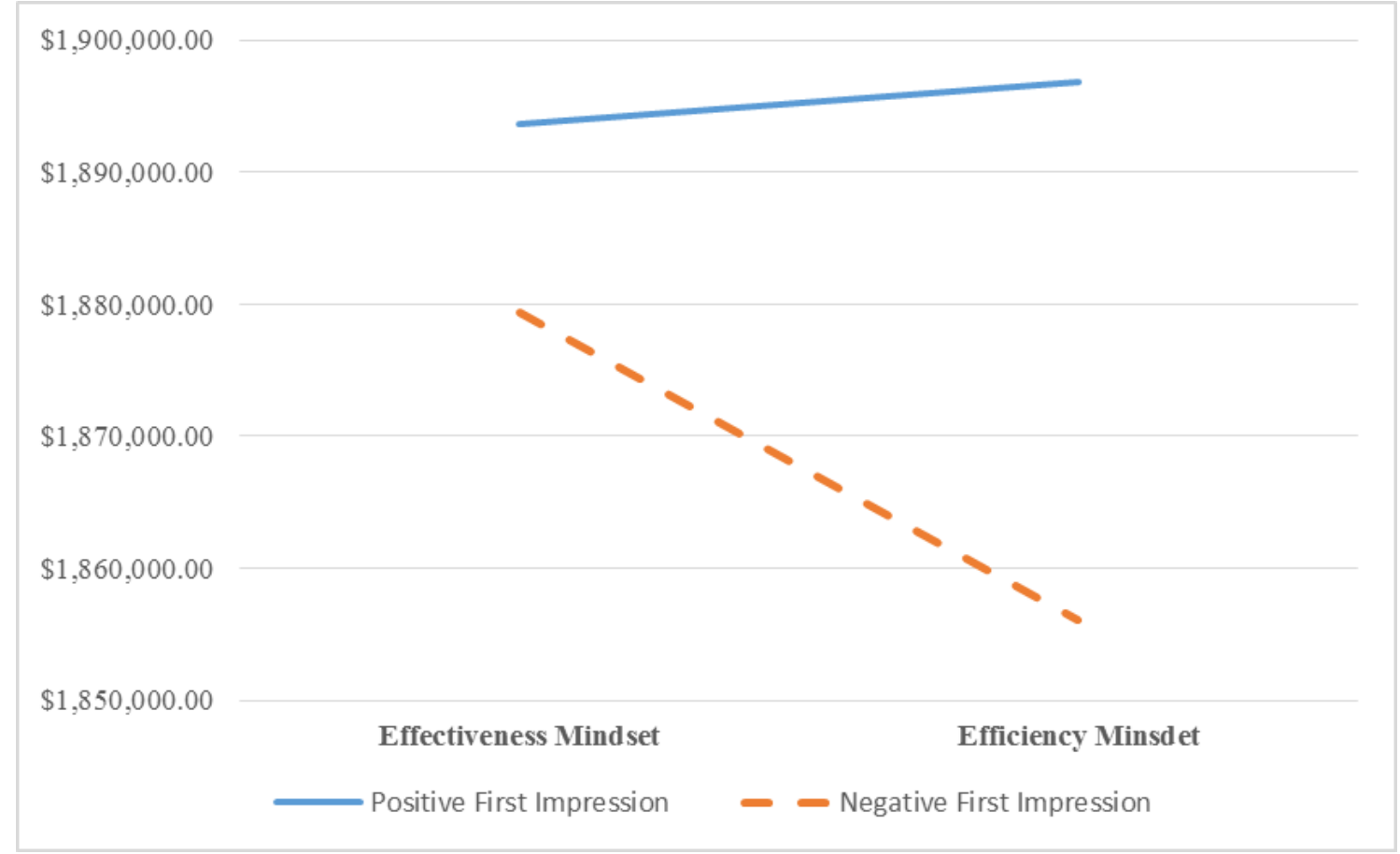


FIGURE 3-2

Graph of Marginal Means of Risk of Material Misstatement according to the Mindset Condition

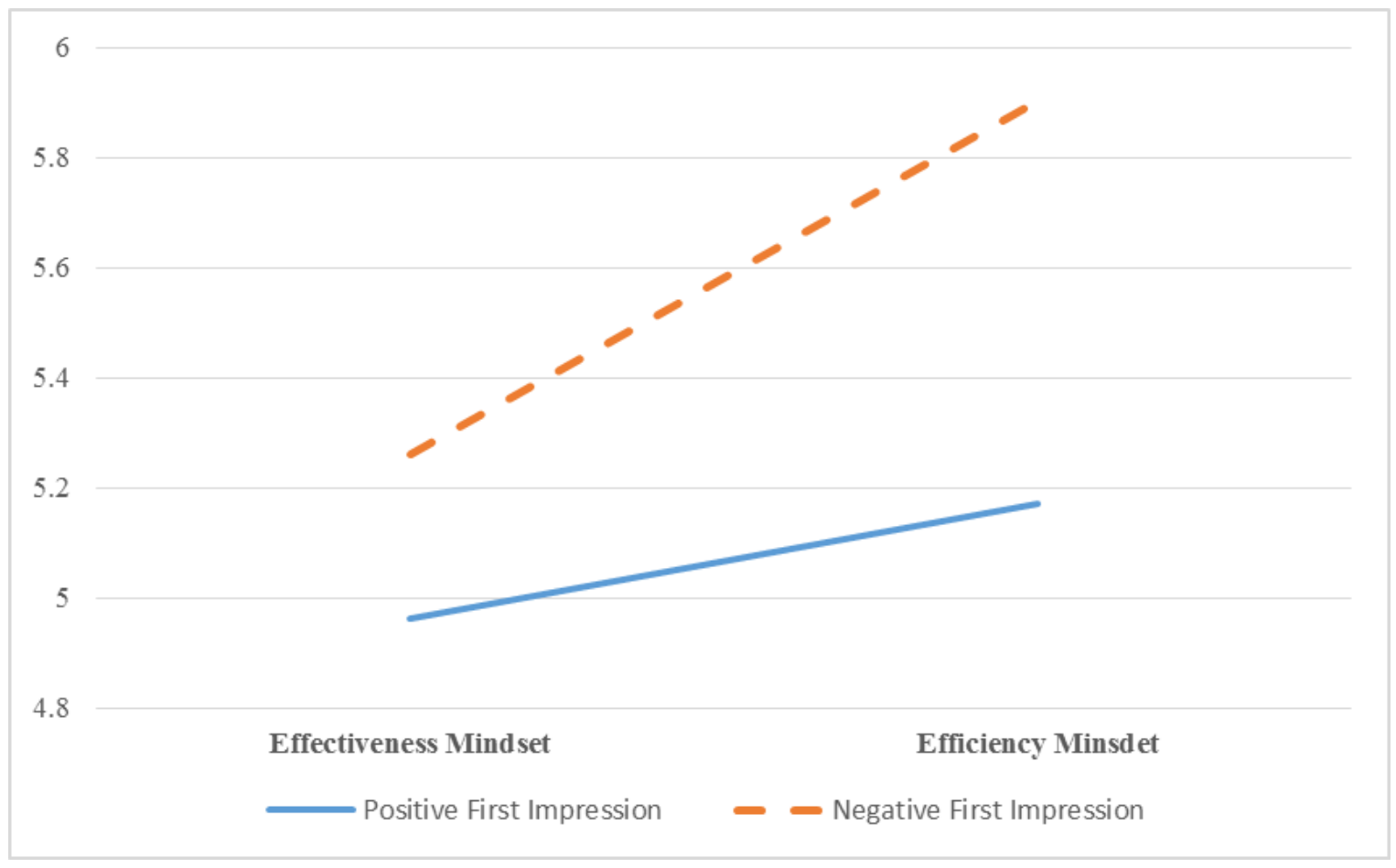


Table 3-1

\section{Participant Demographics}

Gender

Female

Male

$\mathrm{n}$

Number Percent

$22 \quad 17.70 \%$

$102 \quad 82.30 \%$

$124 \quad 100.00 \%$

Type of Accounting Firm

Big Four
Regional
Local
Other
$\mathrm{n}$

$80 \quad 64.52 \%$

$19 \quad 15.32 \%$

$16 \quad 12.90 \%$

$9 \quad 7.26 \%$

$124 \quad 100.00 \%$

Role in Accounting Firm

\begin{tabular}{|c|c|c|c|}
\hline Staff Auditor & & 58 & $46.77 \%$ \\
\hline Senior Auditor & & 36 & $29.03 \%$ \\
\hline Audit Manager & & 22 & $17.74 \%$ \\
\hline Partner & & 6 & $4.84 \%$ \\
\hline Other & & 2 & $1.61 \%$ \\
\hline $\mathrm{n}$ & & 124 & $100.00 \%$ \\
\hline$\underline{n}$ & Mean & (S.D.) & \\
\hline 124 & 30.02 & (7.63) & \\
\hline 124 & 5.32 & $(6.94)$ & \\
\hline
\end{tabular}


TABLE 3-2

Descriptive Statistics of Auditor Participants' Inventory Valuation and Risk of Material Misstatement

Panel A: Cell Means (SD) [n] for Inventory Valuation

FIRST IMPRESSIONS*MINDSET

$\begin{array}{ccc}\text { Efficiency } & \text { Effectiveness } & \text { Overall } \\ \$ 1,933,333.33 & \$ 1,910,714.29 & \$ 1,922,950.82 \\ (\$ 136,167.79) & (\$ 152,362.35) & (\$ 143,054.12) \\ {[33]} & {[28]} & {[61]}\end{array}$

Negative

$$
\begin{array}{ccc}
\$ 1,871,666.67 & \$ 1,903,030.30 & \$ 1,888,095.24 \\
(\$ 178,925.59) & (\$ 157,092.43) & (\$ 167,214.92) \\
{[30]} & {[33]} & {[63]}
\end{array}
$$

Overall

$$
\begin{array}{ccc}
\$ 1,903,968.25 & \$ 1,906,557.38 & \$ 1,905,241.94 \\
(\$ 159,712.84) & (\$ 153,697.60) & (\$ 156,150.15) \\
{[63]} & {[61]} & {[124]}
\end{array}
$$

Panel B: Cell Means (SD) [n] for Risk of Material Misstatement

FIRST IMPRESSIONS*MINDSET

Positive

Negative

Overall
5.77

[30] Efficiency

4.88

(1.87)

5.30

(1.92)

[63]
Effectiveness

$$
4.89
$$

[28]

5.27

$$
5.10
$$

[61]
Overall

4.89

(1.81)

[61]

5.51

(1.77)

[63]

5.20

(1.81)

[124] 
TABLE 3-3

Auditor Participants' Inventory Valuation and Risk of Material Misstatement

Panel A: Cell Means (SD) [n] for Inventory Valuation PERCEIVED FIRST

IMPRESSIONS*MINDSET

$\begin{array}{ccc}\text { Efficiency } & \text { Effectiveness } & \text { Overall } \\ \$ 1,951,515.15 & \$ 1,912,500.00 & \$ 1,932,307.69 \\ (\$ 120,211.30) & (\$ 145,358.29) & (\$ 133,589.50) \\ {[33]} & {[32]} & {[65]}\end{array}$

Negative

$\$ 1,851,666.67$
$(\$ 182,172.40)$

[30]

Overall

$$
\begin{array}{ll}
\$ 1,900,000.00 & \$ 1,875,423.73 \\
(\$ 164,750.89) & (\$ 174,042.43)
\end{array}
$$

$\begin{array}{cc}\$ 1,906,557.38 & \$ 1,905,241.94 \\ (\$ 153,697.60) & (\$ 156,150.15) \\ {[61]} & {[124]}\end{array}$
$(\$ 159,712.84)$ [63]

Panel B: Cell Means (SD) [n] for Risk of Material Misstatement PERCEIVED FIRST IMPRESSIONS*MINDSET Positive

Efficiency
4.91
$(1.79)$

Negative

$$
5.73
$$

Overall

$\begin{array}{cc}\text { Effectiveness } & \text { Overall } \\ 5.22 & 5.06 \\ (1.68) & (1.73) \\ {[32]} & {[65]}\end{array}$

4.97

5.36

(1.72)

[29]

5.10

5.20

(1.69)

[61] 
Table 3-4

ANOVA Analysis: Effect of First Impression on Auditors' Judgment of Inventory Valuation and the Risk of Material Misstatement under the Efficiency Mindset

Panel A: Dependent variable: Inventory Valuation (Adjusted $\mathrm{R}^{2}=0.142$ )

\begin{tabular}{lrrrrrr}
\hline Source & DF & Sum of Squares & Mean Square & F value & P \\
\hline Model & 6 & 356600000000 & 59430000000 & 2.717 & 0.022 \\
Error & 56 & 1225000000000 & 21870000000 & & \\
Corrected Total & 62 & 1582000000000 & & & & \\
\hline Source & DF & Sum of Squares & Mean Square & F value & $\mathrm{P}$ \\
\hline Age & 1 & 53720000000 & 53720000000 & 2.456 & 0.123 \\
Gender & 1 & 3215912879 & 3215912879 & 0.147 & 0.703 \\
Years of Work Experience & 1 & 176300000000 & 176300000000 & 8.060 & 0.006 \\
Type of Accounting Firm & 1 & 5581993479 & 5581993479 & 0.255 & 0.615 \\
Role in Accounting Firm & 1 & 37650000000 & 37650000000 & 1.721 & 0.195 \\
First Impression & 1 & 64790000000 & 64790000000 & 2.962 & 0.091
\end{tabular}

Panel B: Dependent variable: Risk of Material Misstatement (Adjusted $\mathrm{R}^{2}=0.075$ )

\begin{tabular}{lrrrrr}
\hline Source & DF & Sum of Squares & Mean Square & F value & \multicolumn{1}{l}{ P } \\
\hline Model & 6 & 37.795 & 6.299 & 1.842 & 0.107 \\
Error & 56 & 191.474 & 3.419 & & \\
Corrected Total & 62 & 229.270 & & & \\
\hline Source & DF & Sum of Squares & Mean Square & F value & P \\
\hline Age & 1 & 0.851 & 0.851 & 0.249 & 0.620 \\
Gender & 1 & 1.439 & 1.439 & 0.421 & 0.519 \\
Years of Work Experience & 1 & 0.194 & 0.194 & 0.057 & 0.813 \\
Type of Accounting Firm & 1 & 4.266 & 4.266 & 1.248 & 0.269 \\
Role in Accounting Firm & 1 & 1.474 & 1.474 & 0.431 & 0.514 \\
First Impression & 1 & 13.298 & 13.298 & 3.889 & 0.054
\end{tabular}


Table 3-5

ANOVA Analysis: Effect of First Impression and Mindset on Auditors' Judgment of Inventory Valuation and the Risk of Material Misstatement

Panel A: Dependent variable: Inventory Valuation (Adjusted $\mathrm{R}^{2}=0.004$ )

\begin{tabular}{|c|c|c|c|c|c|}
\hline Source & $\mathrm{DF}$ & Sum of Squares & Mean Square & F value & $\mathrm{P}$ \\
\hline Model & 3 & $6.08601 \mathrm{E}+10$ & 20286685980 & 0.829 & 0.481 \\
\hline Error & 120 & $2.93823 \mathrm{E}+12$ & 24485272370 & & \\
\hline Corrected Total & 123 & $2.99909 \mathrm{E}+12$ & & & \\
\hline Source & $\mathrm{DF}$ & Sum of Squares & Mean Square & F value & $\mathrm{P}$ \\
\hline First Impression & 1 & 37095071870 & 37095071870 & 1.515 & 0.221 \\
\hline Mindset & 1 & 589785284 & 589785284 & 0.024 & 0.877 \\
\hline First Impression $*$ Mindset ${ }^{\mathrm{b}}$ & 1 & 22476262750 & 22476262750 & 0.918 & 0.170 \\
\hline \multicolumn{6}{|l|}{ Simple effects: } \\
\hline $\begin{array}{l}\text { Simple effect of First Impression } \\
\text { under Mindset-Efficiency }\end{array}$ & 1 & 59757936510 & 59757936510 & 2.441 & 0.060 \\
\hline $\begin{array}{l}\text { Simple effect of First Impression } \\
\text { under Mindset-Effectiveness }{ }^{\mathrm{b}}\end{array}$ & 1 & 894365197 & 894365197 & 0.037 & 0.424 \\
\hline
\end{tabular}

Panel B: Dependent variable: Risk of Material Misstatement (Adjusted $\mathrm{R}^{2}=0.015$ )

\begin{tabular}{|c|c|c|c|c|c|}
\hline Source & DF & Sum of Squares & Mean Square & F value & $\mathrm{P}$ \\
\hline Model & 3 & 15.854 & 5.285 & 1.642 & 0.183 \\
\hline Error & 120 & 386.106 & 3.218 & & \\
\hline Corrected Total & 123 & 401.960 & & & \\
\hline Source & $\mathrm{DF}$ & Sum of Squares & Mean Square & F value & $\mathrm{P}$ \\
\hline First Impression & 1 & 12.396 & 12.396 & 3.853 & 0.052 \\
\hline Mindset & 1 & 1.776 & 1.776 & 0.552 & 0.459 \\
\hline First Impression $*$ Mindset ${ }^{\mathrm{b}}$ & 1 & 1.990 & 1.990 & 0.619 & 0.217 \\
\hline \multicolumn{6}{|l|}{ Simple effects: } \\
\hline \multicolumn{6}{|l|}{ Simple effect of First Impression } \\
\hline under Mindset-Efficiency ${ }^{\mathrm{b}}$ & 1 & 12.388 & 12.388 & 3.850 & 0.026 \\
\hline \multicolumn{6}{|l|}{ Simple effect of First Impression } \\
\hline under Mindset-Effectiveness ${ }^{\mathrm{b}}$ & 1 & 2.186 & 2.186 & 0.679 & 0.206 \\
\hline
\end{tabular}

${ }^{\mathrm{b}}$ The hypothesis tests are one-tailed tests, therefore the interaction p-values have been halved. All other results are reported as two-tailed tests. 
Table 3-6

ANOVA Analysis: Effect of Perceived First Impression and Mindset on Auditors' Judgment of Inventory Valuation and the Risk of Material Misstatement

Panel A: Dependent variable: Inventory Valuation (Adjusted $\mathrm{R}^{2}=0.101$ )

\begin{tabular}{lrrrrrr}
\hline Source & DF & Sum of Squares & Mean Square & F value & P & \\
\hline Model & 47 & $1.559 \mathrm{E}+12$ & 33168641170 & 1.750 & 0.015 \\
Error & 76 & $1.440 \mathrm{E}+12$ & 18949560620 & & \\
Corrected Total & 123 & $2.999 \mathrm{E}+12$ & & & & \\
\hline Source & DF & Sum of Squares & Mean Square & F value & P & \\
\hline Gender & 1 & 45208393200 & 45208393200 & 2.386 & 0.127 \\
$\quad$ First Impression (IFQ) & 28 & 1021059854000 & 36466423360 & 1.924 & 0.013 \\
$\quad \begin{array}{l}\text { Mindset } \\
\text { First Impression (IFQ)*Mindset }\end{array}$ & 1 & 32410624460 & 32410624460 & 1.710 & 0.195 \\
$\quad$ Simple effects: & 17 & 633551749900 & 37267749990 & 1.967 & 0.012 \\
$\quad$ Simple effect of First Impression & & & & & \\
$\quad$ under Mindset-Efficiency & & & & & \\
$\quad$ Simple effect of First Impression & 1 & 1848325905 & 1848325905 & 0.078 & 0.006 \\
$\quad$ under Mindset-Effectiveness & & & & & & \\
& 1 & 156027147100 & 156027147100 & 6.549 & 0.391
\end{tabular}

Panel B: Dependent variable: Risk of Material Misstatement (Adjusted $\mathrm{R}^{2}=0.038$ )

\begin{tabular}{lrrrrrr}
\hline Source & DF & Sum of Squares & Mean Square & F value & P & \\
\hline Model & 46 & 140.693 & 3.059 & 0.901 & 0.644 \\
Error & 77 & 261.267 & 3.393 & & \\
Corrected Total & 123 & 401.960 & & & & \\
\hline Source & DF & Sum of Squares & Mean Square & F value & P & \\
\hline First Impression $(I F Q)$ & 28 & 79.981 & 2.856 & 0.842 & 0.689 \\
Mindset & 1 & 4.193 & 4.193 & 1.236 & 0.270 \\
First Impression(IFQ)*Mindset & b & 17 & 62.364 & 3.668 & 1.081 & 0.193
\end{tabular}

Simple effects:

Simple effect of First Impression under Mindset-Efficiency ${ }^{\mathrm{b}}$

Simple effect of First Impression under Mindset-Effectiveness ${ }^{\mathrm{b}}$

$\begin{array}{lllll}1 & 10.676 & 10.676 & 3.293 & 0.036 \\ 1 & 0.976 & 0.976 & 0.301 & 0.292\end{array}$

\footnotetext{
${ }^{\mathrm{b}}$ The hypothesis tests are one-tailed tests, therefore the interaction p-values have been halved. All other results are reported as two-tailed tests.
} 


\section{Appendix 3-1}

\section{Research Study Materials}

\section{Instructions:}

For this case study, please assume that you are an auditor for a client called 'MicroClone, Inc.', a manufacturer of IBM-compatible high-end personal computers. During this case, you will be asked to analyze the balance of finished goods inventory. There are currently 8,000 computers in MicroClone's finished goods inventory.

A detailed analysis of MicroClone's inventory revealed that 25\% (2,000 units) of the finished goods inventory is comprised of 4th generation computers and the remaining 75\% (6,000 units) is represented by 5 th generation computers (the latest microprocessor chip available on the market). MicroClone's inventory of 2,000 units of 4 th generation computers is presently valued at cost $(\$ 1,000$ per unit), for a total of $\$ 2,000,000$.

It has come to your attention that there may be a problem concerning the 4th generation inventory: During the fourth quarter, MicroClone began shipping personal computers using the 5th generation chips. Therefore, it is possible that the value of the 4th generation computers remaining in the inventory might be overstated, because 4th generation computers will eventually become obsolete by industry standards. Consequently, the appropriate value of a 4th generation computer may be as low as $\$ 800$ per computer, instead of $\$ 1,000$ as currently valued. Thus, MicroClone's estimate of 4 th generation computers could be overstated by as much as

$\$ 200$ per unit, yielding a potential over-valuation of $\$ 400,000$ - at the most. However, it is quite possible that 4th generation computers are appropriately valued at $\$ 2,000,000$ and that no write down in inventory is necessary. The next step of the audit is for you to speak with client personnel so that you can come to your own conclusion about the inventory valuation.

Your supervisor has asked that you meet with the controller of MicroClone to discuss the inventory issue. This is your first year on the MicroClone audit, and this will be the first time you meet the controller. The supervisor's instructions are as follows:

\section{Efficiency Mindset Condition}

"The firm is concerned about the way our professionals analyze clients' inventory valuations. Specifically, we are concerned that our auditors may conduct inefficient investigations when testing the inventory valuation, which may lead to excess costs. Speaking with the controller is one of the final steps in our audit program for MicroClone. My main concern is that we work efficiently on this audit so that we don't exceed our time budget. I need you to speak to the controller so we can efficiently complete our inventory valuation tests without incurring excess audit costs in this area."

\section{Effectivness Mindset Condition}

"The firm is concerned about the way our professionals analyze clients' inventory valuations. 
Specifically, we are concerned that our auditors may conduct ineffective investigations when testing the inventory valuation, which may lead to inappropriate conclusions. Speaking with the controller is one of the final steps in our audit program for MicroClone. My main concern is that we effectively perform the inventory testing, and I'm not concerned with how many hours we spend. I need you to speak to the controller so we can effectively perform our inventory valuation tests and reach the appropriate conclusion in this area."

You will have the opportunity to interact with the controller via video. Your aim is to discuss with the controller the appropriate valuation estimate for the 4th generation computers, which can range from $\$ 1,600,000$ to $\$ 2,000,000$. Materiality for this client's financial statements is $\$ 300,000$. Therefore, there is some concern about this potential over-valuation situation.

After the interview, you will be asked to make a decision as to the final inventory valuation amount for the 4th generation computers. It is in the best interest of the client company to maintain a high asset valuation.

\section{Script from video with accompanying dialogue from the participants}

The interview begins:

You: Good morning. I am part of the audit team and I would like to have a few minutes to chat about the valuation of the $4^{\text {th }}$ generation computers."

\section{Positive First Impression Condition}

Controller: "Good morning! Come in! How can I help? I can make time for some questions now."

\section{Negative First Impression Condition}

Controller: "You auditors always stop by at the worst times. Just come in. What do you need? Let's just get it over with."

You: "MicroClone has begun shipping personal computers using the $5^{\text {th }}$ generation chips. We're concerned that your $4^{\text {th }}$ generation computers may have lost value, and therefore, are not properly valued. What evidence do you have that the $4^{\text {th }}$ generation computers are properly valued?"

Controller:"MicroClone prides itself on innovation. Our products are so popular that we are confident our customers are willing to pay a premium for our brand, even for older models."

You: "Has the company ever had any difficulty selling previous versions of the computer?" 
Controller: "MicroClone has no history of inventory valuation problems. We've successfully sold nearly our entire stock of $1^{\text {st }}, 2^{\text {nd }}$, and $3^{\text {rd }}$-generation computers without significant writedowns of our inventory account. We are sure that the $4^{\text {th }}$ generation computers will be the same."

You: "My records show that the $4^{\text {th }}$ generation of computers are valued at $\$ 1,000$ per unit. What evidence do you have that MicroClone will be able to sell all of your $4^{\text {th }}$ generation computers at that price?"

Controller: "We believe that the valuation of $\$ 1,000$ per unit is reasonable. In fact, one of our sales managers has informed us that one of our competitors - MilleniCom - is currently out of $4^{\text {th }}$ generation computers. We just received a memo from MilleniCom inquiring about the number of $4^{\text {th }}$ generation computers we have in stock. It seems that they are considering buying a large number of our $4^{\text {th }}$ generation computers at our current selling price."

You: "What if MilleniCom doesn't purchase your $4^{\text {th }}$ generation computers? Would you have to lower the $\$ 1,000$ price to sell the remainder of those computers?"

Controller: "We still shouldn't have any problem selling them. We've got recent contracts signed by two universities specifying that all incoming students will be required to purchase $4^{\text {th }}$ generation computers for the upcoming school year. So you see, we have other outlets for those computers."

You: "Why would the universities specify older generation computers when the $5^{\text {th }}$ generation computers are available?"

Controller: "The $5^{\text {th }}$ generation computers are not stable yet. Our marketing manager sent over a memo saying that the $5^{\text {th }}$ generation computers seem to suffer from an overheating problem. He suggests we advise customers to continue buying $4^{\text {th }}$ generation computers. As a result, we don't expect sales volume for the $4^{\text {th }}$ generation computers to be affected by the introduction of $5^{\text {th }}$ generation computers, thus $4^{\text {th }}$ generation sales should remain steady over the nextyear."

You: $\quad$ "My research shows that the $5^{\text {th }}$ generation computers will be much faster than the $4^{\text {th }}$ generation computers. Won't many of your customers prefer to buy the $5^{\text {th }}$ generation computers to take advantage of the improved technology?"

Controller: "I don't think that will be a problem. Our 4th generation computers can soon be upgraded with 5th generation chips, which will increase 4th generation performance to an equivalent of 5th generation computers. I just received a memo from our technical manager who confirmed that it will soon be an option to upgrade 4th generation machines to 5th 
generation computers at minimal cost.

Given the upgradeability, we can probably sell these computers at the same price as 5th generation computers."

You: "Why does MicroClone believe their customers would buy a 4th generation computer, and upgrade it, when they could simply buy a 5th generation computer?"

Controller: "Our $5^{\text {th }}$ generation computers are more expensive than previous models due to enhanced product features. Marketing analysis suggests that there will be steady demand for the $4^{\text {th }}$ generation because many of our customers won't buy at the higher price point."

You: "What about the user experience between the $4^{\text {th }}$ and $5^{\text {th }}$ generation computers? Do customers demonstrate a preference for the $5^{\text {th }}$ generation computers over the $4^{\text {th }}$ generation?"

Controller: "Actually no. Focus groups indicate that many of our customers would like to purchase $4^{\text {th }}$ generation computers in order to become familiar with our products before committing to our more expensive $5^{\text {th }}$ generation computers."

You: $\quad$ "Are there any other reasons you believe would demonstrate that the $4^{\text {th }}$ generation computers are appropriately valued at $\$ 1,000$ ?”

Controller: "Yes. We can also export the $4^{\text {th }}$ generation computers to developing markets where we probably sell them at our existing selling price. Our head of customer service sent me an email saying that our orders for $4^{\text {th }}$ generation computers in China and India are expected to grow next year. I am sorry to have to end our discussion now, I have a meeting coming up."

You: "No problem. Thank you for your time."

\section{Inventory Valuation Questions}

1. What is your assessment of the risk of a material misstatement of the $4^{\text {th }}$ generation computers in the inventory account? (9-point scale, Extremely low risk-Extremely high risk)

2. Please provide an explanation of how you arrived at the assessment.

3. Based on your understanding of the MicroClone, Inc. inventory account, what is the appropriate inventory valuation for the $4^{\text {th }}$ generation computers?

\section{Post-experiment Questions}

1. Your audit supervisor is very concerned about exceeding the time budget on this audit. 
(True-False)

2. How comfortable are you with asking the controller for more information about the inventory? (7-point scale, Very Uncomfortable-Very Comfortable)

3. In your opinion, how likely will the controller be to accept your proposed inventory valuation? (7-point scale, Very Unlikely-Very Likely)

4. How much did the evidence provided by the controller influence your inventory valuation decision? (7-point scale, Minimum Influence-Maximum Influence)

5. How much did your impressions of the controller influence your inventory valuation decision? (7-point scale, Minimum Influence-Maximum Influence)

6. I believe this client to be trustworthy. (7-point scale, Strongly Disagree-Strongly Agree)

7. I believe this client to be competent. (7-point scale, Strongly Disagree-Strongly Agree)

8. I believe this client to be honest. (7-point scale, Strongly Disagree-Strongly Agree)

9. Please rate the controller on each of the following items by clicking in the circle that best represents your opinion. (each pair is rated on a 7-point scale)

- Sincere-Insincere

- Warm-Cold

- Poised-Awkward

- Exciting-Boring

- Energetic-Unenergetic

- Enthusiastic-Unenthusiastic

- Bold-Timid

- Sensitive-Insensitive

- Self-assertive-Reserved

Demographic Questions

1. Age

2. Gender

- Male

- Female

3. Years of Work Experience

4. Type of Accounting Firm

○ Big 4 Firm

- Regional Firm

- Local Firm

O Other

5. Role in Accounting Firm

- Staff Auditor

- Senior Auditor

- Audit Manager

- Partner

- Other 


\title{
CHAPTER FOUR: CHANGING THE NATURE OF AUDIT PROCEDURES TO DETER FRAUD
}

\author{
A. Scott Fleming \\ West Virginia University \\ scott.fleming@mail.wvu.edu \\ D. Kip Holderness \\ West Virginia University \\ kip.holderness@mail.wvu.edu \\ Alyssa S.J. Ong \\ West Virginia University \\ asong@mix.wvu.edu
}




\section{INTRODUCTION}

AU 316 (AICPA 2002) recommends that auditors incorporate "elements of unpredictability" in selecting audit procedures to be performed in response to the assessed risks of material misstatement due to fraud. In keeping with the audit policy recommendations, auditors could vary the nature, timing, or extent of audit procedures. Prior research suggests that designing unpredictable procedures can assist with the detection of fraud that is concealed from standard audit procedures (Hoffman and Zimbelman 2009; Fellingham and Newman 1985; Shibano 1990). Changing the nature of audit procedures fits with suggestions from prior research about designing unpredictable procedures to assist with fraud detection as a change in timing or extent still uses the same audit procedures from prior years. Erickson et al. (1997) provide evidence that changing the nature of audit procedures would be more effective with fraud detection. However, archival and experimental research suggests that auditors continue to collect the same audit evidence items yearly, keeping the nature of the evidence constant (Bedard 1989; Glover et al. 2003). In addition, fraud studies find that when auditors are explicitly asked to assess fraud risks they change the extent but not the nature of audit evidence (Zimbelman 1997). Bedard et al. (1999) find the same results in auditing studies unrelated to fraud. Wilks and Zimbelman (2004) suggest that these findings regarding the lack of variation in the nature of audit procedures is troubling since changing the extent of audit evidence collection is not as effective as changing the nature of audit procedures. One reason for the lack of the variation in the nature of audit procedures is the employment of audit checklists (Asare and Wright 2004). When the audit plan is too predictable, auditees familiar with the audit plan can anticipate which areas will receive lesser attention (or no attention) and intentionally commit fraud with very low risk of being detected (Bowlin 2011). Thus, changing the nature of audit procedures is critical to fraud detection. This study examines an additional benefit of varying audit procedures. We posit that changing the nature of audit procedures may deter fraud because it creates ambiguity, and individuals tend to be averse to such ambiguity. 
Individuals' aversion to ambiguity influences the decisions they make. Individuals who are averse to ambiguity prefer to take action on an issue when the probabilities of success or failure are clearly defined (Ellsberg 1961). Given the chance, individuals tend to prefer the option with known probabilities over the option with unknown probabilities (Ellsberg 1961). In the same vein, Frish and Baron (1988) find that individuals are averse to missing information when making decisions especially when the information can be manipulated by another party or is known only after a decision has been made. Changing the nature of audit procedures will result in individuals' inability to predict what the auditors will be testing, creating ambiguity and increasing the perception that individuals do not have adequate amount of information about the auditors plans and the risk of fraud detection. When the chosen audit procedures for the upcoming audit are unknown, the perception of the risk of detection is higher than when the audit procedures are predictable. Individuals will then be less likely to attempt to commit fraud when auditors are constantly varying the nature of audit procedures. In addition to increasing the probability of fraud detection, changing the nature of audit procedures can possibly lead to fraud deterrence.

There has been a $13 \%$ increase in the narcissism scores on the Narcissistic Personality Inventory (Raskin and Terry 1988) between the early 1980's to 2006 (Twenge et al. 2008). The increase in narcissism scores is especially predominant among the Millennial Generation (Twenge and Campbell 2009). Prior psychology research suggest that narcissists' self-perceived superiority is a major element of their self-esteem (Raskin \& Terry 1988; Paulhus 1998). Within the area of auditing, Johnson et al. (2013) find that narcissistic managers are perceived by auditors to pose a greater fraud risk. When a task is perceived as a challenge, narcissists interpret this as a great opportunity to prove that they are superior over others (Wallace and Baumeister 2002). Changing the nature of audit procedures will make the auditors' tests unpredictable, deterring individuals who are averse to ambiguity. However, if narcissists 
view the unpredictability as a challenge, they are more likely to attempt to commit fraud to demonstrate that they are superior over others and the auditors. The variation in audit procedures might fuel narcissistic individuals to commit fraud to satiate their need to be superior to the system. In this situation, changing the nature of audit procedures might not deter fraud, but actually lead to an increase in fraud occurrence.

This study examines the individual's perception of the ambiguity present in the yearly variation of audit procedures and how his/her aversion to ambiguity and narcissistic trait influence the individual's decision to commit fraud. To do so, we conduct a $2 \times 2$ interactive simulation, collecting data from a simulation involving 141 participants playing the role of inventory managers of a hypothetical firm in which managers, who know about the likelihood that auditors vary audit procedures, have the opportunity to choose to misappropriate assets of the company's inventory or choose not to commit fraud at all. We find that when individuals are presented with both variation absent or variation present conditions, they are more likely to prefer the variation absent condition when they want to commit inventory theft. We also find that when auditors vary the nature of audit procedures, individuals perceive the risk of detection to be greater than when auditors keep the same audit procedures from year to year.

This study makes several contributions to extant literature. First, we extend prior research on ambiguity aversion to the fraud detection and prevention setting, focusing on potential fraudster's perception of auditors' audit planning decisions. Previous ambiguity aversion research within the accounting area centered on auditors' reaction to ambiguous situations. This is the first study to examine how auditors can use ambiguity aversion to their benefit and increase the effectiveness of the audit. Second, we examine how ambiguity aversion is influenced by various personality characteristics such as narcissism. From a practical perspective, this paper could aid auditors and regulators by showing that incorporating elements of unpredictability in audit plans can possibly deter fraud in addition to assisting 
with fraud detection.

The remainder of this paper proceeds as follows: Section II provides a background review of the relevant literature and the hypotheses development. Section III outlines the research method and the experimental design of the study. Section IV provides results of the experimental study and Section V includes a discussion and concluding remarks.

\section{BACKGROUND AND HYPOTHESES DEVELOPMENT}

\section{Variation in the Nature of Audit Procedures}

Variation in audit procedures are used not only to assist in fraud detection (Wilks and Zimbelman 2004; AICPA 2002), but also to assist accounting firms with lowering audit risk to reach the planned audit risk (Colbert and Luehlfing 1996; Bedard, Mock, and Wright 1999). Prior research indicates that increasing audit evidence persuasiveness by increasing the extent and nature of audit tests will lead to lower audit risks (Mock and Wright 1993, 1999; Elder and Allen 2003). However, Budescu et al. (2012) find contrasting evidence with regards to the decrease in audit risk when there is variation in extent and nature of audit procedures. They suggest that variation in the nature and extent of audit procedures does not automatically lead to enhanced audit effectiveness as audit risk can potentially increase, not decrease, depending on the type of variation in audit procedures and the type of misstatement.

AU 316 states that how an audit is conducted is affected by the judgment of the risk of material misstatement due to fraud (AICPA 2002). One factor revolves around the predictability of auditing procedures:

"The auditor should incorporate an element of unpredictability in the selection from year to year of auditing procedures to be performed - for example, performing substantive tests of selected account balances and assertions not otherwise tested due to their materiality or risk, adjusting the timing or testing from that otherwise expected, using differing sampling methods, and performing procedures at different locations or at locations on an unannounced basis." (AU 316.50) 
Auditors exhibit a great dependence on prior year audit programs, which leads to using a large majority of the same procedures (Bennett and Hatfield 2012; Bedard 1989). When the audit plan is too predictable, individuals might recognize the patterns and develop fraud schemes that circumvent yearly audit procedures (Bowlin 2011). To address the identified risks of material misstatement due to fraud, variations in the nature, timing, or extent of audit procedures that involve substantive testing and tests of operating effectiveness of controls need to be conducted depending on the risks identified, the account balances, classes of transactions, and related assertions (AU 316.51). The nature of audit tests involve the types of tests available to collect evidence, extent refers to the increase or decrease in sample size used for testing, whereas the timing of audit tests refers to when an audit test is performed or the time period used for audit evidence collection (Bedard, Mock, and Wright 1999; Wilks and Zimbelman 2004).

Mock and Wright (1993) find that changing the extent of audit procedures is the primary method auditors use to address differences in audit risk. Fraud studies find that auditors do not change the nature of planned evidence even when prompted to assess fraud risk, suggesting a greater preference towards changing the extent and timing over the nature of audit procedures (Bedard 1989; Zimbelman 1997; Glover et al. 2003). A study done to examine the effects of SAS no. 82 on documented changes to the planned audit program by Mock and Turner (2005) indicate that there was a slight increase in variation in nature of audit procedures from Year 1 to Year 2. This suggests that auditors are willing to modify the nature of audit procedures based on SAS no. 82 evaluations. A possible explanation for auditors' lack of variation in the nature of audit procedures is the limited availability of new or unique evidence items to employ (Wilks and Zimbelman 2004). To overcome this issue of lack of awareness on methods to vary audit procedures, AU 316 provides recommendations and examples for varying the nature, timing, and extent of audit procedures for areas such as inventory quantities, revenue recognition, management estimates, asset misappropriation, and management override of controls. 


\section{The Nature of Audit Procedures}

Auditors conduct test of controls and perform substantive testing (AICPA 2002). Within the two broad categories of test of controls and substantive testing, auditors have available audit tests that differ in perceived efficiency and effectiveness (Bedard et al. 1999). Varying the nature of audit procedures may involve the use of external evidence from public records, physically inspecting assets instead of relying on numbers from spreadsheets, or using computer-assisted audit techniques in addition to performing confirmations or requiring different documents that test the same accounts. Interviewing additional employees for more detailed information, changing the testing location, and making oral inquiries of major customers and suppliers are also ways to vary the nature of collecting audit evidence (AU 316.53). Varying the nature of audit procedures is considered to be more effective in a strategic setting than varying the extent and timing of audit evidence collection (Wilks and Zimbelman 2004).

\section{Ambiguity Aversion}

Ambiguity is defined as uncertainty over probabilities (Camerer and Weber 1992). Ambiguity aversion, identified by Ellsberg (1961), shows how ambiguity influences the use of probabilities when individuals' make decisions and their preferences for options with known versus unknown probabilities. Also known as the Ellsberg Paradox, Ellsberg uses a thought experiment to show the paradox in decision theory when an individual's choice violates the expectations of Savage's (1954) subjective expected utility theory (Ellsberg 1961). Below is a brief illustration of the thought experiment (Ellsberg 1961):

The first scenario:

There are two urns each with 100 balls: Urn 1, containing 50 red balls and 50 black balls, and Urn 2, containing an unknown proportion of red balls and black balls. Individuals are given the opportunity to select which urn they would like to make a bet on and draw a ball from. They will receive $\$ 100$ if they draw a red ball when they make a red bet and vice versa. They would receive nothing if they draw a ball that does not correspond to the color of the bet.

The second scenario: 
An urn containing 90 equal-sized balls has 30 red balls and 60 black and yellow balls in unknown proportions. There will be two lotteries. Individuals are asked to choose from two options (A or B, A' or B') for each lottery. Each lottery has a guaranteed reward of $\$ 100$ and is based on different triggers. Individuals either receive $\$ 100$ or $\$ 0$ for each lottery. The probability of winning, $p$, is listed along with each option.

The options for Lottery 1:

A: A reward of $\$ 100$ if a red ball is drawn $(p=1 / 3)$.

$B$ : A reward of $\$ 100$ is given if a black ball is drawn $(0 \leq p \leq 2 / 3)$.

The options for Lottery 2:

A': A reward of $\$ 100$ if a red ball or a yellow ball is drawn $(1 / 3 \leq p \leq 1)$.

$B^{\prime}$ : A reward of $\$ 100$ if a black ball or a yellow ball is drawn $(p=2 / 3)$.

Ellsberg (1961) finds that most individuals prefer Urn 1 in the first scenario regardless of hedging a red bet or a black bet, indicating that individuals' prefer an outcome with known probability even when the likelihood is the same ( $\mathrm{p}=0.5$ for red and $\mathrm{p}=0.5$ for black). The risk for both outcomes is the same, because the potential payoff or loss is the same for both urns. This two-urn example shows that individuals' preference is driven by aversion to ambiguity, and not aversion to risk (Gilboa 2009). The probability of getting a reward with a red or black bet with Urn 2 is $0 \leq p \leq 1$. For the second scenario, individuals' prefer options A and B' over A' and B because the precise probability for winning the $\$ 100$ is known and options A' and B have vague probability distributions. The subjective expected utility theory would suggest that individuals would choose Urn 2, options A and A'. Both scenarios show that individuals prefer the options with known probabilities because of their aversion to ambiguity, not because of their aversion to risk.

In addition, Ellsberg (1961) finds that individuals are generally ambiguity-averse when given a choice between purely chance-based prospects but they would prefer ambiguous ability- based prospects over unambiguous chance-based prospects. This is due to the positive perceptions of individual's competence, which is expected to overcome the ambiguity involved in situations where individuals are perceived to have some control over the outcome (Heath \& Tversky 1991). Einhorn and Hogarth (1986) documented that when there are low probabilities of future losses, individuals react conservatively to 
ambiguity whereas when the probability of loss is high, people react in a less conservative manner. Individuals are averse to missing information when making decisions (Frisch \& Baron 1988). This is true especially when that information is known and can be manipulated by another party or is made known after a decision has been made (Frish \& Baron 1988).

Varying the audit procedures every year would result in individuals' perception of having missing information with regards to what will be tested and when the auditors will carry out the audit tests. The use of different audit procedures each year can be categorized as a chance-based prospect from the perspective of the individual as they have no control over the actions of the auditors. Audit procedures which are set and unchanging from year-to-year allows individuals to learn the patterns and find ways to work around it. Research in psychology suggest that how people react to ambiguity is influenced by the incentives (Einhorn and Hogarth 1985). Individuals who would like to increase their financial position would have the incentive to commit fraud but they would prefer to avoid the costs that would be incurred if they get caught. Since the goal of fraudsters is generally to perpetrate the fraud for as long as possible and avoid getting caught (diNapoli 2008), they would have to predict which audit procedures are employed each year and figure out the probabilities of success based on the different sets of audit procedures used.

Given that individuals are generally averse to ambiguity when the prospect is chance- based, we posit that when auditors vary the audit plan each year, individuals will be less likely to commit fraud due to the ambiguity involved in the variation of audit procedures. When the audit procedures are predictable and unchanging from year to year, individuals will be more likely to commit fraud because of their knowledge of the audit plan and the reduced probability of the detection of the fraud. Using an experimental setting to test the variation in the nature of audit procedures is crucial as auditors rarely make changes to the nature of planned evidence in practice (Zimbelman 1997; Glover et al. 2003). This 
leads to the following hypothesis:

\section{H1: Incorporating an element of unpredictability through a change in the nature of audit procedures will decrease the likelihood that individuals choose to commit fraud.}

\section{Narcissism}

Although we will collect data on several personality characteristics, we have a specific prediction regarding the effect of narcissism on susceptibility to ambiguity aversion. The American Psychiatric Association (2000) defines narcissism as a pervasive and enduring pattern of grandiose behavior (in fantasy or actual behavior), the need for admiration, and a lack of empathy. Narcissists also tend to be strongly motivated to approach desirable outcomes but only weakly motivated to avoid negative outcomes (Foster and Trimm 2008). It would seem that narcissists manipulate public impressions by exaggerating their talents but they actually exaggerate their talents and abilities because they truly believe they are superior over others (Raskin et al. 1991). Narcissists are especially passionate in their pursuit of personal glory (John and Robins 1994; Robins and Beer 2001). They are more concerned about selfenhancement when compared with other individuals and this can encourage narcissists to invest maximum effort when opportunities for self-enhancement arise (John and Robins 1994; Wallace and Baumeister 2002). When the task goal is perceived as a difficult challenge, narcissists interpret this as a perfect opportunity to demonstrate their superiority over others; Task success is taken as an impressive sign of personal superiority and when tasks are difficult, narcissists tend to perform well (Wallace and Baumeister 2002). Conversely, when tasks are easy, it does not reflect exceptional ability and leads to lower motivation/desire to perform the tasks (Wallace and Baumeister 2002).

The appearance of performing well at work and reaping great financial benefits to seem superior over others financially is self-enhancing. If committing fraud could increase a narcissist's level of wealth and/or authority (feeling of superiority) within the company, this would be perceived as a desirable outcome and worth a great investment of effort. In addition, the chance of being caught because of the 
fraud would seem to be a negative outcome that factors much less into the decision to commit fraud. The knowledge that auditors will vary audit procedures will raise the difficulty of the task, possibly driving narcissistic individuals to commit fraud. When audit procedures are predictable, successfully perpetrating a fraud scheme would seem as if it can be done by anyone, decreasing the narcissists' desire to exhibit exceptional ability and their motivation to commit fraud. This leads to the following hypotheses:

$\mathrm{H}_{2 \mathrm{~A}}$ : When variation in the nature of audit procedures is present, the fraud occurrence proportion of narcissistic individuals will be higher than when variation in the nature of audit procedures is absent.

\section{$H_{2 B}$ : When variation in the nature of audit procedures is present, the fraud occurrence proportion of non-narcissistic individuals will be lower than when variation in the nature of audit procedures is absent.}

This study specifically looks at the "Prevent and Deter Controls" piece of the fully ascribed metamodel of white collar crime presented by Dorminey et al. (2012). The meta-model of white collar crime is depicted in Figure 4-1. The ambiguity created from auditors' variation in audit procedures relates to the deterrence piece that is the main focus of this study. To be able to focus on the fraud deterrence piece, we incorporate elements from the Perpetrator(s) and the Crime triangles to provide individuals with the opportunity to commit fraud and convert the gains of the fraud into personal wealth.

[Insert Figure 4-1 About Here]

\section{EXPERIMENTAL DESIGN AND METHODS}

\section{Participants}

This study is conducted in two parts. 270 participants elected to participate in Part One of this study via Amazon Mechanical Turk (MTurk). They had to be at least 18 years of age and located in the United States. A study by Kees et al. (2017) find that MTurk participants are older, more educated, and have higher personal income levels than student samples and samples from professional research 
companies like Qualtrics and Lightspeed. The quality of the data received from MTurk is also better than the data obtained from other samples. Overall, they find that MTurk is a viable platform to recruit participants. Participants were told that three days after completing Part One, the Part Two of this study will be available on MTurk. 141 participants completed Part Two over 10 days. We tested the hypotheses using the 141 observations. The mean age of participants is 34.49 years and the average years of work experience is 18.32 years. Table 4-1 presents the participant demographics of the 141 participants. Participants received monetary compensation in exchange for participation. They were also awarded an additional bonus depending on their performance in the simulation in the second part of the study.

[Insert Table 4-1 About Here]

\section{Design}

This study involved a $2 \times 2$ experiment in which we manipulated the variation of the nature of audit procedures (auditing both or only one warehouse - triggering ambiguity aversion) and we measured participants' levels of narcissism (low or high). Data was collected electronically via Qualtrics survey platform. A 10-period simulation was designed to reflect the variation or lack thereof in the audit procedures. Participants were told that there were two warehouses and each warehouse had five bins. Participants then had the opportunity to indicate in each period whether they chose to take an asset from one of the five bins in Warehouse A, one of the five bins in Warehouse B, or not to commit fraud at all. In every period, there was a $20 \%$ chance that the fraud would be discovered by the auditors. The repeatedtrial design of the experiment allowed participants to incorporate the knowledge of audit procedures used by the auditors in the previous periods when making decisions for subsequent periods.

\section{Pilot Tests}

Prior to arriving at the design and methods used in the study, we conducted 6 rounds of pilot tests with students and on MTurk. In the first round with three independent variables (narcissism, variation in audit procedures, audit extent framing or compensation framing), 105 students tested two different 
versions of the study. The difference between the two versions was the use of audit extent framing (just one week vs. one entire week) as the third independent variable for one version and the use of compensation framing (short term vs. long term) as the third independent variable for the second version. This pilot was done to ensure that any issues with the simulation was identified and corrected before we opened the study on MTurk.

On MTurk, we conducted five different pilot tests and had 1024 participants complete Part One of the study. A total of 665 participants completed Part Two. Analysis of each round of the MTurk pilot tests were conducted with observations that have complete Part One and Part Two responses. The first MTurk pilot test was similar to the student pilot test. We tested the two different versions and decided to move forward with the compensation framing version. In addition, the results from the pilot test was unanticipated and a departure from theory. The results suggested that participants were stealing more when auditors varied the nature of audit procedures. This prompted changes to the wording in the case background to clarify the audit procedures and the addition of some case comprehension questions. We also included a question after the simulation asking participants to identify their audit procedure preference should they have an interest in taking a processor.

The second MTurk pilot test with the compensation framing version was conducted after making changes from the previous pilot. Results indicated that the proportion of fraud occurrence was higher when auditors varied the nature of audit procedures, however, over $80 \%$ of participants indicated in the post-simulation question that they preferred it when auditors did not vary the nature of audit procedures if they wanted to take a processor. The proportion of fraud occurrence was higher when compensation was framed as short-term compared to when compensation was framed as long-term. We were perplexed by the difference between behavior and what the participants indicated they preferred and decided that perhaps being exposed to only one condition (variation present or variation absent) lead to some 
discrepancy between action and preference.

For the third MTurk pilot test, we changed the design of the simulation, exposing participants to both the variation present and variation absent conditions. They were told at the start of each period if auditors were going to audit only one warehouse or both warehouses.

Results still showed the proportion of fraud occurrence to be higher when participants were told that auditors were varying the nature of audit procedures. Regarding compensation framing, results for the long-term and short-term conditions were similar to the earlier pilot test. Also similar to the pilot test before this one, participants indicated that they preferred the variation absent condition if they wanted to steal. Further discussion about the practicality of the compensation framing variable lead to the exclusion of compensation framing in the study. Although results for compensation framing were in the expected direction, it is not possible for companies to withhold compensation for multiple periods to reduce the proportion of fraud occurrence. As the inclusion of this variable would not lead to practical changes in the field, we felt that the exclusion of this variable moving forward was justified.

Due to inconsistency between action and preference of participants, we took a closer look at the study design and wording. We made changes to the wording of the questions and case background based on suggestions from an experienced experimental design researcher. The biggest change came from replacing the word "audit" in the simulation as most individuals might have associated that with IRS tax audits. Also, we included an open-ended question asking participants why others would indicate that they preferred the variation-absent condition but ended up taking more processors when the auditors varied the nature of audit procedures. Upon making the changes described above, the fourth MTurk pilot test was conducted as a 2 (variation in the nature of audit procedures) x 2 (narcissism) experiment whereby participants were only exposed to either the variation-absent or variation-present condition. Results were similar to earlier pilots regarding the proportion of fraud occurrence in the variation condition. However, 
the difference in proportion of fraud occurrence between the variation conditions decreased.

The fifth and last MTurk pilot test was conducted with one major departure from the fourth MTurk pilot test: the simulation was conducted by exposing participants to both the variation-absent and variation-present conditions for different periods. Just as with the previous pilot tests, the proportion of fraud occurrence was higher in the variation-present condition compared to the variation-absent condition. Approximately $55 \%$ of participants indicated that they preferred it when auditors kept the nature of the audit procedures constant when they wanted to take a processor. A closer look at participants' preference and their actions indicated that approximately $80 \%$ of the participants acted in accordance with their preference. Three changes were made to arrive at the simulation design employed in this study: (1) included wording in the case background to specify what auditors did in the past and how that would differ moving forward (in the variation present-condition) or how it would remain the same (in the variation-absent condition), (2) restricting participants to either the variation-present or variation-absent condition, and (3) adding questions from the Theory of Planned Behavior in Part One of the study. Separating participants into the different conditions allowed us to ask about their intentions to steal before the simulation began and to compare the response about intentions between the two conditions. Incorporating questions from the Theory of Planned Behavior gave us the opportunity to potentially examine participants' attitudes and beliefs about stealing and their actions in the simulation. Table 4-2 summarizes the pilot tests changes across times.

[Insert Table 4-2 about here]

\section{Variation of Audit Procedures}

We manipulated the variation (change in nature) of the audit procedure in the simulation. The simulation was in Part Two of the study. Participants were told that in the past, the auditors of the company have verified inventory at both warehouses. Each warehouse contained five bins of processors 
and in each period, auditors would split their time at both warehouses and randomly select one bin from each warehouse to perform a count to verify the number of processors. In the variation absent condition, participants were informed that consistent with what the auditors have done in the past, the auditors would continue to split their time between both warehouses in each period. They would randomly select one bin from each warehouse to perform counts. In the variation present condition, participants were told that moving forward the auditors would randomly select two bins from only one warehouse to perform verification counts. However, the participants would not know which warehouse was selected by the auditors until after they made the decision to take a processor or refrain from doing so. Regardless of the decision the participants made in each period, they were notified after that decision about the warehouse chosen by the auditors. Therefore, they started each new period knowing the specific warehouse the auditors chose in the period before. In each period, participants had eleven choices: (1-5) yes, they want take a computer processor from Bin 1 [2/3/4/5] of Warehouse A, (6-10) yes, they want to take a computer processor from Bin 1 [2/3/4/5] of Warehouse B, and (11) no, they do not want to take any computer processors. Ambiguity is introduced in this study through the need for participants to guess which bin and warehouse the auditors would select and then having to make a decision that would reduce their chances of detection. It is important to note that the risk of detection across both the variation absent and variation present conditions are the same.

\section{Narcissism}

The second independent variable is the level of participants' narcissism. This variable defines the participant, characterized by a grandiose self-concept, a strong sense of entitlement, a tendency to exploit others, and a lack of empathy. This variable was measured using the Extreme Factor of the Narcissism Spectrum Scale (NSS) (Malkin 2015). The NSS has a list of 9 items that reflect narcissistic sentiments and is broken down into three factors: Extreme, Healthy, and Echoism. Individuals are considered to exhibit high levels of narcissism when they score high on the Extreme factor, whereas if they score high 
on the Echoism factor it means they lack narcissistic qualities. A high score for the Healthy factor indicates an association with few indicators of psychopathy and positive attributes such as self-esteem (Malkin 2015). Participants completed the NSS in Part One of the study and the Extreme factor was used to categorize individuals as narcissistic or non-narcissistic in this study.

\section{Ambiguity Aversion}

Ambiguity aversion was measured using the Multiple Stimulus Types Ambiguity Tolerance ScaleII (MSTAT-II) (McLain 2009). This 13-item 5-point Likert scale has a Cronbach alpha of 0.83 and reliability of 0.82 . This MSTAT-II scale has a higher reliability when compared to alternative measures such as Budner's (1962) Tolerance of Ambiguity Scale, which has a Cronbach alpha of 0.47, and provides a more valid measurement of ambiguity tolerance in contexts beyond social psychology (McLain 2009). Just like the NSS, participants completed the MSTAT-II in Part One of the study.

\section{Dependent Variable - Proportion of Fraud Occurrence}

In each period, participants have 11 different options. Options one to five: yes, they want take a computer processor from Bin 1 [2/3/4/5] of Warehouse A; Options six to 10: yes, they want to take a computer processor from Bin 1 [2/3/4/5] of Warehouse B; and option 11: no, they do not want to take any computer processors. Fraud is deemed to have occurred when participants indicate in the simulation that they elect to take a computer processor from one of bins from either warehouse for a particular period. If participants indicated that they would take a processor (options one to 10), it was coded as 1 whereas if they decided not to take a processor it was coded as 0 . The dependent variable is computed by adding up each participant's decision for the periods they were employed divided by the number of periods they remain employed in the simulation to get a proportion of fraud occurrence. Data on the dependent variable was collected using Qualtrics.

\section{Theory of Planned Behavior}

The Theory of Planned Behavior (Ajzen 1985) posits that human behavior is guided by three 
aspects: behavioral beliefs, normative beliefs, and control beliefs. Behavioral beliefs are beliefs about the possible outcomes of the behavior and the evaluations of these outcomes. For each individual, behavioral beliefs lead to the individual's attitude towards the behavior. Normative beliefs refer to the beliefs about the expectations of others and the motivation to adhere to these expectations. Individual's subjective norms are the result of their normative beliefs. Control beliefs, which leads to perceived behavioral control, relate to the presence and power of factors that may impede or facilitate the behavior. Together, an individual's attitude toward the behavior, subjective norms, and perceived behavioral control direct the development of behavioral intention. When attitude towards the behavior, subjective norms, and perceived behavioral control are favorable, the intention to perform the behavior of interest would be greater than if the perception of the three factors are not favorable. Intentions therefore have a strong effect on actual behavior (Ajzen 2018). Figure 4-2 depicts the theory in diagram form.

[Insert Figure 4-2 about here]

Due to the contrast in participants' preference and actions in the pilot tests, we included the Theory of Planned Behavior to assist with discerning and identifying why participants might prefer one option and act differently when another less-preferred option is presented. We are mainly interested in comparing participants' responses to questions from the three factors and how that relates to their intentions to steal and whether it corresponds to the proportion of fraud occurrence in the simulation. For each factor, a lower score indicates a more favorable perception towards stealing compared to a higher score. As such, there should be an inverse relationship between the scores for each of the three factors and participants' intention to steal (LIKELIHOOD_STEAL). There should also be an inverse relationship between the scores for each of the three factors and the proportion of fraud occurrence (FRAUD_OCCURRENCE_PROPORTION). 


\section{Control Variables}

Besides the NSS and the MSTAT-II, participants answered questions tailored from the Theory of Planned Behavior (Beck and Ajzen 1991) regarding the behavior of taking an item from their employer, gambling habits, and demographic-related questions in Part One of the study. We also asked if participants have ever had any interaction with internal and external auditors. We controlled for all these variables in this study.

\section{Procedures}

The experiment was split into two parts. Participants saw the description to Part One of this study on Amazon Mechanical Turk. In Part One, participants completed the MSTAT-II, NSS, Theory of Planned Behavior, gambling attitudes, and demographic questions. Participants who completed Part One were then notified three days later to complete Part Two on MTurk. Email reminders were sent out to participants approximately one week after they completed Part One. In Part Two, participants were told that the experiment was a simulation of the audit portion of inventory testing for Piccolo Processors, Inc., a company that manufactures and ships computer processors to its clients. The company has two warehouses and the participant were asked to assume that he/she has a role which gave him/her access to both warehouses. For each period that they remained an employee of Piccolo Processors, Inc., they would receive a salary of 5 Lira $(\$ 0.20)$. Participants knew that they could take a processor from the warehouses each period and sell it for 20 Lira $(\$ 0.80)$ each period. They were then informed of the auditors' history of performing inventory verification and their audit strategy moving forward. There was a $20 \%$ chance that auditors would detect that a processor was missing and if the theft was detected, the participants would lose their salary for that particular period and be terminated from the company. The simulation would then end. After reading the case materials, participants had to correctly answer all the comprehension check questions before starting the first period of the simulation.

At the start of each period, participants decided if they wanted to take a processor from any of the 
five bins in Warehouse A, any of the five bins in Warehouse B, or if they did not want to take any processors. After they have made their decision, participants were asked about their belief about the likelihood the auditors would detect that a processor was missing. They would then receive information about which warehouse was chosen by the auditors (if they were in the variation present condition) and if the auditors detected that a processor was missing during the inventory counts (if participants indicated that they wanted to take a processor). Participants then moved on to the next period. If the auditors detected that a processor was missing, the simulation ended immediately and participants would move on to the final section of the study. Participants who did not choose to take any processors or took a processor but did not get caught by the auditors would move on to the next section of the study after being employed by Piccolo Processors, Inc. for 10 periods. In the final section, participants answered a few process measures questions.

Participants were paid $\$ 0.20$ for participating in Part One, $\$ 0.20$ per period for participation in the simulation in Part Two, plus $\$ 0.80$ per period for successful fraud (undetected by the auditors in the audit). Solely from the simulation, participants can be compensated a minimum of $\$ 0$ (if they decided to take a processor in the first period and it was detected by the auditors) and a maximum of $\$ 10$ (if they decided to take a processor for all ten periods and it was undetected by the auditors). As an incentive for participants to complete both Part One and Part Two, participants were paid a $\$ 0.50$ reward on top of any bonuses they may have earned through the simulation. Incorporating any rewards and the bonus based on their performance in the simulation, the minimum amount a participant could be paid for this entire study was $\$ 0.70$ whereas the maximum amount was $\$ 10.70$. After the completion of Part Two of the study, participants were compensated based on the decisions they made and the audit outcomes in the simulation within one week. The total time taken for both parts of the study was approximately 25 minutes. Figure 43 shows the flow of the experiment. 
[Insert Figure 4-3 about here]

\section{RESULTS}

\section{Descriptive Statistics}

As reported earlier, 270 participants from MTurk elected to participate in Part One of the study and from that number, 141 participants completed Part Two. The data from the 141 participants were used to test the hypotheses presented in this paper. The simulation generated 908 observation periods from the 141 participants for conducting empirical analysis. ${ }^{11}$ Of the 908 periods that were played in the simulation, participants chose to commit fraud during 394 of those periods. The fraud detection rate was set to $20 \%$ and was displayed at random through Qualtrics. 88 fraud occurrences, which was about $22 \%$ of all fraud occurrences, were detected. On a participant-level, 109 participants $(77 \%)$ chose to commit fraud at least once during the simulation. Out of the 109 participants that chose to commit fraud, the average times participants took a processor during the 10-period simulation was 3.6. Figure 4-4 depicts the number of participants that chose to take a processor for each period of the simulation. Fraud occurrence (FRAUD_OCCURRENCE) is the number of periods participants decide to take a processor during the simulation. The dependent variable, FRAUD_OCCURRENCE_PROPORTION, or the number of periods participants chose to take a processor out of the number of periods played, has a minimum of 0 and a maximum of 1 . The mean proportion of fraud occurrence for all 141 participants is 0.58 . Table 4-3 presents descriptive statistics on key variables, including those that were used to conduct statistical tests as well as those not included but collected during the study.

\section{[Insert Table 4-3 and Figure 4-4 About Here]}

AMBIGUITY_AVERSION is the composite score from the MSTAT-II. The higher the score, the more averse to ambiguity an individual is. The NSS has three factors and the composite scores of each

\footnotetext{
${ }^{11}$ The simulation lasted for 10 periods but if participants decided to commit fraud and the fraud was detected, the simulation ended immediately, and they would move on to the next section of the study. As a result, not everyone completed all 10 periods of the simulation.
} 
factor lead to three different variables. Extreme narcissism (NARCISSISM), the variable central to this study, has a mean of 9.04 .

\section{The Effect of Variation in the Nature of Audit Procedures on Individuals' Decision to Commit Fraud}

The first hypothesis predicts that incorporating an element of unpredictability through a change in the nature of audit procedures will decrease the likelihood that individuals choose to commit fraud. Therefore, we expect that in the VARIATION_NATURE present condition, or when there is variation in nature of audit procedures, the proportion of fraud occurrence should be lower compared to the VARIATION_NATURE absent condition. Figure 4-5 presents the average proportion of fraud occurrence by the variation present/absent experimental condition. When variation is present, the average proportion of fraud occurrence is slightly higher (0.59) than when variation is absent (0.56). Results from a t-test comparing the means of FRAUD_OCCURRENCE_PROPORTION (untabulated) indicate that the difference between these means are not significant $(\mathrm{t}=0.426, p=0.335$, one-tailed). Hypothesis 1 is not supported.

\section{[Insert Figure 4-5 About Here]}

Responses from the open-ended post-simulation question asking participants why individuals might steal when variation is present but indicate that they prefer to steal when variation is absent provides some insight into why Hypothesis 1 was not supported. Many participants responded with variations of "when the cat is away the mouse comes out to play", suggesting that some participants perceived it to be easier to get away with fraud when auditors were busy at the other warehouse and that motivated them to steal more in the VARIATION_NATURE present condition. They felt that the odds of success were higher (50\%) when all they needed to do was select the right warehouse compared to when auditors were testing inventory at both warehouses even though the actual chance of detection was the same between both conditions. Another possible reason gleaned from the open-ended post-simulation 
question was the desire of participants to obtain the highest amount of the simulation bonus possible. Some participants mentioned that even though they were in the VARIATION_NATURE present condition and perceived the risk of detection to be greater, they decided to steal anyway to get more compensation from their time spent on this MTurk study. A few participants who gave this reason also felt inclined to add that they would never actually steal from their employer. Before the simulation began, participants were asked about the likelihood (LIKELIHOOD_STEAL) that they would take a processor from either warehouse, with 0 being very unlikely and 100 being very likely. As a robustness check, a t-test comparing the means of the LIKELIHOOD_STEAL variable and the VARIATION_NATURE variable was conducted. Means from the LIKELIHOOD_STEAL variable suggest that when variation is present, individuals have a greater intention of taking a processor than when variation is absent. The untabulated results of the t-test indicate that the difference between the LIKELIHOOD_STEAL means when variation is absent or present is not significant $(\mathrm{t}=0.675, p=0.251$, one-tailed).

Questions related to the Theory of Planned Behavior were broken down into three variables: STEAL_ATTITUDE, STEAL_PERC_BEHAVIORAL_CONTR, and STEAL_SUBJECTIVE_NORMS respectively for the three factors that influence an individual's behavioral intention. Analyzing the correlations between the three factors, LIKELIHOOD_STEAL, and FRAUD_OCCURRENCE_PROPORTION for all participants, STEAL_ATTITUDE and STEAL_PERC_BEHAVIORAL_CONTR have inverse relationships with LIKELIHOOD_STEAL and FRAUD_OCCURRENCE_PROPORTION. This is consistent with our expectation that individuals' favorable attitude towards stealing and their perceived behavioral control will lead to a greater intention to steal and proportion of fraud occurrence during the simulation. However, contrary to expectations, the correlation between LIKELIHOOD_STEAL and STEAL_SUBJECTIVE_NORMS was positive. We find the same positive correlation between FRAUD_OCCURRENCE_PROPORTION and 
STEAL_SUBJECTIVE_NORMS. This suggests that even though individuals indicated that it was not the norm to steal and doing so will be frowned upon by others, the intention and actual stealing behavior show a disregard for what others might think about their actions.

As the correlation test results for all observations were not as expected, we divided participants into the VARIATION_NATURE absent or present conditions. Examining observations in the VARIATION_NATURE absent condition, there are inverse relationships between the three Theory of Planned Behavior factors and the LIKELIHOOD_STEAL variable. The relationship between FRAUD_OCCURRENCE_PROPORTION and the three Theory of Planned Behavior factors are also in the opposite direction. When VARIATION_NATURE is present, the relationships between STEAL_ATTITUDE and STEAL_PERC_BEHAVIORAL_CONTR on LIKELIHOOD_STEAL and FRAUD_OCCURRENCE_PROPORTION are all in the opposite direction. The relationship between STEAL_SUBJECTIVE_NORMS and LIKELIHOOD_STEAL is positively correlated $(\mathrm{r}=0.348, \mathrm{p}=0.004)$. This indicates that when participants were aware that auditors will vary the nature of audit procedures, they had a greater intention to steal even when they acknowledge that others would frown upon this behavior. Focusing on the proportion of fraud occurrence for participants who are in the VARIATION_NATURE present condition, STEAL_SUBJECTIVE_NORMS and FRAUD_OCCURRENCE_PROPORTION are also positively correlated (r=0.199, p=0.106, one-tailed). Results from these correlation tests and open-ended questions suggests that participants were more likely to have a higher proportion of fraud occurrence when auditors varied the nature of audit procedures in the simulation because they perceived it as a better opportunity take advantage of the company when the auditors were not testing in one of the warehouses. It is also likely that participants acted differently in the VARIATION_NATURE present condition even though it was not the condition that they preferred because they wanted to make the most out of this opportunity to get the highest amount of bonus possible. The 
positive correlation between the subjective norms factor and the intention and stealing behavior could be due to participants' perception that their actions in this simulation will not be known by others and because they are not actually stealing from a real company, their actions will not be condemned by others. The perception of a great opportunity to steal when auditors might not be testing a warehouse and the knowledge that others would not know about the theft could explain why participants indicate that they prefer to steal when auditors do not vary the nature of audit procedures but actually steal when auditors vary the nature of audit procedures.

\section{The Effect of Narcissism and Ambiguity on the Proportion of Fraud Occurrence}

Hypothesis 2 predicts that when variation in the nature of audit procedures is present, the fraud occurrence proportion of (a) narcissistic individuals will be higher and (b) non-narcissistic individuals will be lower than when variation in the nature of audit procedures is absent. Table 4-4 presents the descriptive statistics by experimental condition for the FRAUD_OCCURRENCE_PROPORTION dependent variable. Cell means provide preliminary evidence consistent with our hypotheses that when the variation nature of audit procedures is present, narcissistic individuals will steal more whereas nonnarcissists will steal less when compared to the VARIATION_NATURE absent condition.

\section{[Insert Table 4-4 About Here]}

To formally test Hypothesis 2, a VARIATION_NATURE (absent vs. present) x NARCISSISM (continuous variable) ANCOVA was used to test differences between means for significance. We specifically examine how the absence or presence of variation in audit procedures and individuals' narcissistic tendencies interact to influence the number of times they choose to commit fraud out of the number of periods they are in the simulation. Overall, results suggest that the interaction between an individual's narcissism levels and the ambiguity from audit procedure variation can impact individual's 
willingness to commit fraud $(\mathrm{F}(1,12)=5.767, \mathrm{p}<0.001)$. Simple effects tests ${ }^{12}$ examining the narcissism conditions indicate that when individuals are narcissistic, the proportion of fraud occurrence is higher when variation is present compared to when variation is absent ( $p=0.065$, one-tailed). This suggests that controlling for all the other variables, variation in the nature of audit procedures results in an increase in the proportion of fraud occurrence of narcissists. Hypothesis $2 \mathrm{~A}$ is supported. Although the proportion of fraud occurrence when variation is present is lower than when variation is absent for non-narcissistic individuals, the difference is not significant ( $p=0.471$, one tailed). Analysis of Figure $4-6^{12}$ suggests an increase in the proportion of fraud occurrence for narcissists moving from the VARIATION_NATURE absent to the VARIATION_NATURE present conditions. Also, Figure 4-6 shows a slight decrease in the proportion of fraud occurrence for non-narcissistic individuals moving from the VARIATION_NATURE absent to the VARIATION_NATURE present conditions. Thus, we find partial support for $\mathrm{H} 2$. Results are summarized in Table 4-5.

[Insert Table 4-5 and Figure 4-6 About Here]

\section{Additional Analyses}

Psychology theory (Raskin and Terry 1988) predicts that it is important for narcissistic individuals to believe that they are superior over the company and its controls. When a task is deemed to be more challenging, narcissists are more motivated to attempt it than if the task is deemed to be easy and can be easily accomplished by any individual. T-tests (untabulated) of process measure variables shows that the narcissistic individuals indicated that it was more important for them to feel superior over the company and its controls compared to non- narcissists ( $\mathrm{t}=1.318, p=0.093$, one-tailed). Narcissists also place a greater importance on taking processors just to see if they can get away with it $(\mathrm{t}=3.712, p<0.001$, onetailed) and indicate that they are confident they can successfully hide the theft from the auditor when

\footnotetext{
${ }^{12}$ Figure 4-6 was graphed and simple effect tests were conducted using the NARCISSISM variable that was split at the median.
} 
compared to non- narcissists ( $\mathrm{t}=2.798, p=0.003$, one-tailed). These results provide a better understanding of why the proportion of fraud occurrence increased when auditors varied the nature of audit procedures in the simulation.

For each period, participants were asked about the likelihood a missing processor would be detected regardless of whether they chose to take a processor or not. T-tests comparing the means of the belief that the missing processor will be detected indicate that when VARIATION_NATURE is present, participants believe that the chances of auditor detection is greater than when VARIATION_NATURE is absent ( $\mathrm{t}=3.840, p<0.001$, one tailed). Dividing the sample into periods when participants chose to steal versus periods when they did not steal, the belief that the missing processor will be detected is still higher when VARIATION_NATURE is present than when VARIATION_NATURE is absent (steal: $\mathrm{t}=1.857$, $p=0.032$, one tailed; no steal: $\mathrm{t}=3.418, p<0.001$, one tailed). The results here make our findings for Hypothesis 1 more unanticipated given the perceived risks to successfully take a processor is higher for the VARIATION_NATURE present condition, the proportion of fraud occurrence should be lower. When participants were presented with both conditions and asked which condition they would prefer assuming that they would take a processor, $57.4 \%$ of the participants chose the VARIATION_NATURE absent condition. Once again, this suggests that individuals believed that it was easier to get away with inventory theft when auditors did not vary the nature of audit procedures.

\section{CONCLUSION}

This study examines the impact of variation in the nature of audit procedures and individuals' narcissistic tendencies on willingness to commit fraud. Auditors generally use the same audit programs from year to year. When the audit plan becomes too predictable, individuals might recognize the patterns and take advantage of areas where auditors are less likely to test.

Changing the nature of audit procedures can reduce that predictability and keep companies and 
individuals "on their toes". The ambiguity introduced from the unpredictability can reduce individuals' intention to attempt fraud, increasing the perception that the risk of detection is higher than it would be if auditors keep the same audit plan from year to year. This idea is reinforced by our finding that individuals prefer for auditors to maintain the same audit procedure than to vary the audit procedures if individuals wanted to commit inventory theft. In this study we also find that when auditors vary the nature of audit procedures, narcissists view it as a challenge and are more likely to steal to see if they can get away with it. Narcissists are more likely to commit fraud then because it is important for them to feel superior over the company and its controls when compared to non-narcissists. This ends up increasing the proportion of fraud occurrence when auditors vary the nature of audit procedures because narcissistic individuals view it as a greater challenge than when auditors stick to the same audit plan.

The consequence of auditor detection in this simulation is not the same as the many consequences individuals face in reality when they are guilty of stealing from their company. The difference in pressure in this simulation compared to what happens in real life could cause individuals to be more daring and increase their willingness to commit fraud since the upside to successful theft is much higher than the downside of getting caught by the auditors. We could be seeing a higher rate of fraud in the study compared to theft rates auditors/fraud experts see in the field because ethical considerations for this simulation does not mirror the considerations individuals go through when they have to actually go through with the fraud. Even though the magnitude of the ethical consideration is not the same for a simulation, participants had commented that they "felt dirty" or "felt bad about what they did" in the simulation but they decided to take processors anyway for the extra cash. We believe that the ability to elicit such feelings through the simulation shows that the case is somewhat realistic.

The results from the study provide new insight into the impact of variation in audit procedures on fraud occurrence. Changing the nature of audit procedures as recommended by the auditing standards can 
result in the perception of a higher risk of detection if individuals are looking to commit fraud. However, auditors need to be aware that if there are many narcissists within the company who are familiar with the audit plan, variation in the nature of audit procedures might not be the best strategy as it might increase fraud occurrence when narcissists see it as a challenge. If auditors are aware of such a situation, it might be better to vary the timing or extent of audit procedures. Future research can look into how variation in the timing and/or extent of audit procedures would impact narcissists' willingness to commit fraud. 


\section{References}

Ajzen, I. (1985). From intentions to actions: A theory of planned behavior. In Action control (pp. 11-39). Springer Berlin Heidelberg.

Ajzen, I. (2018). Behavioral Interventions Based on the Theory of Planned Behavior. Retrieved from https://people.umass.edu/aizen/pdf/tpb.intervention.pdf on 3/5/2018

American Institute of Certified Public Accountants (AICPA). (2002). Consideration of Fraud in a Financial Statement Audit. Statement on Auditing Standards No. 99. New York, NY: AICPA.

American Psychiatric Association. (2000). Diagnostic and Statistical Manual-Text Revision (DSM-IV-TRim, 2000). Washington, DC: American Psychiatric Association.

Asare, S. K., \& Wright, A. M. (2004). The Effectiveness of Alternative Risk Assessment and Program Planning Tools in a Fraud Setting. Contemporary Accounting Research, 21(2), 325-352.

Beck, L., \& Ajzen, I. (1991). Predicting dishonest actions using the theory of planned behavior. Journal of research in personality, 25(3), 285-301.

Bedard, J. C. (1989). An archival investigation of audit program-planning. Auditing-A Journal Of Practice \& Theory, 9(1), 57-71.

Bedard, J. C., Mock, T. J., \& Wright, A. M. (1999). Evidential planning in auditing: A review of the empirical research. Journal of Accounting Literature 18: 96-142.

Bennett, G. B., \& Hatfield, R. C. (2012). The Effect of the Social Mismatch between Staff Auditors and Client Management on the Collection of Audit Evidence. The Accounting Review, 88(1), 31-50.

Bowlin, K. (2011). Risk-based auditing, strategic prompts, and auditor sensitivity to the strategic risk of fraud. The Accounting Review, 86(4), 1231-1253.

Budescu, D. V., Peecher, M. E., \& Solomon, I. (2012). The joint influence of the extent and nature of audit evidence, materiality thresholds, and misstatement type on achieved audit risk. Auditing: A Journal of Practice \& Theory, 31(2), 19-41.

Budner, S. (1962). Intolerance of ambiguity as a personality variable. Journal of personality, 30(1), 29-50.

Camerer, C., and M. Weber. 1992. Recent Developments in Modeling Preferences: Uncertainty and Ambiguity. Journal of Risk \& Uncertainty, 5 (4):325-370.

Colbert, J. L., \& Luehlfing, M. S. (1996). Engagement risk. CPA Journal, 66(3), 54

Dorminey, J., Fleming, A. S., Kranacher, M. J., \& Riley Jr, R. A. (2012). The evolution of fraud theory. Issues in Accounting Education, 27(2), 555-579.

Einhorn, H. J., and R. M. Hogarth. 1986. Decision making under ambiguity. Journal of Business 59: 225-255.

Elder, R. J., \& Allen, R. D. (2003). A longitudinal field investigation of auditor risk assessments and sample size decisions. The Accounting Review, 78(4), 983-1002.

Ellsberg, D. (1961). Risk, ambiguity, and the Savage axioms. Quarterly Journal of Economics, 75, 643-669.

Erickson, M., Mayhew, B. W., \& Felix, W. L. (2000). Why do audits fail? Evidence from Lincoln Savings and Loan. Journal of Accounting Research, 38(1), 165-194.

Fellingham, J. C., \& Newman, D. P. (1985). Strategic considerations in auditing. The Accounting Review, 634-650. 
Foster, J. D. and R.F. Trimm. (2008). On being eager and uninhibited: Narcissism and approachavoidance motivation. Personality and Social Psychology Bulletin, 34(7):1004-1017.

Frisch, D., \& Baron, J. (1988). Ambiguity and rationality. Journal of Behavioral Decision Making, 1, 149-157.

Gilboa, I. (2009). Theory of Decision under Uncertainty. Cambridge, MA: Cambridge University Press.

Glover, S. M., Prawitt, D. F., Schultz Jr, J. J., \& Zimbelman, M. F. (2003). A test of changes in auditors' fraud-related planning judgments since the issuance of SAS No. 82. Auditing: A Journal of Practice \& Theory, 22(2), 237-251.

Heath, C. \& Tversky, A. (1991). Preference and Belief: Ambiguity and Competence in Choice under Uncertainty. Journal of Risk and Uncertainty. 4:5-28.

Hoffman, V. B., \& Zimbelman, M. F. (2009). Do strategic reasoning and brainstorming help auditors change their standard audit procedures in response to fraud risk? The Accounting Review, 84(3), 811-837.

John, O. P., \& Robins, R. W. (1994). Accuracy and bias in self-perception: individual differences in self-enhancement and the role of narcissism. Journal of Personality and Social Psychology, 66(1), 206.

Johnson, E. N., J.R. Kuhn Jr., B. Apostolou, and J.M. Hassell. (2013). Auditor perceptions of manager narcissism as a fraud attitude risk factor. Auditing: Journal of Practice \& Theory, 32(1): 203-219.

Kees, J., Berry, C., Burton, S., \& Sheehan, K. (2017). An Analysis of Data Quality: Professional Panels, Student Subject Pools, and Amazon's Mechanical Turk. Journal of Advertising, 46(1), 141-155.

Malkin, C. (2015). Rethinking Narcissism: The Bad---and Surprising Good---About Feeling Special. HarperCollins.

McLain, D. L. (2009). Evidence of the properties of an ambiguity tolerance measure: The Multiple Stimulus Types Ambiguity Tolerance Scale-II (MSTAT-II). Psychological Reports 105: 975988.

Mock, T. J., \& Turner, J. L. (2005). Auditor identification of fraud risk factors and their impact on audit programs. International Journal of Auditing, 9(1), 59-77.

Mock, T. J., \& Wright, A. (1993). An exploratory study of auditors' evidential planning judgments. Auditing, 12(2), 39.

Mock, T. J., \& Wright, A. M. (1999). Are audit program plans risk-adjusted? Auditing: A Journal of Practice \& Theory, 18(1), 55-74.

diNapoli, T. P. (2008). Red Flags for Fraud. State of New York Office of the State Comptroller.

Paulhus, D. L. (1998). Interpersonal and intrapsychic adaptiveness of trait self-enhancement: A mixed blessing? Journal of Personality and Social Psychology, 74(5), 1197.

Raskin, R., \& Terry, H. (1988). A principal-components analysis of the Narcissistic Personality Inventory and further evidence of its construct validity. Journal of Personality and Social Psychology, 54(5), 890.

Raskin, R., Novacek, J., \& Hogan, R. (1991). Narcissistic self-esteem management. Journal of Personality and Social Psychology, 60(6), 911.

Robins, R. W., \& Beer, J. S. (2001). Positive illusions about the self: Short-term benefits and long- term costs. Journal of Personality and Social Psychology, 80, 340-352

Rushton, J. P., Chrisjohn, R.D., \& Fekken, G. C. (1981). The altruistic personality and the selfreport altruism sale. Personality and Individual Differences, 1, 292-302. 
Savage, L. J. (1954). The foundations of statistics. Courier Corporation.

Shibano, T. (1990). Assessing audit risk from errors and irregularities. Journal of Accounting Research, 110-140.

Twenge, J. M., S. Konrath, J. D. Foster, W. K. Campbell, and B. J. Bushman. (2008). Egos inflating over time: A cross-temporal meta-analysis of the Narcissistic Personality Inventory. Journal of Personality, 76(4): 875-901.

Twenge, J. M. and W. K. Campbell. (2009). The narcissism epidemic: Living in the age of entitlement. New York, NY: Simon and Schuster.

Wallace, H. M., \& Baumeister, R. F. (2002). The performance of narcissists rises and falls with perceived opportunity for glory. Journal of Personality and Social Psychology, 82(5), 819.

Wilks, T. J., \& Zimbelman, M. F. (2004). Using game theory and strategic reasoning concepts to prevent and detect fraud. Accounting Horizons, 18(3): 173-184.

Zimbelman, M. F. (1997). The effects of SAS No. 82 on auditors' attention to fraud risk factors and audit planning decisions. Journal of Accounting Research, 75-97. 
FIGURE 4-1

Fully Ascribed Meta-Model of White-Collar Crime (Dorminey et al. 2012)

\section{Figure 1: A Meta-Model of Fraud \& White Collar Crime}

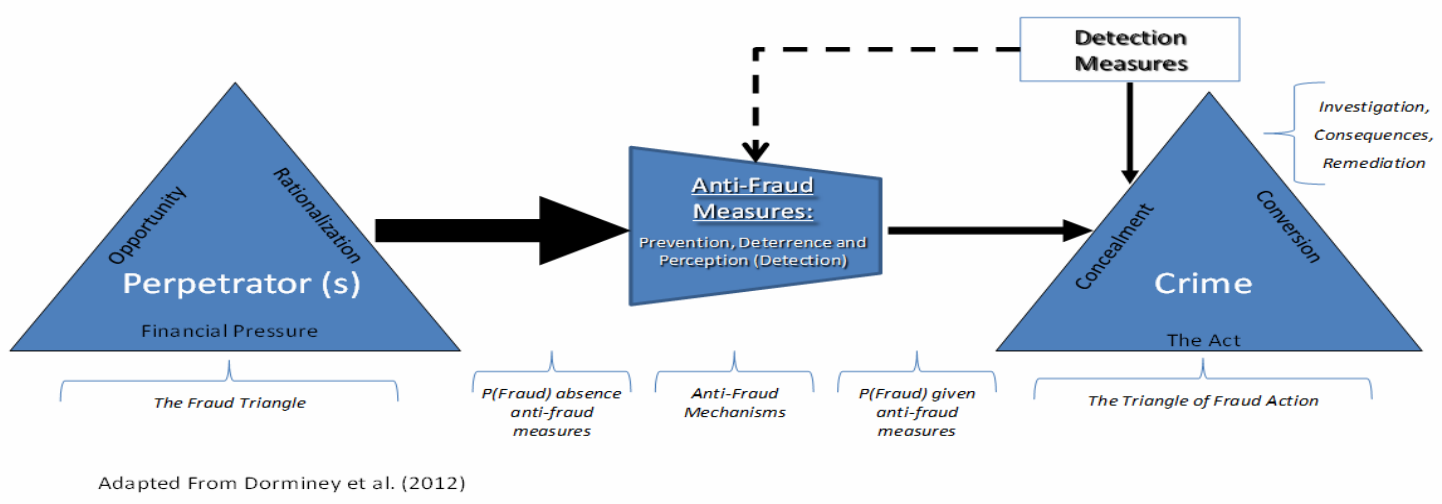


FIGURE 4-2

Theory of Planned Behavior Diagram from Ajzen (2018)

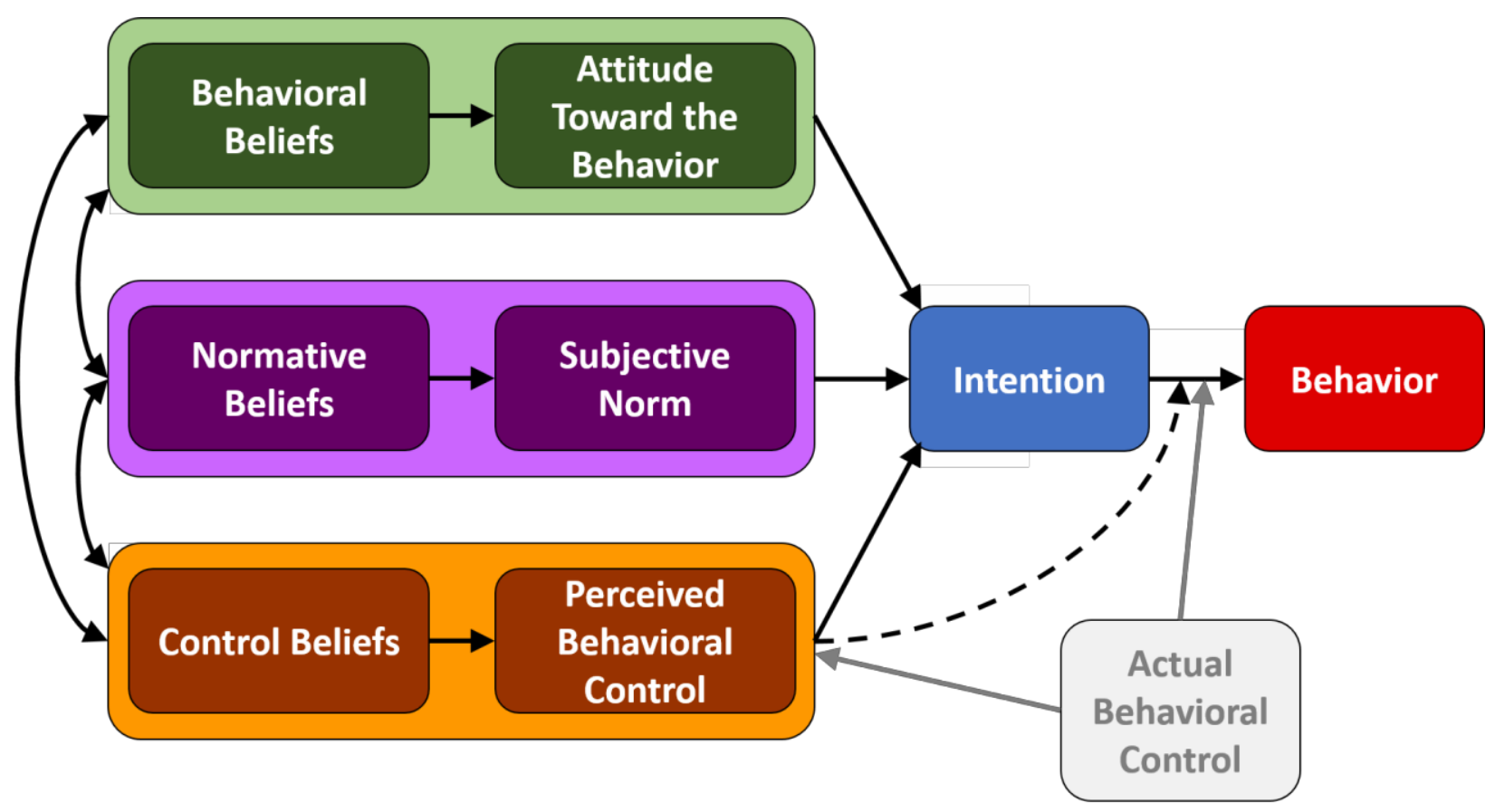


FIGURE 4-3

\section{Methods - Experiment Sequence}

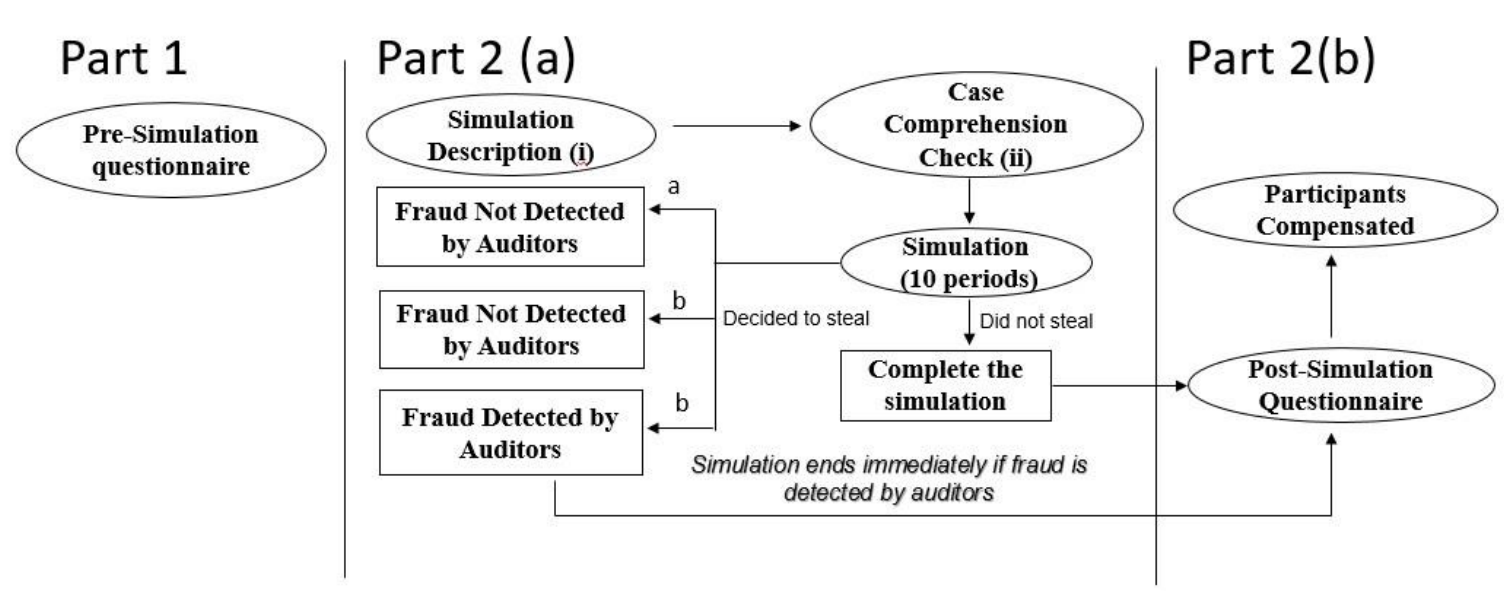

i. Participants read about the company's audit background, their role as warehouse manager, and the compensation structure. Variation in audit procedures manipulation presented here.

ii. Participants answer a series of questions regarding the case. They must accurately answer the comprehension check questions before moving forward.

a. Auditors did not audit the warehouse chosen by the participants

b. Auditors audited the specific warehouse chosen by the participants 
FIGURE 4-4

Graph of Number of Participants that Chose to Take a Processor in Each Period of the Simulation

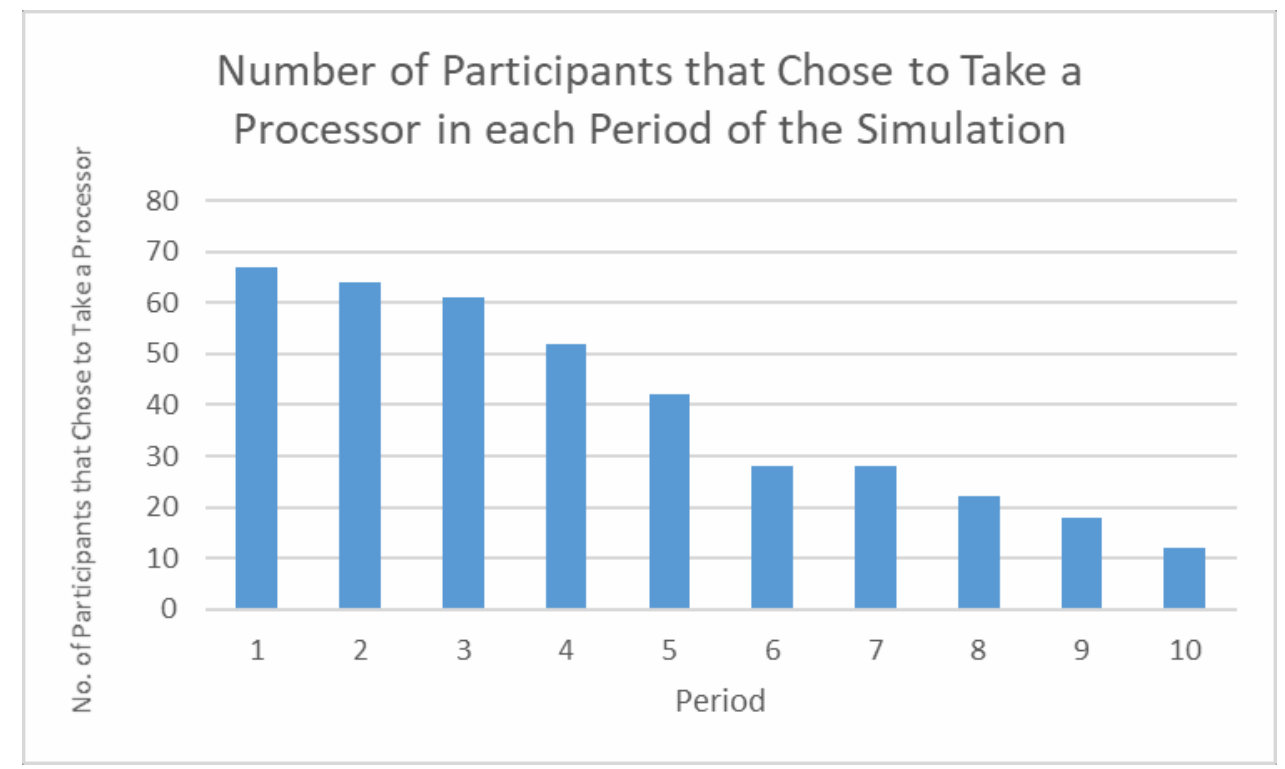


FIGURE 4-5

Graph of Proportion of Fraud Occurrence According to the Variation in Nature of Audit Procedures Conditions

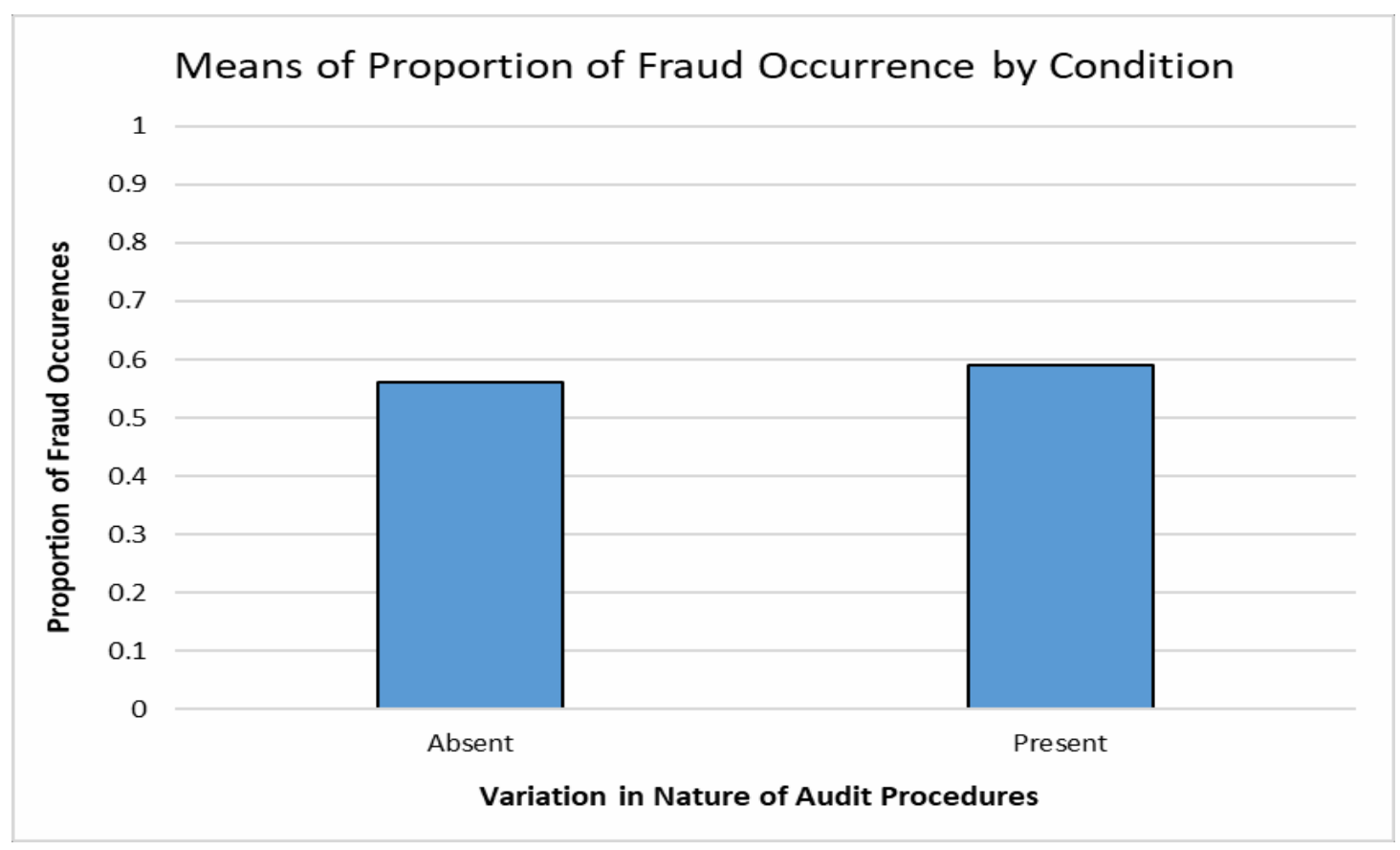


FIGURE 4-6

Graph of Marginal Means of FRAUD_OCCURRENCE_PROPORTION according to Variation Condition

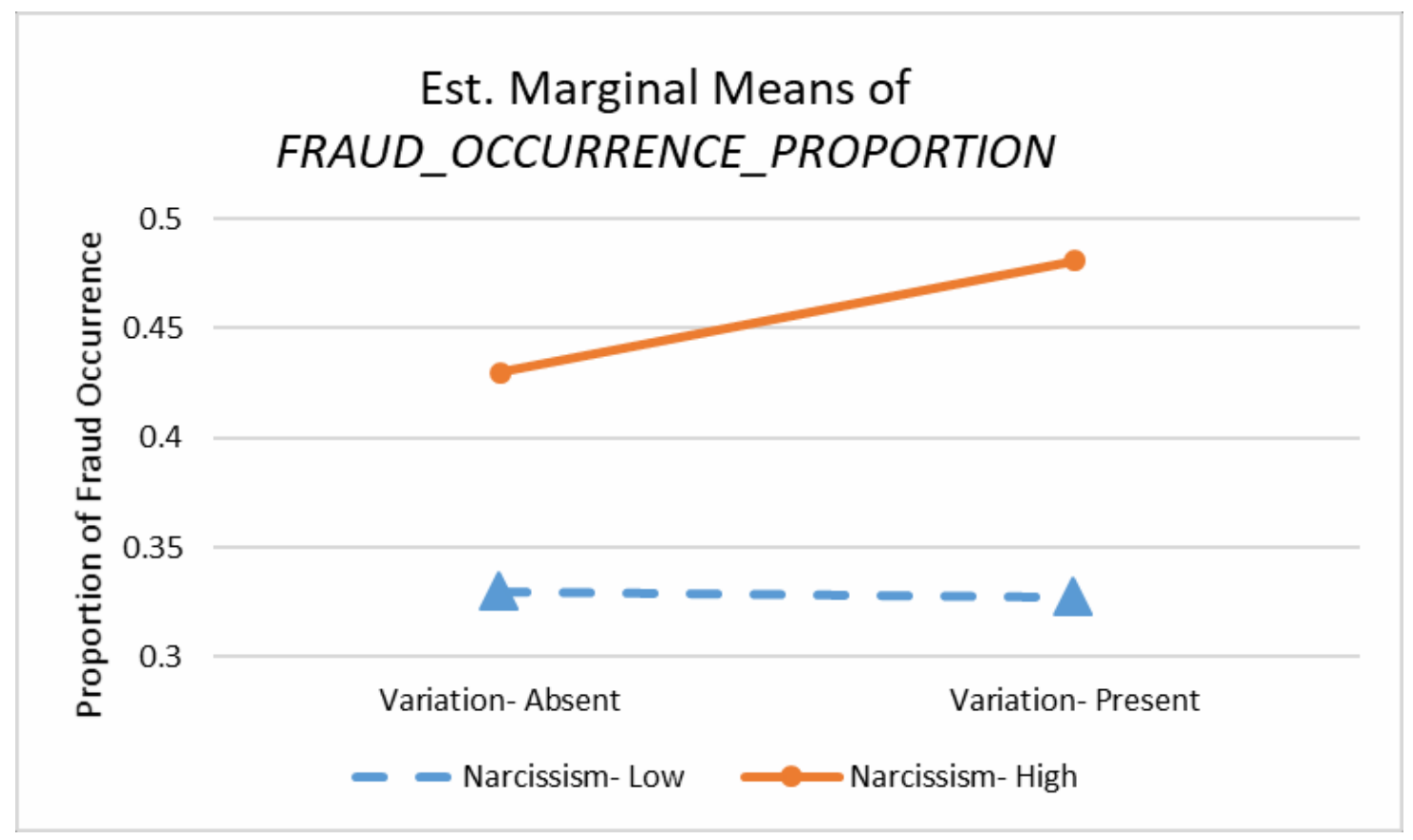


TABLE 4-1

\section{Participant Demographics}

\begin{tabular}{|c|c|c|c|c|}
\hline & & & Number & Percent \\
\hline \multirow[t]{3}{*}{ Gender } & Female & & 65 & $46.10 \%$ \\
\hline & Male & & 76 & $53.90 \%$ \\
\hline & $\mathrm{n}$ & & 141 & $100.00 \%$ \\
\hline \multirow[t]{3}{*}{ Interacted with Internal Auditors } & Yes & & 60 & $42.55 \%$ \\
\hline & No & & 81 & $57.45 \%$ \\
\hline & $\mathrm{n}$ & & 141 & $100.00 \%$ \\
\hline \multirow[t]{4}{*}{ Interacted with External Auditors } & Yes & & 52 & $36.88 \%$ \\
\hline & No & & 89 & $63.12 \%$ \\
\hline & $\mathrm{n}$ & & 141 & $100.00 \%$ \\
\hline & $\underline{\boldsymbol{n}}$ & Mean & (S.D.) & \\
\hline Age & 141 & 34.49 & $(12.75)$ & \\
\hline Years of Work Experience & 141 & 18.32 & $(12.25)$ & \\
\hline
\end{tabular}


Table 4-2

Pilot Tests Changes Across Time

\begin{tabular}{|c|c|c|c|c|}
\hline $\begin{array}{l}\text { Pilot } \\
\text { Test }\end{array}$ & Independent Variables & $\begin{array}{l}\text { Within/ } \\
\text { Between } \\
\text { Participant }\end{array}$ & Participants & Changes from Previous Pilot \\
\hline 1 & $\begin{array}{l}\text { a. Variation of Audit Procedures, } \\
\text { Narcissism, Auditor Extent Framing } \\
\text { b. Variation of Audit Procedures, } \\
\text { Narcissism, Compensation Framing }\end{array}$ & Between & Students & $\mathrm{n} / \mathrm{a}$ \\
\hline 2 & $\begin{array}{l}\text { a. Variation of Audit Procedures, } \\
\text { Narcissism, Auditor Extent Framing } \\
\text { b. Variation of Audit Procedures, } \\
\text { Narcissism, Compensation Framing }\end{array}$ & Between & MTurk & No change \\
\hline 3 & $\begin{array}{l}\text { Variation of Audit Procedures, } \\
\text { Narcissism, Compensation Framing }\end{array}$ & Between & MTurk & $\begin{array}{l}\text { 1. Wording changes to clarify } \\
\text { audit procedures } \\
\text { 2. Addition of case } \\
\text { comprehension questions } \\
\text { about auditor detection rate } \\
\text { 3. Addition of post-simulation } \\
\text { question about nature of audit } \\
\text { procedures preference } \\
\text { 4. Decided to use } \\
\text { compensation framing as the } \\
\text { third independent variable }\end{array}$ \\
\hline 4 & $\begin{array}{l}\text { Variation of Audit Procedures, } \\
\text { Narcissism, Compensation Framing }\end{array}$ & Within & MTurk & $\begin{array}{l}\text { 1. Participants were exposed } \\
\text { to both variation conditions, } \\
\text { instead of just one condition. }\end{array}$ \\
\hline 5 & $\begin{array}{l}\text { Variation of Audit Procedures, } \\
\text { Narcissism }\end{array}$ & Between & MTurk & $\begin{array}{l}\text { 1. Dropped compensation } \\
\text { framing as an independent } \\
\text { variable. } \\
\text { 2. Replaced the word "audit", } \\
\text { and clarified the wording on } \\
\text { some post-simulation } \\
\text { questions } \\
\text { 3. Added an open-ended } \\
\text { question after the simulation } \\
\text { to ask about difference in } \\
\text { actions and preference } \\
\text { 4. Reverted back to one } \\
\text { variation condition only for } \\
\text { each participant }\end{array}$ \\
\hline 6 & $\begin{array}{l}\text { Variation of Audit Procedures, } \\
\text { Narcissism }\end{array}$ & Within & MTurk & $\begin{array}{l}\text { 1. Participants were exposed } \\
\text { to both variation conditions, } \\
\text { instead of just one condition. }\end{array}$ \\
\hline
\end{tabular}


TABLE 4-3

\section{Descriptive Statistics}

Periods Played (N)

Periods when Fraud Occurred

Periods when Fraud was Not Detected

Participants that Chose to Commit Fraud (at least once)

Participants that Got Caught by Auditors

Participants that Did Not Commit Fraud

Total number of Participants in

Simulation

\section{Variables}

FRAUD_OCCURRENCE

FRAUD_OCCURRENCE_PROPORTION

PRE_LIKELIHOOD_STEAL

AMBIGUITY_AVERSION

NARCISSISM

STEAL_ATTITUDE

STEAL_PERC_BEHAVIORAL_CONTR

STEAL_SUBJECTIVE_NORMS

GAMBLING

\begin{tabular}{|c|c|}
\hline Vumber & Percent \\
\hline 908 & $100.00 \%$ \\
\hline 394 & $43.39 \%$ \\
\hline 306 & 32 \\
\hline
\end{tabular}

$\begin{array}{cr}109 & 77.30 \% \\ 88 & 62.41 \% \\ 32 & 22.70 \% \\ & \\ 141 & 100.00 \%\end{array}$

$\underline{n}$ Minimum Maximum Mean Median Deviation

1410

10

2.79

2.00

2.601

$141 \quad 0$

1410

1

100

$141 \quad 21$

1413

65

0.58

31.17

0.67

0.39

1415

$141 \quad 4$

1414

141

12

15

39.70

20.00

30.91

15

9.04

39.00

9.75

35

24.99

9.00

2.40

28

16.23

27.00

5.19

19

10.77

16.00

4.93

31

15.45

10.00

2.45

3.82 


\section{TABLE 4-4}

Cell Means (SD) [n] for Participants' Fraud Occurrence Proportion

$\begin{array}{lccc}\text { VARIATION_NATURE*NARCISSISM } & \text { High } & \text { Low } & \text { Overall } \\ \text { Present } & 0.661 & 0.496 & 0.590 \\ & (0.325) & (0.410) & (0.370) \\ & {[38]} & {[29]} & {[67]} \\ \text { Absent } & 0.584 & 0.527 & 0.562 \\ & (0.390) & (0.429) & (0.403) \\ & {[45]} & {[29]} & {[74]} \\ \text { Overall } & 0.620 & 0.511 & 0.575 \\ & (0.361) & (0.416) & (0.387) \\ & {[83]} & {[58]} & {[141]}\end{array}$


TABLE 4-5

ANCOVA Analysis: Effect of Variation in the Nature of Audit Procedures and Narcissism on Willingness to Commit Fraud

Model: Dependent variable: FRAUD_OCCURRENCE_PROPORTION (Adjusted $\mathrm{R}^{2}=0.279$ )

\begin{tabular}{llllll}
\hline Source & DF & Sum of Squares & Mean Square & F value & P \\
\hline Model & 34 & 45.876 & 1.349 & 11.313 & $<0.001$ \\
Error & 872 & 104.003 & 0.119 & & \\
Corrected Total & 906 & 149.879 & & & \\
\hline Source & DF & Sum of Squares & Mean Square & F value & P \\
\hline ID & 1 & 1.363 & 1.363 & 11.425 & 0.001 \\
PERIOD & 1 & 1.509 & 1.509 & 12.652 & $<0.001$ \\
AMBIGUITY_AVERSION & 1 & 2.490 & 2.490 & 20.874 & $<0.001$ \\
GAMBLING & 1 & 0.205 & 0.205 & 1.715 & 0.191 \\
STEAL_ATTITUDE & 1 & 3.221 & 3.221 & 27.010 & $<0.001$ \\
STEAL_PERC_BEHAVIORAL_CONTR & 1 & 3.681 & 3.681 & 30.861 & $<0.001$ \\
STEAL_SUBJECTIVE_NORMS & 1 & 0.065 & 0.065 & 0.547 & 0.460 \\
YEARS_WORK_EXPERIENCE_ & 1 & 0.100 & 0.100 & 0.842 & 0.359 \\
GENDER & 1 & 2.151 & 2.151 & 18.032 & $<0.001$ \\
AGE & 1 & 0.110 & 0.110 & 0.919 & 0.338 \\
INTERNAL_AUDIT_EXPERIENCE & 1 & 0.000 & 0.000 & 0.000 & 0.988 \\
EXTERNAL_AUDIT_EXPERIENCE & 1 & 2.385 & 2.385 & 19.995 & $<0.001$ \\
VARIATION_NATURE & 1 & 0.065 & 0.065 & 0.545 & 0.460 \\
NARCISSISM & 12 & 9.766 & 0.814 & 6.823 & $<0.001$ \\
VARIATION_NATURE*NARCISSISM & 9 & 6.190 & 0.688 & 5.767 & $<0.001$
\end{tabular}

Simple effects:

Simple effect of NARCISSISM under VARIATION_NATURE-

Simple effect of NARCISSISM

$1 \quad 1.081$

1.081

8.120

0.002

under VARIATION_NATURE-

Present

$1 \quad 1.724$

1.724

$12.953<0.001$

Simple effect of

VARIATION_NATURE

under NARCISSISM -High

Simple effect of

$\begin{array}{lllll}1 & 0.307 & 0.307 & 2.306 & 0.065\end{array}$

VARIATION_NATURE under NARCISSISM -Low ${ }^{\mathrm{b}}$

$1 \quad 0.001$

0.001

0.005

0.471

${ }^{\mathrm{b}}$ The hypothesis tests are one-tailed tests, therefore the interaction p-values have been halved. All other results are reported as two-tailed tests. 


\section{Appendix 4-1}

\section{Research Study Materials}

\section{Part 1}

Multiple Stimulus Types Ambiguity Tolerance Scale-II

Instructions: Please select an option for each statement that best represents you. Strongly disagree (1) to strongly agree (5)

1. I don't tolerate ambiguous situations well.

2. I would rather avoid solving a problem that must be viewed from several different perspectives.

3. I try to avoid situations that are ambiguous.

4. I prefer familiar situations to new ones.

5. Problems that cannot be considered from just one point of view are a little threatening.

6. I avoid situations that are too complicated for me to easily understand.

7. I am tolerant of ambiguous situations.

8. I enjoy tackling problems that are complex enough to be ambiguous.

9. I try to avoid problems that don't seem to have only one "best" solution.

10. I generally prefer novelty over familiarity.

11. I dislike ambiguous situations.

12. I find it hard to make a choice when the outcome is uncertain.

13. I prefer a situation in which there is some ambiguity.

\section{Narcissism Spectrum Scale (NSS)}

Instructions: On a scale of 1 (strongly disagree) to 5(strongly agree), indicate how much you agree or disagree with each item.

4. I secretly believe I'm better than most people.

5. Obstacles rarely slow me down.

6. I'm great at a lot of things compared to most people.

7. I press on even in challenging tasks.

8. I know there's something special about me.

9. It's hard for me to enjoy compliments.

10. I'm self-confident, but caring.

11. I don't like to talk about myself.

12. I feel uneasy when I'm the focus of attention. 


\section{Theory of Planned Behavior Questionnaire}

1. For me to take an item from my employer is
a) Good - Bad (7-point scale)
b) Pleasant - Unpleasant (7-point scale)
c) Foolish - Wise (7-point scale)
d) Useful - Useless (7-point scale)
e) Attractive - Unattractive (7-point scale)

2. If I take an item from my employer, most of the people who are important to me would (Not Care Disapprove, 7-point scale)

3. No one who is important to me thinks it is OK to take an item from my employer. (Agree Disagree, 7-point scale)

4. Most people who are important to me will look down on me if I take an item from my employer. (Likely - Unlikely, 7-point scale)

5. For me to take an item from my employer is (Easy - Difficult, 7-point scale)

6. If I want to, I can take an item from my employer (Definitely True - Definitely False, 7-point scale)

7. I can imagine times when I might take an item from my employer even if I hadn't planned to. (Likely - Unlikely, 7-point scale)

8. Even if I had a good reason, I could not bring myself to take an item from my employer. (Likely Unlikely, 7-point scale)

\section{Gambling Habits Questionnaire}

During the past 12 months, how often have you bet/gambled, even casually, for money or valuables in the following ways? Not at all (1) to Once a Week or More (4)

1. Card games (such as poker, blackjack)

2. Personal skill games (such as pool, darts, coin tossing, video games)

3. Betting on sports

4. Lottery (such as scratch cards, numbers, lotto)

5. Bingo

6. Dice games

7. Gambling machines

8. Horse racing

9. Online (internet) gambling

10. Dominoes

11. Personal challenges (like a dare)

12. Bet/gambled in some other way 


\section{Demographic Questions}

1. Gender
○ Male
○ Female

2. Age

3. Years of working experience

4. During your work experience, have you interacted with internal auditors? (Yes/No)

5. External auditors are responsible for making sure the company's financial reporting is accurately represented. During your work experience, have you interacted with external auditors? (Yes/No)

\section{Part 2}

\section{Simulation Instructions}

Piccolo Processors, Inc. is a company that manufactures and ships computer processor products to its clients. The company has two warehouses - Warehouse A and Warehouse B. For this case, please assume you are an employee of Piccolo, and that your job requires you to spend time at both warehouses.

This simulation will last for multiple periods. For every period you remain employed by Piccolo Processors, you will be compensated 5 Lira. With access to both warehouses, it is possible for you to take a computer processor from either warehouse in each period. Each item you take can be sold on the black market for 20 Lira.

Piccolo Processors employs auditors to periodically verify inventory. Processors are kept in five different bins in each warehouse (see picture below). In the past, auditors have verified inventory at both warehouses. In other words, to detect missing computer processors, the auditors randomly select one bin from Warehouse A and one bin from Warehouse B and perform a count to verify the number of processors. Thus, there is a $20 \%$ chance that the auditors will detect that a processor is missing.

If you choose to take a processor from Warehouse A or Warehouse B, you will be terminated from your position if the auditors detect that the processor is missing. If you are terminated, you will keep all salary earned previously. In addition, you will keep the value of the processors you successfully removed from the warehouses. However, you will not be compensated for the period in which you were terminated, and you will be unable to continue the simulation.

At the conclusion of this simulation, you will be compensated based upon the Lira awarded. The conversion rate is 25 Lira to $\$ 1$. For example, 75 Lira are worth $\$ 3$.

\section{Audit Procedures}

When auditors verify inventory at Warehouse A and Warehouse B:

In the past, auditors have verified inventory at both warehouses. Consistent with what they have been doing in the past, the auditors will split their time between two warehouses.

Processors are kept in five different bins in each warehouse (see picture below). To detect missing computer processors, the auditors will randomly select two bins and perform a count to verify that all processors are in place. That is, they will randomly select one bin from each warehouse when verifying 
inventory. Consequently, you estimate that there is a $20 \%$ chance that a missing processor will be detected by the auditors.

Each period will proceed as follows:

1. You will decide whether to take a computer processor from one of the five bins in Warehouse A, take a processor from one of the five bins in Warehouse B, or not take a processor at all.

2. You will learn the results of the inventory verification. In other words, you will learn whether the auditors discovered a missing processor (if one was taken).

When auditors verify inventory at Warehouse A or Warehouse B:

In the past, auditors have verified inventory at both warehouses. Moving forward, the auditors will spend all of their time at one warehouse (though it is impossible to predict which warehouse).

Processors are kept in five different bins in each warehouse (see picture below). To detect missing computer processors, the auditors randomly select two bins in a warehouse and perform a count to verify the number of processors. That is, they will randomly select two bins from their chosen warehouse and zero bins in the other warehouse when verifying inventory. Consequently, you estimate that there is a $40 \%$ chance that a missing processor will be detected at the warehouse the auditors select, and $0 \%$ chance that a missing processor will be detected at the warehouse the auditors do not select.

Each period will proceed as follows:

1. You will decide whether to take a computer processor from one of the five bins in Warehouse A, take a processor from one of the five bins in Warehouse B, or not take a processor at all.

2. You will learn the results of the inventory verification. In other words, you will learn which warehouse(s) the auditors examined, and whether the auditors discovered a missing processor (if one was taken).

If the auditors use these procedures, what is the likelihood that you would take a processor from either warehouse? (Unlikely-Likely, 0-100)

\section{Comprehension Questions}

1. In this simulation, you have access to which warehouse?

○ Warehouse A

- Warehouse B

○ Both warehouses

2. How many warehouses will the auditors perform inventory verification at per period?
$\circ$ One
o Two
It depends. They could audit one or both warehouses. 
3. What is your salary per period?
- 5 Lira
- 20 Lira
○ 50 Lira

4. A computer processor taken from either warehouse is worth

Lira.?
○ 5 Lira
- 10 Lira
- 20 Lira

\section{Variation Absent Condition}

5. The auditors split their time between warehouses and perform inventory verification at Warehouse A and Warehouse B. How many bins will they choose to verify in Warehouse B?
○ 5 bins
○ 4 bins
○ 3 bins
- 2 bins
$\circ 1$ bins
○ No bins

\section{Variation Present Condition}

5. The auditors spend all their time at one warehouse, and perform inventory verification at Warehouse A or Warehouse B. If the auditors randomly select Warehouse B, how many bins will they choose to verify in Warehouse B?

○ 5 bins

○ 4 bins

○ 3 bins

- 2 bins

○ 1 bin

- No bins

6. The auditors spend all their time at one warehouse, and perform inventory verification at Warehouse A or Warehouse B. If the auditors randomly select Warehouse B, how many bins will they choose to verify in Warehouse A?
○ 5 bins
- 4 bins
○ 3 bins
- 2 bins
- 1 bin
- No bins 


\section{Simulation}

Period $n$ (Audit in Both Warehouses)

You know that the auditors will split their time between Warehouse A and Warehouse B this period. In other words, they will select one bin from Warehouse A and one bin from Warehouse B. Do you choose to take a processor from one of the warehouses?

$\circ$ Yes- Bin 1 of Warehouse A

- Yes- Bin 2 of Warehouse A

- Yes- Bin 3 of Warehouse A

- Yes- Bin 4 of Warehouse A

- Yes- Bin 5 of Warehouse A

- Yes- Bin 1 of Warehouse B

- Yes- Bin 2 of Warehouse B

- Yes- Bin 3 of Warehouse B

- Yes- Bin 4 of Warehouse B

- Yes- Bin 5 of Warehouse B

- No, I choose not to take a processor from either warehouse

Period $n$ (Audit in One Warehouse)

You know that the auditors will spend all their time at one warehouse this period. In other words, they will select two bins from the chosen warehouse and no bins from the other warehouse. However, you do not know if they will conduct inventory verification at Warehouse A or Warehouse B. Do you choose to take a processor from one of the warehouses?

- Yes- Bin 1 of Warehouse A

- Yes- Bin 1 of Warehouse A

- Yes- Bin 2 of Warehouse A

- Yes- Bin 3 of Warehouse A

- Yes- Bin 4 of Warehouse A

- Yes- Bin 5 of Warehouse A

- Yes- Bin 1 of Warehouse B

- Yes- Bin 2 of Warehouse B

- Yes- Bin 3 of Warehouse B

- Yes- Bin 4 of Warehouse B

- Yes- Bin 5 of Warehouse B

- No, I choose not to take a processor from either warehouse

(All)

If participants indicate that they will choose to take a processor from one of the bins:

What do you believe is the likelihood that the missing processor will be detected by the auditors? (0$100 \%)$

If participants indicate that they choose not to take a processor at all:

Assume you did take a processor. What do you believe is the likelihood that the missing processor will be detected by the auditors? (0-100\%) 
Attention Check Question before Period 6 Begins

In this simulation, you have the chance to take inventory from which warehouse?

○ Warehouse A

- Warehouse B

○ Both warehouses

Results of the Audit if Participants Chose Not to Commit Fraud (Both warehouses)

The auditors split their time at both warehouses but you did not choose to take a processor this period. You will now proceed to the next period.

Results of the Audit if Participants Chose to Commit Fraud and it was Detected (Both warehouses) You chose to take a computer processor. However, Piccolo Processors, Inc.'s auditors split their time between both warehouses when verifying inventory and discovered the missing processor.

You will not be paid a salary for this period, and your employment with Piccolo Processors is terminated immediately. However, you will keep all salary from previous periods and the value of any processors you previously took.

Results of the Audit if Participants Chose to Commit Fraud and it was Not Detected (Both warehouses) You chose to take a computer processor. The auditors split their time between both warehouses when verifying inventory but the missing processor was not detected. Accordingly, you will earn an additional 20 Lira compensation for this period.

Results of the Audit if Participants Chose Not to Commit Fraud (One warehouse-Audited A[B]) This period, Piccolo Processors, Inc.'s auditors spent all their time verifying inventory at Warehouse A [B]. You will now proceed to the next period.

Results of the Audit if Participants Chose to Commit Fraud and it was Detected (One warehouse-Audited $A[B])$

Piccolo Processors, Inc's auditors chose to spend all their time verifying inventory at Warehouse A[B].

You chose to take a computer processor at Warehouse A[B]. However, Piccolo Processors, Inc.'s auditors performed inventory verification and discovered the missing processor.

You will lose all of your compensation for this period and your employment with Piccolo Processors, Inc. is terminated immediately. You will not be paid a salary for this period. However, you will keep all salary from previous periods and the value of any processors you previously took.

Results of the Audit if Participants Chose to Commit Fraud and it was Not Detected (One warehouseAudited A[B])-Auditors Audited the Exact Warehouse that Participants Chose to Steal from

Piccolo Processors, Inc.'s auditors verified inventory at Warehouse A[B].

You chose to take a computer processor. The auditors performed inventory verification, but the missing processor was not detected. Accordingly, you will earn an additional 20 Lira compensation for this period. 
Results of the Audit if Participants Chose to Commit Fraud and it was Not Detected (One warehouseAudited A[B]) Auditors Audited a Different Warehouse that Participants Chose to Steal from

Piccolo Processors, Inc.'s auditors verified inventory at Warehouse A[B].

You chose to take a computer processor. The missing processor could not be detected as the auditors did not verify inventory at Warehouse B[A]. Accordingly, you will earn an additional 20 Lira compensation for this period.

\section{(All) Process Measures Questions}

1. In which of the following situations would you rather take a processor?

○ The auditors split their time verifying inventory at both Warehouse A and Warehouse B. They randomly select one bin from each of the warehouses.

○ The auditors spend all their time verifying inventory at only one warehouse, though you do not know which one will be selected. Auditors will randomly select two bins at the chosen warehouse and none at the other warehouse.

2. Assume that the auditors spent all their time verifying inventory at one [two] warehouses, selecting two [one] bins from the chosen warehouse [and none from the other]. How worried were you that the missing computer processor would be detected? (Sliding scale. 1 to 11 , with 11 being very worried)

3. It is important to me to feel superior over the company and its controls (Strongly DisagreeStrongly Agree, 7-point scale).

4. It is important to me to feel superior over the company and its controls. (Strongly DisagreeStrongly Agree, 7-point scale).

5. I am confident that I can beat the odds and successfully avoid detection by the auditors when taking a processor (Strongly Disagree-Strongly Agree, 7-point scale).

6. We have noticed in previous studies that many people say they would prefer to take processors when auditors split their time between warehouses, but they are actually more likely to take processors when auditors spend all of their time at one warehouse. In your opinion, why do you think some individuals do this? (Open-ended question) 


\section{Summary and Contributions}

\section{CHAPTER FIVE: CONCLUSION}

This dissertation examines fraud occurrence and audit intervention from three different perspectives: (1) the perpetrator, (2) the auditor, and (3) auditor interventions that could deter perpetrators from committing fraud. The three papers aim to offer contributions to both literature and practice.

The first study examines whether the rationalization attribute of the fraud triangle applies to individuals with high levels of trait impulsivity. According to the fraud triangle theory, all three attributes of pressure, opportunity, and rationalization have to be present when individuals decide to engage in a fraudulent act (Albrecht 1991). This study adds to the literature by using a different tool, MouselabWEB, to look at the different factors that individuals' are focused on when making decisions to engaged in or refrain from fraud. With the tool, I was able to record the amount of time individuals spent on the different pieces of information presented to them and to infer whether they took the time to neutralize their behavior before making the decision to engage in fraud behaviors. The results of the study suggest that when opportunity and pressure are present, impulsive individuals are quicker with decision making than non-impulsive individuals. Impulsive individuals seem to bypass considerations about the potential consequences of the fraud. These findings should be of interest to forensic accounting and fraud examination researchers and anti-fraud professionals as they better understand fraud perpetrators and work to introduce a better fraud model.

The second study investigates how first impressions and auditor mindsets interact to influence auditors' risk assessments. Prior first impression research suggests that individuals' first impressions can influence their subsequent judgments (Olivola and Todorov 2010). Combined with the fact that first impressions are subconsciously formed almost instantaneously (Willis and Todorov 2006), it could be difficult for auditors to overcome biased judgments associated with first impressions. Time pressure may lead auditors to adopt an efficiency mindset, which reduces objectivity. Results from an experiment with 
124 auditors suggest that when auditors are in the efficiency mindset, they are more swayed by first impressions than auditors in the effectiveness mindset, valuing the risk that the inventory account is materially misstated as lower when their impression of the client personnel is positive and higher when their impression of the client personnel is negative. When auditors are in the effectiveness mindset, the valuation of the risk of material misstatement of the inventory account does not differ between positive and negative first impression conditions. These findings have practical implications for auditors and suggest that firms should consider having audit supervisors remind auditors to stay effective when conducting audit tasks to mitigate first impression biases.

Lastly, the third study explores how auditors can use individuals' aversion to ambiguity to their advantage and assist in the efforts to deter fraud by varying the nature of audit procedures from year to year. Changing the nature of audit procedures makes the audit plan less predictable and may lead to less fraud attempts by individuals who are looking to exploit areas that auditors have traditionally overlooked during the audit. Narcissistic individuals are perceived by auditors to pose a greater fraud risk (Johnson et al. 2013) and are more likely to attempt to complete a task when it is perceived to be challenging; in short, they pursue challenging tasks because they perceive that others are not able to achieve success with those same tasks and they have the need to feel superior over others (Raskin and Terry 1988). Variation in the nature of audit procedures could be a simple audit intervention that leads to fraud deterrence. However if narcissists perceive the variation in the nature of audit procedures to be a challenge, they might attempt to commit fraud just to feel superior over the company's controls and its auditors. Results do not show a difference between the rate of fraud occurrence when variation in the nature of audit procedures are absent or present. However, when the auditors vary the nature of audit procedures, individuals perceive the risk of detection to be higher even when the rate of detection between the variation and non-variation conditions are the same. Findings also suggest that the rate of fraud occurrence is higher for narcissistic individuals when auditors 
vary the nature of audit procedures than when the auditors stick to the same audit plan from year to year. This has practical implications for auditors and audit policy makers as audit standards currently call for auditors to vary the audit procedures when there is a risk of material misstatement due to fraud. Following the recommendations of auditing standards to vary the nature of audit procedures might lead to a higher occurrence of fraud if individuals are narcissistic. Auditors should be aware of the different effects of variation in the nature of audit procedures for narcissistic and non-narcissistic individuals when designing audit plans.

\section{Suggestions for Future Research}

Future research can extend each of the three papers. The first study contributes to the literature by focusing on the impulsivity trait of individuals and how that trait can influence the way individuals approach fraud when the opportunity to benefit from a fraud is present. This study adds to the fraud literature by providing the foundation for future fraud models that include impulsive individuals. The results from this study can also contribute to future studies on concealment as concealment methods would differ for individuals who take time to deliberate before engaging in a fraud act than for individuals who decide to engage in fraud acts first before trying to conceal their actions. Future research may also examine concealment strategies of impulsive versus non-impulsive individuals. The second study extends the psychology and auditing literature by showing that auditors can overcome first impression biases by being in the effectiveness mindset. Future research can investigate how other personality traits such as self-esteem, extroversion-introversion, and professional skepticism interact with first impression biases to influence risk assessments and audit judgments. Lastly, the third study contributes to literature by providing initial evidence related to individuals' perception of fraud detection when auditors vary the nature of audit procedures. The study provides evidence that narcissistic individuals may see auditors' attempts at varying the nature of audit procedures as a challenge and that motivates them to attempt fraud at a higher rate than if 
auditors do not make changes to nature of audit procedures. Future research can look into how changing the extent and/or timing of audit procedures would impact narcissists' fraud behaviors.

\section{References}

Albrecht, W.S. 1991. Fraud in Governmental Entities: The Perpetrators and Types of Fraud. Government Finance Review, 7(6), 27-30.

Johnson, E. N., J.R. Kuhn Jr., B. Apostolou, and J.M. Hassell. (2013). Auditor perceptions of manager narcissism as a fraud attitude risk factor. Auditing: Journal of Practice \& Theory, 32(1): 203-219.

Olivola C.Y., \& Todorov, A. (2010). Fooled by first impressions? Reexamining the diagnostic value of appearance-based inferences. Journal of Experimental Social Psychology 46: 315-324

Raskin, R., \& Terry, H. (1988). A principal-components analysis of the Narcissistic Personality Inventory and further evidence of its construct validity. Journal of Personality and Social Psychology, 54(5), 890.

Willis, J., \& Todorov, A. (2006). First impressions: Making up your mind after a 100-ms exposure to a face. Psychological science, 17(7), 592-598. 